\title{
Investigations into the regulation of histone H2B monoubiquitination
}

\author{
Dissertation \\ for the award of the degree \\ "Doctor rerum naturalium (Dr. rer. nat.)" \\ Division of Mathematics and Natural Sciences \\ of the Georg-August-Universität Göttingen \\ submitted by \\ Andrei Shchebet \\ born in Stolin, Belarus
}

Göttingen, 2011 
Members of the Thesis Committee:

Prof. Dr. Steven A. Johnsen (Reviewer)

Molecular Oncology,

University of Göttingen Medical School, Göttingen

Prof. Dr. med. Heidi Hahn (Reviewer)

Molecular Developmental Genetics,

University of Göttingen Medical School, Göttingen

Prof. Dr. Markus Wahl

Structural Biochemistry,

Freie Universität Berlin 
Date of the oral examination: 18th April 2011 


\section{Affidavit}

I hereby declare that the PhD thesis entitled "Regulation of histone H2B monoubiquitination" has been written independently and with no other sources and aids than quoted.

\section{Andrei Shchebet}

March, 2011

\section{Göttingen}




\section{Publications}

Pirngruber J, Shchebet A, Johnsen SA (2009a) Insights into the function of the human $\mathrm{P}-\mathrm{TEFb}$ component $\mathrm{CDK} 9$ in the regulation of chromatin modifications and co-transcriptional mRNA processing. Cell Cycle 8: 3636-3642

Pirngruber J, Shchebet A, Schreiber L, Shema E, Minsky N, Chapman RD, Eick D, Aylon Y, Oren M, Johnsen SA (2009b) CDK9 directs H2B monoubiquitination and controls replication-dependent histone mRNA 3'-end processing. EMBO Rep 10: $894-900$ 
В целях природы обуздания, В целях рассеять неученья Тьму

Берем картину мироздания да!

И тупо смотрим, что к чему...

А. и Б. Стругацкие 
List of figures..........................................................................................XVI

Summary............................................................................................. XVII

1 Introduction............................................................................................. 1

1.1 RNA polymerase II-mediated transcription overview......................... 1

1.1.1 Role of CTD modifications in the regulation of the transcription events.......................................................................................................................2

1.2 P-TEFb complex ..............................................................................................4

1.2.1 Regulation of P-TEFb activity ...................................................................4

1.2.2 P-TEFb substrates.............................................................................................

1.3 H2B ubiquitination. ........................................................................................6

1.3.1 Overview of chromatin structure................................................................6

1.3.2 H2B monoubiquitination ............................................................................9

1.3.3 Function of H2B ubiquitination ................................................................10

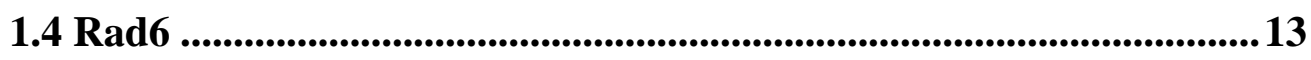

1.4.1 Rad6 in yeast......................................................................................................13

1.4.2 UBE2A (hRAD6) .....................................................................................14

1.4.3 Regulation of Rad6 activity ......................................................................15

1.5 Loss of H2B ubiquitination ......................................................................... 15

1.5.1 Nucleoli and stress conditions ....................................................................16

1.5.1.1 Nucleoli overview ......................................................................16

1.5.1.2 Nucleolar reaction to stress ...........................................................16

1.5.2 Cajal bodies and nucleoli ............................................................................17 
1.5.3 Cajal bodies under stress......................................................................18

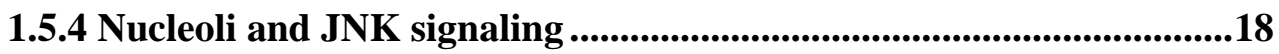

2. Materials ............................................................................20

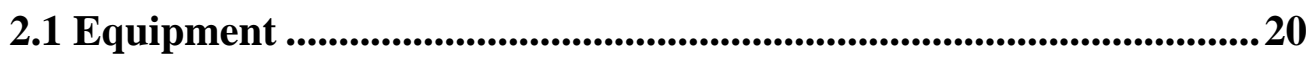

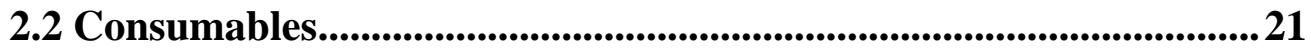

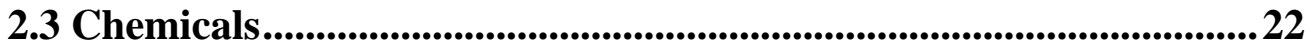

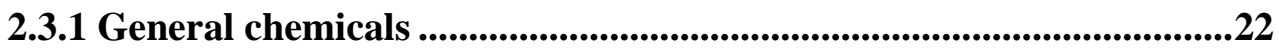

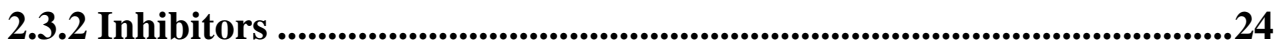

2.4 Kits and reagents ........................................................................................... 25

2.5 Nucleic acids .......................................................................................... 25

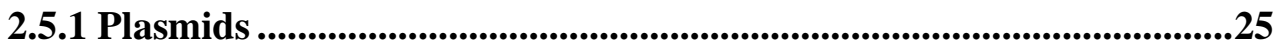

2.5.2 Oligonucleotides ..................................................................................................26

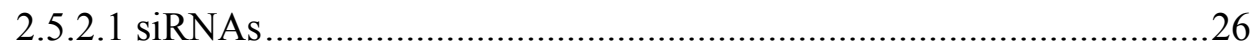

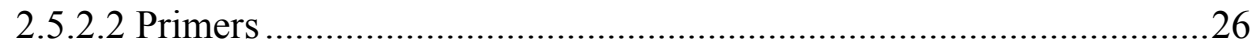

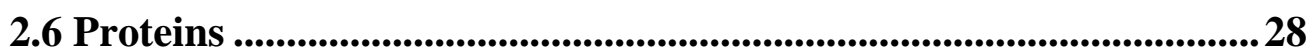

2.6.1 Protein molecular weight markers ............................................................28

2.6.2 Enzymes ….............................................................................................................28

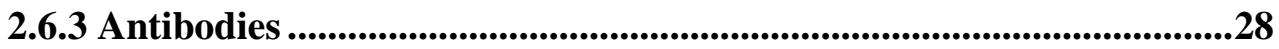

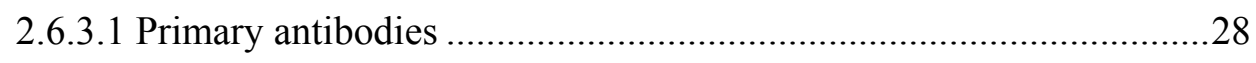

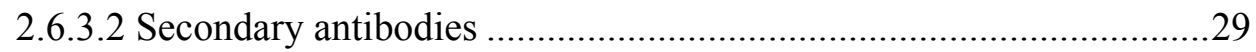

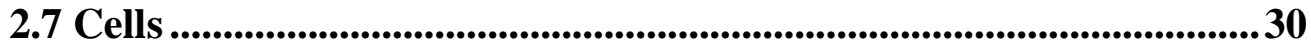

2.7.1 Bacterial cells.................................................................................30

2.7.2 Eucaryotic cells..................................................................................................30 


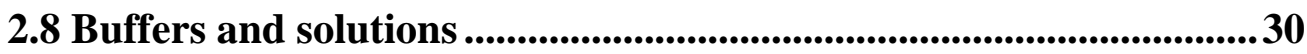

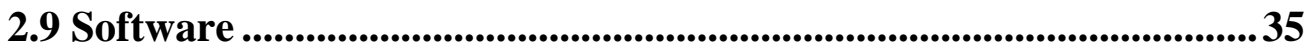

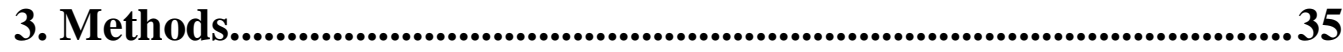

3.1 Cell culture ................................................................................................ 35

3.2 Molecular biology ....................................................................................... 36

3.3 Protein biochemistry ....................................................................38

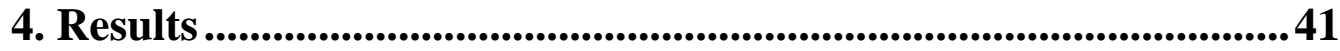

4.1 CDK9 positively regulates global and gene-specific levels of H2B.41

4.1.1 CDK9 activity is necessary for supporting global level of H2Bub1. .41

4.1.2 CDK9, not transcription per se is required for maintaining H2Bub1 on an actively transcribed gene................................................................................43

4.2 CDK9 regulates UBE2A by site-specific phosphorylation ...............44

4.2.1 CDK9 and CCNT1 interact with UBE2A ......................................44

4.2.2 CDK9 phosphorylates UBE2A in vitro and in vivo ...............................45

4.2.3 CDK9 is necessary for both H2B and PCNA monoubiquitination ...47

4.3. H2B is rapidly deubiquitinated following various stress conditions

4.3.1. Different stress factors rapidly reduce H2B monoubiquitination ....48

4.3.2. Nucleolar function is necessary for maintaining H2B ubiquitination

50

4.3.3. JNK activity regulates the level of $\mathrm{H} 2 \mathrm{~B}$ ubiquitination. .53

4.3.4. H2Bub1 levels are reduced due to the activation of a cellular deubiquitinating enzyme .54 
4.3.5 USP22 is needed for the stress-induced JNK-regulated deubiquitination

5 Discussion

5.1 P-TEFb as a key regulator of transcription elongation and cotranscriptional histone modification .......................................................61

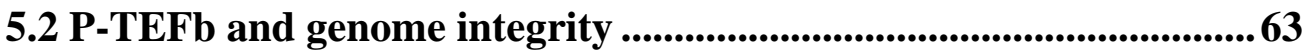

5.3 Stress-induced reduction of H2B ubiquitination...............................66

5.3.1 H2Bub1 is strongly reduced by various treatments ............................66

5.3.2 JNK and nucleolar signaling are involved in reduction of H2Bub1 .67

5.3.3 Stress and DUB activity ........................................................................68

5.4 The role of H2Bub1 in cancer biology ................................................69

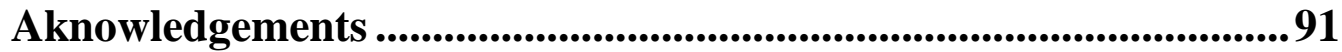

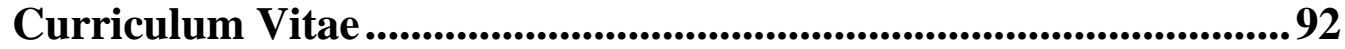


ABBREVATIONS

53BP1

APS

ARF

ATM

ATP

ATR

ATXN7L3

BGP

BRCA1

$\operatorname{Brd} 4$

Bre1

BSA

CB

$\mathrm{CCNH}$

CCNT1

CDK7

CDK9

cDNA

COMPASS

CTD

DAPI

DEPC p53 binding protein 1

Ammonium persulfate

Alternative reading frame product of CDKN2A locus

Ataxia telangiectasia mutated

Adenosin triphosphate

Ataxia telangiectasia and $\operatorname{Rad} 3$ related

Spt-Ada-Gcn5-acetyltransferase

ß-Glycerolphosphate

Breast cancer 1

Bromodomain containing 4

BREfeldin A sensitivity

Bovine serum albumin

Cajal body

Cyclin H

Cyclin T1

Cyclin-Dependent Kinase 7

Cyclin-Dependent Kinase 9

Complementary DNA

Complex proteins associated with Set1p

Carboxyterminal Domain

4',6-diamidino-2-phenylindole

Diethylpyrocarbonate 
DFC

DMEM

DMSO

DNA

DNA-PK

Dot1L

DRB

DSIF

DTT

EDTA

EGF

FACT

FBS

FC

GC

GST

$\mathrm{H} 2 \mathrm{~A}$

H2B

H3

H4

H4

$\operatorname{Hdm} 2$

HEXIM1

HMBA
Dense fibrillar component

Dulbecco/Vogt modified Eagle's minimal essential medium

Dimethyl sulfoxide

Deoxyribonucleic acid

DNA-dependent protein kinase

DOT1-like

5,6-dichloro-1-beta-D-ribofuranosylbenzimidazole

(DRB) Sensitivity Inducing Factor

Dithiothreitol

Ethylenediaminetetraacetic acid

Epidermal growth factor

Facilitates Active Chromatin Transcription

Fetal Bovine Serum

Fibrillar center

Granular component

Glutathione S-transferase

Histone 2A

Histone 2B

Histone 3

Histone 4

Histone 4

Mdm2 p53 binding protein homolog

Hexamethylene bis-acetamide inducible 1

Hexamethylene bisacetamide 


\begin{tabular}{|c|c|}
\hline HoxA & Homeobox A cluster \\
\hline HRP & Horseradish peroxidase \\
\hline HU & Hydroxyurea \\
\hline IAA & Iodacetamide \\
\hline JNK & C-Jun N-terminal kinase \\
\hline MDC1 & Mediator of DNA-damage checkpoint 1 \\
\hline MEKK1 & Mitogen-activated protein kinase kinase kinase \\
\hline MG132 & Carbobenzoxy-L-leucyl-L-leucyl-L-leucinal \\
\hline MYBBP1A & MYB binding protein $(\mathrm{P} 160)$ 1a \\
\hline MyoD & Myoblast determination protein \\
\hline NAC & $N$-acetylcysteine \\
\hline NCL & Nucleolin \\
\hline NELF & Negative elongation factor \\
\hline NEM & N-ethylmaleimide \\
\hline Nopp 140 & Nucleolar phosphoprotein 140 \\
\hline NOR-90 & Nucleolar organizer \\
\hline NP-40 & NonidetTM P40 \\
\hline NPM & Nucleophosmin \\
\hline PCNA & Proliferating Cell Nuclear Antigen \\
\hline PIC & Pre-Initiation Complex \\
\hline PP1 $\alpha$ & Protein phosphatase 1alpha \\
\hline PP2B & Protein phosphatase $2 \mathrm{~B}$ \\
\hline $\operatorname{PPR} \gamma$ & Peroxisome proliferator-activated receptor gamma \\
\hline $\mathrm{P}-\mathrm{TEFb}$ & Positive Transcription Elongation Factor beta \\
\hline
\end{tabular}


RAD18 Radiation sensitivity protein 18

RAD5 Radiation sensitivity protein 5

Rad6 Radiation sensitivity protein 6

RNA Ribonucleic acid

RNAPII RNA Polymerase II

RNF20 Ring finger protein 20

RNF40 Ring finger protein 40

ROS Reactive oxygen species

rRNA Ribosomal ribonucleic acid

SAGA Spt-Ada-Gen5-Acetyltransferase

SAPKs Stress-activated protein kinases

SB203580 4-[5-(4-Fluorophenyl)-2-[4-(methylsulfonyl)phenyl]-1H-imidazol-4yl]pyridine

SCP

Small CTD phosphatase

SDS

Sodium dodecylsulfate

SDS-PAGE Sodium dodecylsulfate polyacrylamide gel electrophoresis

SP600125 1,9-Pyrazoloanthrone

SiRNA Small interfering RNA

SLBP Stem loop-binding protein

snoRNP Small nucleolar ribonucleoprotein

snRNA Small nuclear ribonucleic acid

snRNP Small nuclear ribonucleoproteins

SUPT5H Supressor of Ty Homologue-5

TEMED Tetramethylethylenediamine

TFIID Transcription factor II D 
TIF-IA

UBE2A

UBP10

UBP8

USP22

Transcription initiation factor IA

Ubiquitin-conjugating enzyme E2A

Ubiquitin protease 10

Ubiquitin protease 8

Ubiquitin specific peptidase 22 


\section{List of figures}

Figure 1. Regulation of different transcription stages.

Figure 2. The carboxyl-terminal domain of RNAPII is subjected to various posttranslational modifications and serves as a docking site for many transcriptionrelated factors. .

Figure 3. Variety of histone modifications. ................................................................... 7

Figure 4. Chromatin map of an active human gene. ...................................................... 8

Figure 5. H2B ubiquitination in the context of 30-nm fiber. .......................................... 11

Figure 6. Dynamics and role of H2B monoubiquitination in transcription elongation........12

Figure 7. Multiple functions of Rad6 in yeast. ........................................................... 14

Figure 8. Alignment of amino acid sequences of yeast Rad6 and human UBE2A. ..............15

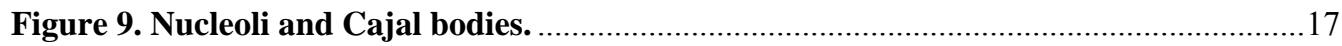

Figure 10. CDK9 activity and RNAPII CTD Ser2 phosphorylation regulate H2B

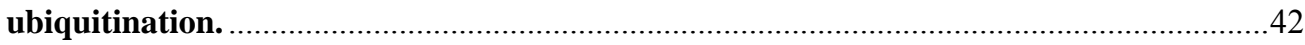

Figure 11. H2Bub1 depends on CDK9 activity but not on transcription per se.................44

Figure 12. UBE2A interacts with CDK9 and CCNT1...................................................45

Figure 13. CDK9 phosphorylates UBE2A in vitro and in vivo. ......................................46

Figure 14. CDK9 regulates PCNA monoubiquitination. .............................................4

Figure 15. Various factors downregulate the H2B ubiquitination.....................................48

Figure 16.The reduction of H2B ubiquitination happens rapidly but is not caused by DNA

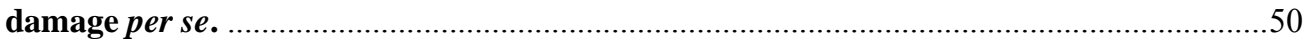

Figure 17. Disruption of nucleolar function causes a loss of histone H2B monoubiquitination.

Figure 18. Disruption of Cajal bodies structure upon stress can be rescued by caffeine. ....53

Figure 19. JNK activity regulates the level of H2B ubiquitination......................................54

Figure 20. An H2B deubiquitinating activity is increased during cellular stress................56

Figure 21. USP22 regulates the level of H2Bub1 and can be phosphorylated by JNK........58

Figure 22. Analysis of UBE-family members..............................................................65

Figure S1. SCP1, SCP2 and SCP3 dephosphorylate Ser2 but not Ser5 of RNAPII CTD. ...59 Figure S2. Heat shock reduces H2B ubiquitination. ...................................................59

Figure S3. Activation of JNK correlates with the reduction of H2Bub1 .............................60

Figure S4. JNK inhibitor rescues H2Bub1 level after actinomycin D treatment. ................60

Figure S5. USP22 is needed for cisplatin-mediated reduction of H2Bub1..........................61 


\section{Summary}

Transcription-associated chromatin modifications are recognized now as important regulators of gene expression. One of them, the monoubiquitination of lysine 120 of histone H2B (H2Bub1), is associated with actively transcribed genes. It was shown to change the physical properties of the chromatin as well as serve as a recognition mark for regulatory chromatin-binding proteins. The misregulation of H2Bub1-modifying machinery has been observed to be tightly linked with different types of cancer. Many aspects of regulation of H2B monoubiquitination remain unknown.

In the course of this study we presented the data which links H2Bub1 to the modifications of RNA polymerase II, proving that H2Bub1 does not depend on transcription per se. We also clarified aspects of the regulation of the H2B ubiquitinating enzymes. A separate interesting question investigated in this study is a rapid and massive loss of H2Bub1 following various cell stresses. Preliminary mechanism and signaling pathways which control this process were discovered. Together, these studies have uncovered important mechanisms controlling H2Bub1 and may serve as a basis for developing more potent strategies to combat cancer. 


\section{Introduction}

\subsection{RNA polymerase II-mediated transcription overview}

The transcription of most genes is mediated by RNA polymerase II (RNAPII). It performs the cycle of transcription in 4 steps: pre-initiation, initiation, elongation and 3'-end processing/termination (Fig. 1).

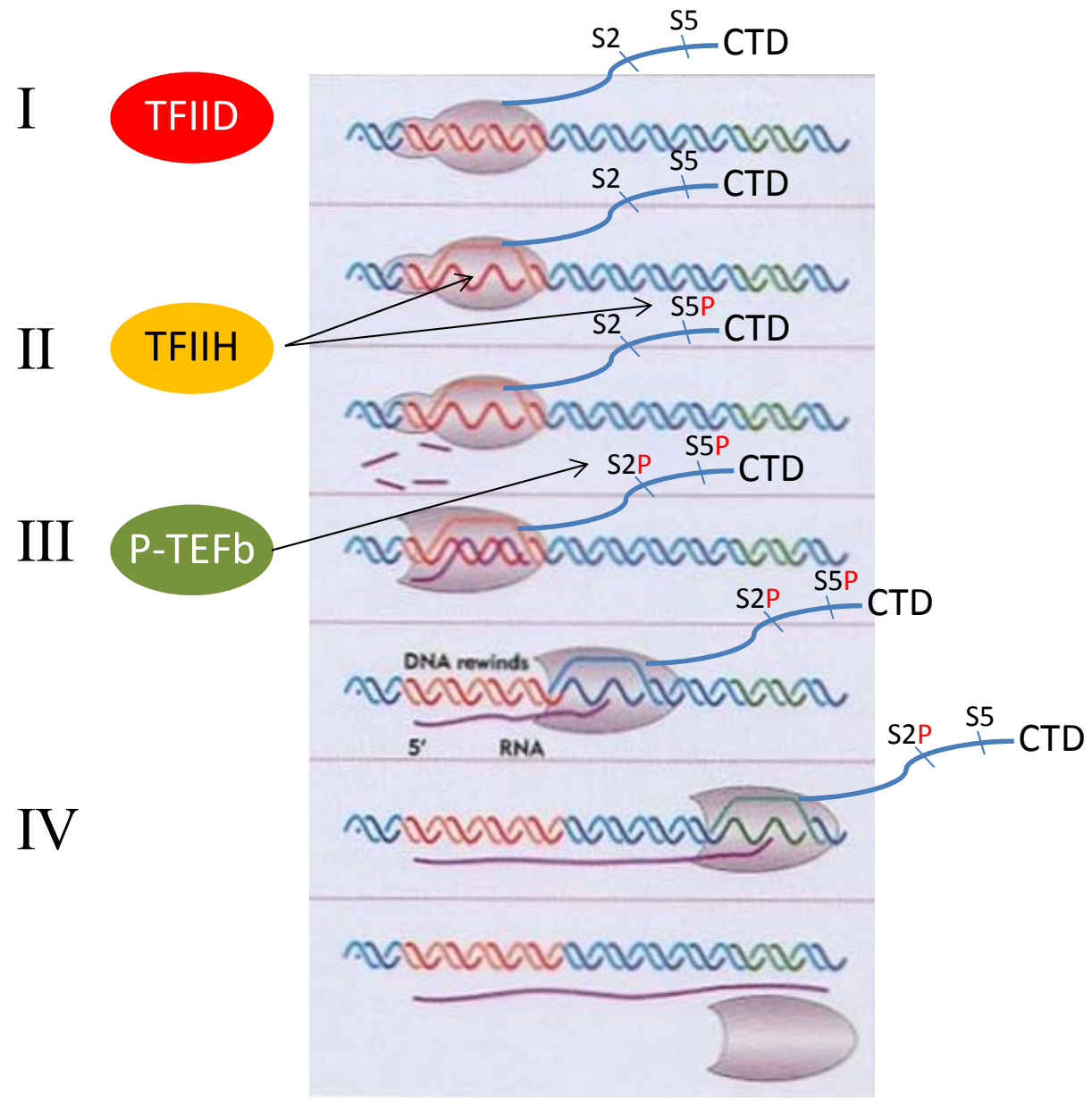

Figure 1. Regulation of different transcription stages. I. Preinitiation. DNA is distorted by the action of TFIID. II. Initiation. TFIIH opens the DNA duplex and 
phosphorylates serine 5 in RNAPII CTD. The production of abortive transcripts takes place or the polymerase is switched to the paused state. III. Elongation. RNAPII is phosphorylated at serine 2 by $\mathrm{P}-\mathrm{TEFb}$ and starts producing full-length transcript. IV. 3'-end processing and termination. The transcript is cleaved by an endonuclease activity and the mRNA is normally polyadenylated (except for histone mRNAs which have stem loop structure). RNAPII CTD is dephosphorylated for the next run and released from DNA. Modified from Lewin's Gene IV.

The pre-initiation step includes the assembly of the Pre-Initiation Complex (PIC) on the promoter. It consists of six general transcription factors and the RNAPII holoenzyme. TFIID is one of these factors. Its subunits create a distortion in the DNA as well as provide proper positioning of the whole complex on the promoter.

The initiation starts when the helicase subunit of TFIIH factor opens the DNA duplex creating a so-called transcription bubble. The kinase component of TFIIH consisting of Cyclin-Dependent Kinase 7, Cyclin H (CDK7/CCNH) and MAT1 phosphorylates serine in the fifth position of RNAPII Carboxyterminal Domain (CTD) repeats. The RNAPII starts producing short abortive transcripts.

For the transition of RNAPII to the next, elongation step, the activity of Positive Transcription Elongation Factor b (P-TEFb) is needed. Its components, Cyclin-Dependent Kinase 9 and Cyclin T1 (CDK9/CCNT1) phosphorylate and inactivate negative elongation factors as well as activate the RNAPII by phosphorylating its second serines in CTD repeats.

At the end of transcription cycle the transcript is terminated and its 3 '-end is processed into either poly-A tail or stem loop. The RNAPII is dephosphorylated to be reused in the next round of transcription (Lee \& Young, 2000).

\subsubsection{Role of CTD modifications in the regulation of the transcription events}

The large subunit of RNAPII has a carboxy-terminal domain which consists of 52 heptapeptide repeats (YSPTSPS) in human (Nonet et al, 1987). CDK9 can phosphorylate serine in second position of each repeat. This phosphorylation marks the onset of productive elongation of transcription (Kim et al, 2002). P-TEFb remains associated with RNAPII as it goes along the gene. Subsequently the number of phosphorylated serines in RNA polymerase CTD 
increases while the enzyme moves toward the 3'-end of the gene (Komarnitsky et al, 2000). At the end of the gene the phosphorylation declines and RNAPII gets rapidly dephosphorylated to be reused in another cycle of transcription (Cho et al, 2001).

Serines in the fifth position of CTD repeats are phosphorylated by the TFIIH components CDK7 and Cyclin $\mathrm{H}$ during the initiation of transcription (Giglia-Mari et al, 2004; Komarnitsky et al, 2000). Unlike p-Ser2 the phosphorylation of Ser5 mostly happens near the 5'-end of the gene (Komarnitsky et al, 2000). Selective phosphorylations of serines in the positions 2 and 5 were the first well-studied elements of a regulatory paradigm later called a "CTD code" (Buratowski, 2003). More recently, Ser7 was also shown to be phosphorylated (Chapman et al, 2007; Egloff et al, 2007). Tyr1 and Thr4 can also be potential phosphorylation sites. Two conserved proline residues (Pro3 and Pro6) can be also modified by peptidyl-prolyl isomerases (Shaw, 2007) thus increasing the complexity and possible number of combinations of modifications. The variety of modification makes the RNAPII CTD a universal docking site for the proteins involved in different stages of transcription (Fig. 2).

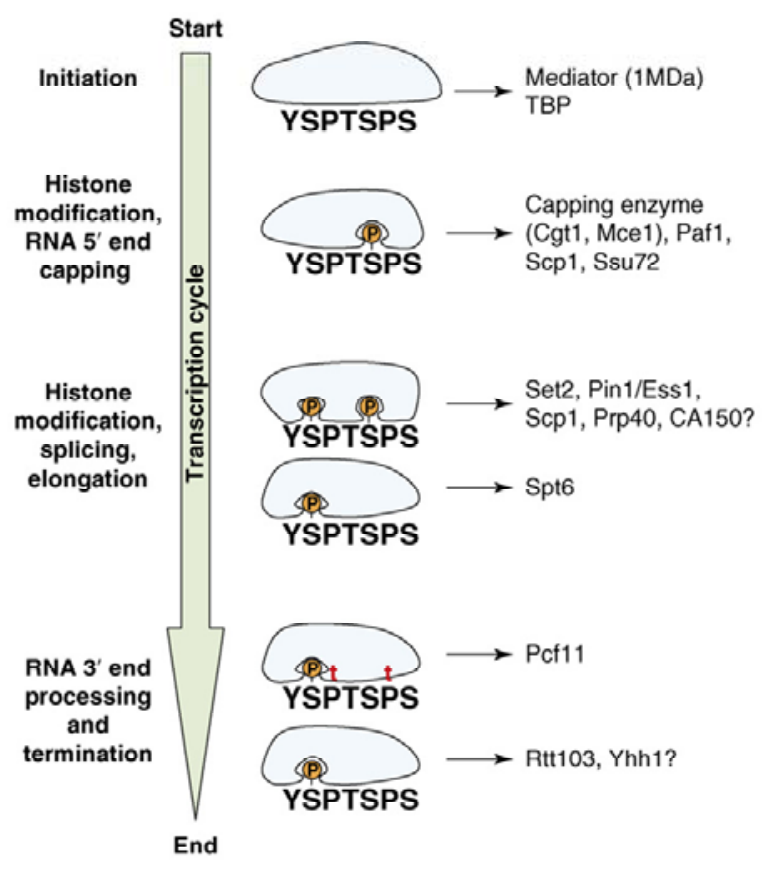


Figure 2. The carboxyl-terminal domain of RNAPII is subjected to various posttranslational modifications and serves as a docking site for many transcription-related factors. The stages of transcription and co-transcriptioonal processes are listed on the left. Yellow circles and red " $t$ "s represent phosphorylations and proline isomerisations, respectively. CTD-binding factors are shown as light blue shapes. The proteins listed on the right were all shown to directly bind the RNAPII CTD. Taken from (Egloff \& Murphy, 2008).

In brief, the unphosphorylated RNAPII binds TBP and Mediator complex in the beginning of transcription cycle (Myers et al, 1998; Usheva et al, 1992). The phosphorylation of serine 5 was shown to promote the binding of RNA capping enzymes (Phatnani \& Greenleaf, 2006) since the cap is required for further mRNA survival. As the serine 2 gets phosphorylated and the polymerase goes into the elongation stage the phosphorylation of serine 5 declines which can be explained by the recruitment of CTD phosphatases to the bi-phosphorylated CTD (Zhang et al, 2006). The elongation factor hSUPT6H binds only Ser2-phosphorylated polymerase (Yoh et al, 2007).

Apart from elongation in yeast p-Ser2 has been also shown to play an important role in 3'-end processing. The Pcfl1, a component of yeast cleavage/polyadenylation factor CFIA, is specifically binding the Ser-2 phosphorylated CDT of RNAPII (Licatalosi et al, 2002).

\subsection{P-TEFb complex}

\subsubsection{Regulation of P-TEFb activity}

The P-TEFb complex plays an important role in the regulation of transcription and transcription-coupled processes such as mRNA processing and chromatin modifications. In this way P-TEFb plays an important role in controlling gene transcription under many conditions and can influence such diverse processes as cell differentiation and DNA damage repair.

In its active form the complex consists of a kinase component CDK9 and cyclin T1 (CCNT1), and less often T2 or K (Fu et al, 1999; Peng et al, 1998). Unlike most other cyclins, CCNT1 is not subjected to a cell cycle-dependent regulation and its amount remains constant throughout the cell cycle (Grana \& Reddy, 1995). However, the activity of P-TEFb complex is tightly regulated.

CDK9-CCNT1 heterodimers are kept in an inactive state in a complex with the HEXIM1 protein and 7SK snRNA (Nguyen et al, 2001; Yang et al, 2001; Yik 
et al, 2003). About half of P-TEFb complexes can be sequestered in this way (Nguyen et al, 2001).

Like other cyclin-dependent kinases, CDK9 has a conserved threonine residue in its T-loop domain. The phosphorylation of this residue changes the conformation of the active center to allow for the interaction with a substrate (Russo et al, 1996). Thr186 in CDK9 can be dephosphorylated by several phosphatases such as PP1 $\alpha$ or PP2B (Chen et al, 2008). This dephosphorylation happens upon UV-irradiation or hexamethylene bisacetamide (HMBA)-induced stress. The activity of these phosphatases is regulated by the $\mathrm{Ca} 2+$-calmodulin pathway. The dephosphorylated form of CDK9 is released from the HEXIM/7SK complex (Chen et al, 2008). Upon release CDK9 can be bound by Brd4 which can specifically recognize acetylated histones (Wu \& Chiang, 2007) and brings the CDK9-CCNT1 complex to the transcription initiation site where it remains inactive until the start of productive elongation(Jang et al, 2005; Yang et al, 2005).

\subsubsection{P-TEFb substrates}

One of the first described targets of P-TEFb was RNA polymerase II CTD whose function and regulation were described above (Marshall et al, 1996). RNAPII is not the only target of CDK9 in the transcription elongation complex. Negative elongation factor, NELF, is known to inhibit the transcription elongation by binding RNAPII together with another inhibitor, 5,6-dichloro-1-beta-Dribofuranosylbenzimidazole (DRB) Sensitivity Inducing Factor DSIF (Wada et al, 1998a; Yamaguchi et al, 1999). P-TEFb phosphorylates the NELF-E subunit which leads to its release from RNAPII binding (Fujinaga et al, 2004). Supressor of Ty Homologue-5 (SUPT5H), a component of DSIF, is also phosphorylated by P-TEFb (Kim \& Sharp, 2001; Wada et al, 1998b). The phosphorylation is localized in CTR1, a repeat domain containing several repeats of PSPSPASY sequence analogous to RNAPII CTD (Ivanov et al, 2000). In contrast to released NELF, the phosphorylated DSIF stays in the complex with RNAPII becoming now a positive factor of elongation (Yamada et al, 2006).

Apart from the regulation of transcription elongation $\mathrm{P}-\mathrm{TEFb}$ was also shown to directly control transcription factor activity. For example, the transcription factor MyoD, a key regulator of myoblasts differentiation (Davis et al, 1987), is phosphorylated by the CDK9/CCNT2 complex. This phosphorylation 
increases MyoD activity and promotes the muscular differentiation (Simone et al, 2002).

Peroxisome proliferator-activated receptor gamma (PPAR $\gamma$ ) is another PTEFb-regulated transcription factor. Upon CDK9-mediated phosphorylation PPAR $\gamma$ is activated which promotes adipocyte differentiation (Iankova et al, 2006).

\subsection{H2B ubiquitination.}

\subsubsection{Overview of chromatin structure}

Chromatin is a complex of DNA, histones and other proteins that form chromosome. The basic unit of the chromatin is the nucleosome. The typical nucleosome is a heterooctamer consisting of two histone $\mathrm{H} 3-\mathrm{H} 4$ dimers which form a stable tetramer as well as two flanking histones H2A-H2B dimers. Standard nucleosome consisting of canonical histones is wrapped by 147 base pairs of DNA (Davey et al, 2002; Luger et al, 1997).

While the core domains of histones perform solely structural function, the $\mathrm{N}$ - and C-terminal tails are exposed outside the nucleosome and often subjected to a wide range of posttranslational modifications including acetylation and ubiquitination of lysines, methylation of lysines and arginines, and phosphorylation of serines and threonines (Turner, 2007) (Fig. 3). 

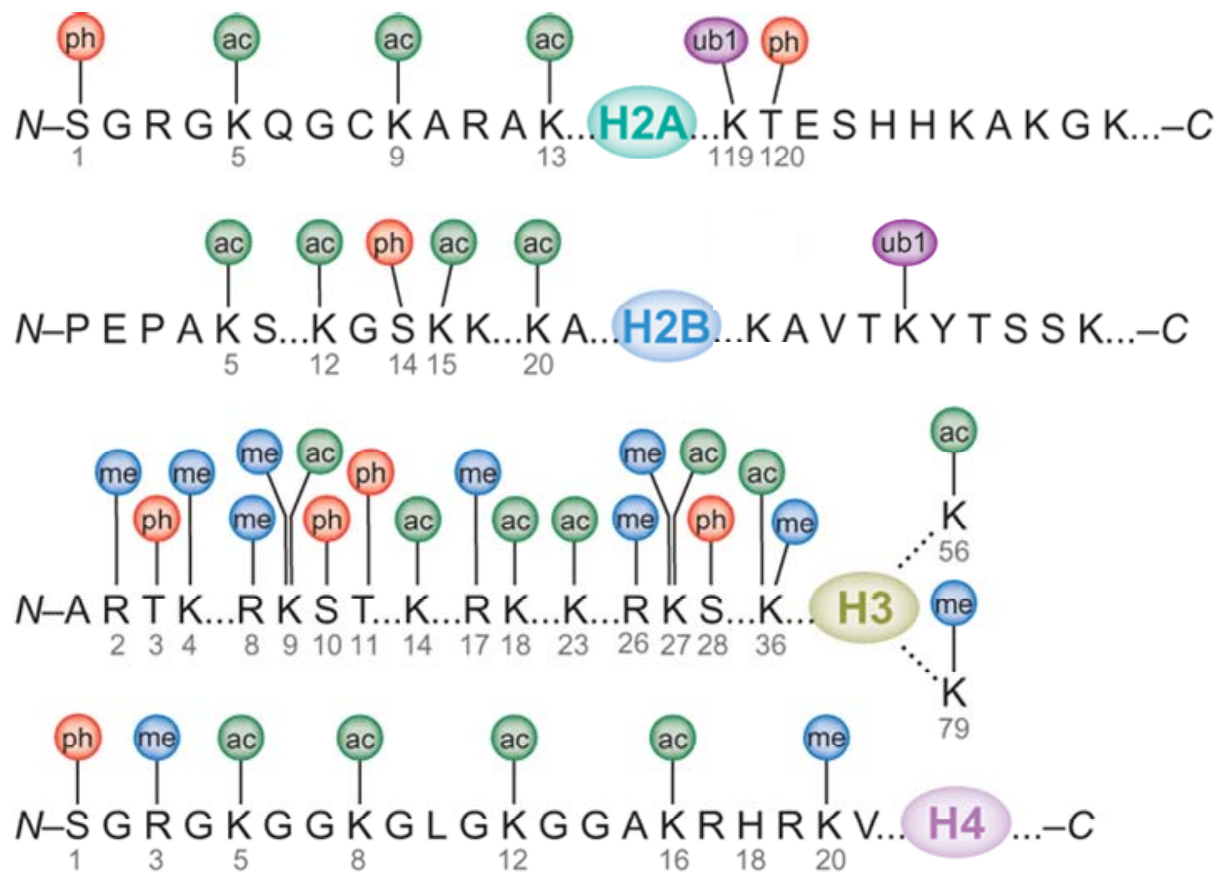

Figure 3. Variety of histone modifications. The core parts of histones are represented as colored ovals. Tails are shown as sequences of aminoacids. Modifications: me-methylation, ph-phosphorylation, ac-acetylation, ub1-monoubiquitination. Taken from: (Bhaumik et al, 2007).

This wide variety of modifications and their relatively uniform distribution in the same regions of many genes (Fig. 4) gave rise to the concept of histone code (Strahl \& Allis, 2000). This hypothesis suggests a combinatorial effect of histones modifications on the recruitment of chromatin-interacting factors with specific biological functions. In general, there are marks mostly associated with inactive chromatin, such as hypoacetylation, H3K9me3 and H3K27me3 while the hyperacetylation, $\mathrm{H} 3 \mathrm{~K} 4 \mathrm{me} 3$ and $\mathrm{H} 3 \mathrm{~K} 36 \mathrm{me} 3$ are found mostly on transcribed genes (Ruthenburg et al, 2007).

The precise location of histone modifications in different regions of a gene is achieved by close integration of chromatin-modifying enzymes with the transcription apparatus (Fig. 4). A good example of such regulation is trimethylation of histone H3K4. It is performed by Set1p methyl transferase which is recruited to the serine 5-phosphorylated RNAPII at the 5'-end of a gene (Liu et 
al, 2005; Ng et al, 2003; Santos-Rosa et al, 2002). Similarly, H3K36me3 is controlled by Set $2 p$ which is associated with a dually Ser2/Ser5-phosphorylated elongating RNAPII and is mostly detected in the middle and 3'-end regions of active genes (Carrozza et al, 2005; Keogh et al, 2005).

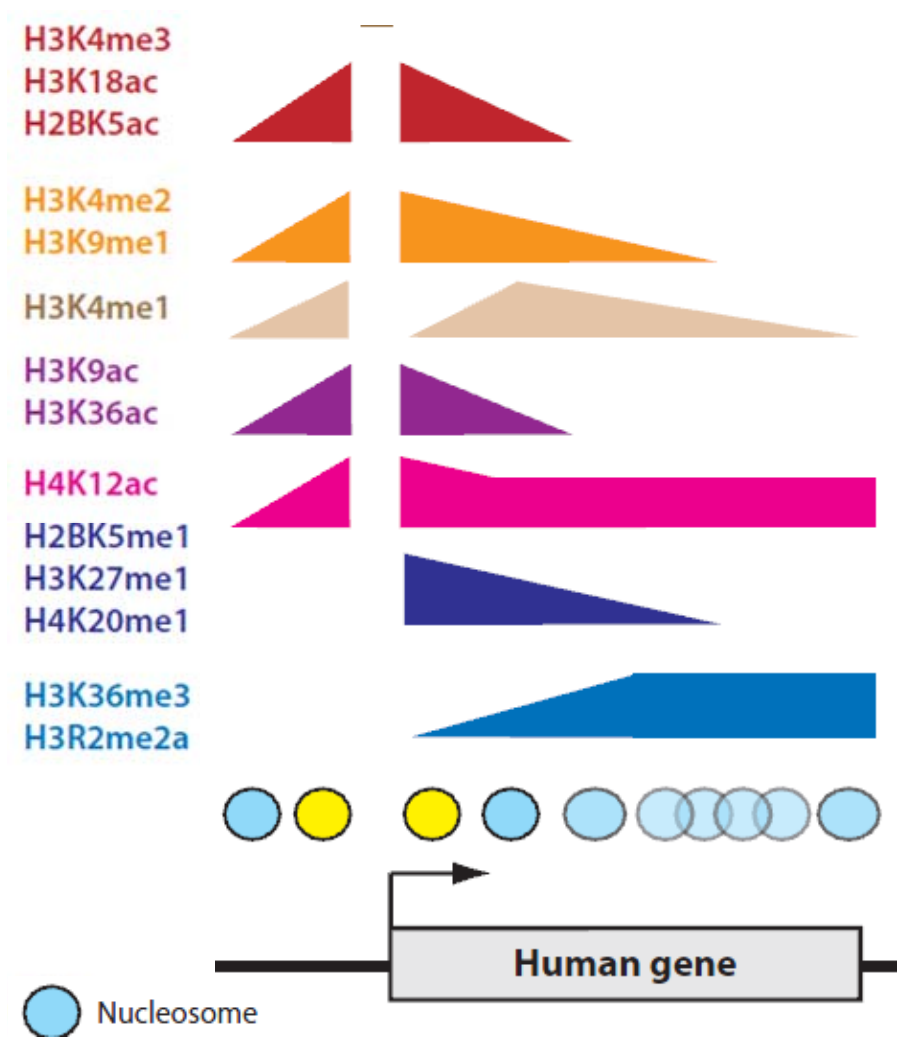

Figure 4. Chromatin map of an active human gene. Modified from (Rando \& Chang, 2009).

Apart from modifications of canonical histones the epigenetic background can be altered by the incorporation of histone variants. Histones H2A and H3 have physiologically important variants while $\mathrm{H} 2 \mathrm{~B}$ and $\mathrm{H} 4$ are mostly invariant (Malik \& Henikoff, 2003).

The H2A.Z variant in mammals is predominantly localized in the enhancer elements, insulator regions and around the transcription a start site (Barski et al, 2007; Schones et al, 2008) 
H2A.Bbd lacks 13 of 14 acetylatable lysines, the ubiquitinatable C-terminal tail and and the acidic region which contacts H4 (Doyen et al, 2006). As a result the H2A.Bbd-containing nucleosomes bind only 118 DNA residues and are significantly less stable (Bao et al, 2004).

In contrast macroH2A contains large non-histone c-terminal tail and is much bigger than canonical H2A (Pehrson \& Fried, 1992). Due to the increased stability of macroH2A-containing nucleosomes they are mostly found in transcriptionally inactive regions such as the inactivated $\mathrm{X}$-chromosome and methylated CpG islands (Choo et al, 2006; Costanzi \& Pehrson, 1998).

The highly transcribed regions of chromatin are also marked by the the H3.3 variant. Being only 5 amino acids different from canonical H3 it nevertheless makes nucleosomes extremely unstable (Jin \& Felsenfeld, 2007). In contrast, H3.1 variant is also found in significant proportion in silenced chromatin regions (Hake \& Allis, 2006).

The H2A.X variant constitutes about $10 \%$ of total H2A in human cells. It is phosphorylated in the region of double strand DNA break by DNA damage response kinases like ATM, ATR and DNA-PK (Burma et al, 2001; Stiff et al, 2004)4-6. The size of phosphorylated region around the break can reach a megabase (Rogakou et al, 1999). The loss of H2A.X causes impaired formation of DNA damage repair loci with reduced accumulation of basic repair factors like MDC1, BRCA1 and 53BP1 while the initial recruitment of this factors still takes place (Celeste et al, 2003; Paull et al, 2000; Ward et al, 2003).

\subsubsection{H2B monoubiquitination}

Monoubiquitination of Lysine in the C-terminal tail of histone $\mathrm{H} 2 \mathrm{~B}$ is conserved from yeast (K123) to human (K120) (Robzyk et al, 2000; Thorne et al, 1987). Like all other ubiquitination reactions this requires the activity of E1, E2 and E3 ubiquitinating enzymes which subsequently transfer the activated ubiquitin molecule to the target protein (Pickart, 2001). The E2 ubiquitin conjugating enzyme for H2B in yeast is called Rad6 (Robzyk et al, 2000). In human this function is assigned to the Rad6 homolog the UBE2A protein (Kim et al, 2009). Bre1 serves as an E3 ubiquitin ligase of H2B in the yeast Saccharomyces cereviseae (Wood et al, 2003). In human Bre1 has two homologs, Bre1A and Bre1B, also refered to as RNF20 and RNF40. A heterodimeric complex of the E3 
ring-finger ubiquitin ligases RNF20 and RNF40 is responsible for the final step of ubiquitin transfer to the $\mathrm{H} 2 \mathrm{~B}$, however, in vitro only RNF20 enzymatic activity is needed for the reaction (Kim et al, 2005; Zhu et al, 2005).

Since monoubiquitination of $\mathrm{H} 2 \mathrm{~B}$ does not lead to protein degradation the ubiquitin moiety has to be removed in order to suppress the signaling when necessary. In yeast two ubiquitin proteases were described, Ubp8 and Ubp10. Ubp8 is a component of the Spt-Ada-Gen5-acetyltransferase (SAGA) complex (Daniel et al, 2004). In humans the ortholog of Ubp8, USP22 was found (Zhang et al, 2008). As in yeast, USP22 requires the interaction with other SAGA complex subunits CG13379 and ATXN7L3 for its deubiquitination activity (Henry et al, 2003; Zhao et al, 2008). Interestingly, unlike yeast, in which H2A is not ubiquitinated, USP22 deubiquitinated not only H2B, but also H2A (Zhao et al, 2008)

Unlike Upb8 the ubiquitin protease Ubp10 is not associated with the active fraction of the genome. Instead it interacts with the silencing protein Sir4 and plays a role in silencing telomeric regions as well as rRNA genes (Emre et al, 2005). No human orthologs of Ubp10 were described so far.

\subsubsection{Function of H2B ubiquitination}

The attachment of a bulky ubiquitin to $\mathrm{H} 2 \mathrm{~B}$ histone was shown to significantly modify the properties of chromatin in vitro. The compaction of the chromatin into $30 \mathrm{~nm}$ fiber was severely impared when ubiquitinated H2B was incorporated into nucleosomes. Besides, such chromatin was shown to be more available for the Dot1L methyltransferase (Fig. 5) (Fierz et al, 2011). 


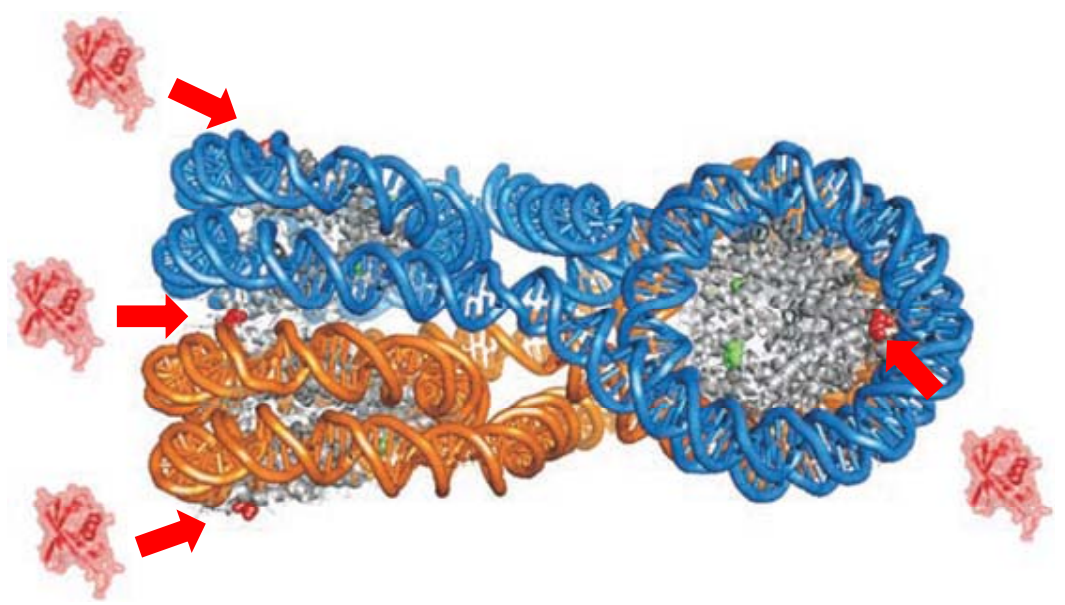

Figure 5. H2B ubiquitination in the context of 30-nm fiber. Tetranucleosome unit extracted from the fiber and rotated by $38.1^{\circ}$. Red arrows indicate the sites of ubiquitin (pink) attachment. Modified from (Fierz et al, 2011)

In yeast, monoubiquitinated $\mathrm{H} 2 \mathrm{~B}$ has been generally associated with the promoters and coding regions of actively transcribed genes (Henry et al, 2003; Kao et al, 2004; Xiao et al, 2005). Yeast strains which have a K123R mutation in H2B demonstrated strong transcriptional defects. H2B ubiquitination was shown to be important for the recruitment of COMPASS methyltransferase complex to the chromatin. This way of epigenetic regulation was called trans-tail histone modifications (Fischle et al, 2003). Di- and trimethylation of lysines 4 and 79 on histone H3 were significantly impaired in strains lacking H2Bub1 (Lee et al, 2007). The absence of H2Bub1 caused the overall reduction of nucleosome occupancy in the transcribed regions of the genes. The initiation of transcription from intragenic cryptic transcription sites was also detected. This way be explained by the fact that H2Bub1 was found to be in a close functional interaction with the FACT (Facilitates Active Chromatin Transcription) complex (Fleming et al, 2008; Pavri et al, 2006). FACT, being a $\mathrm{H} 2 \mathrm{~A} / \mathrm{H} 2 \mathrm{~B}$ chaperone is involved in the disassembly and reassembly of nucleosomes during the transcription (Fig. 6) (Belotserkovskaya et al, 2003). 


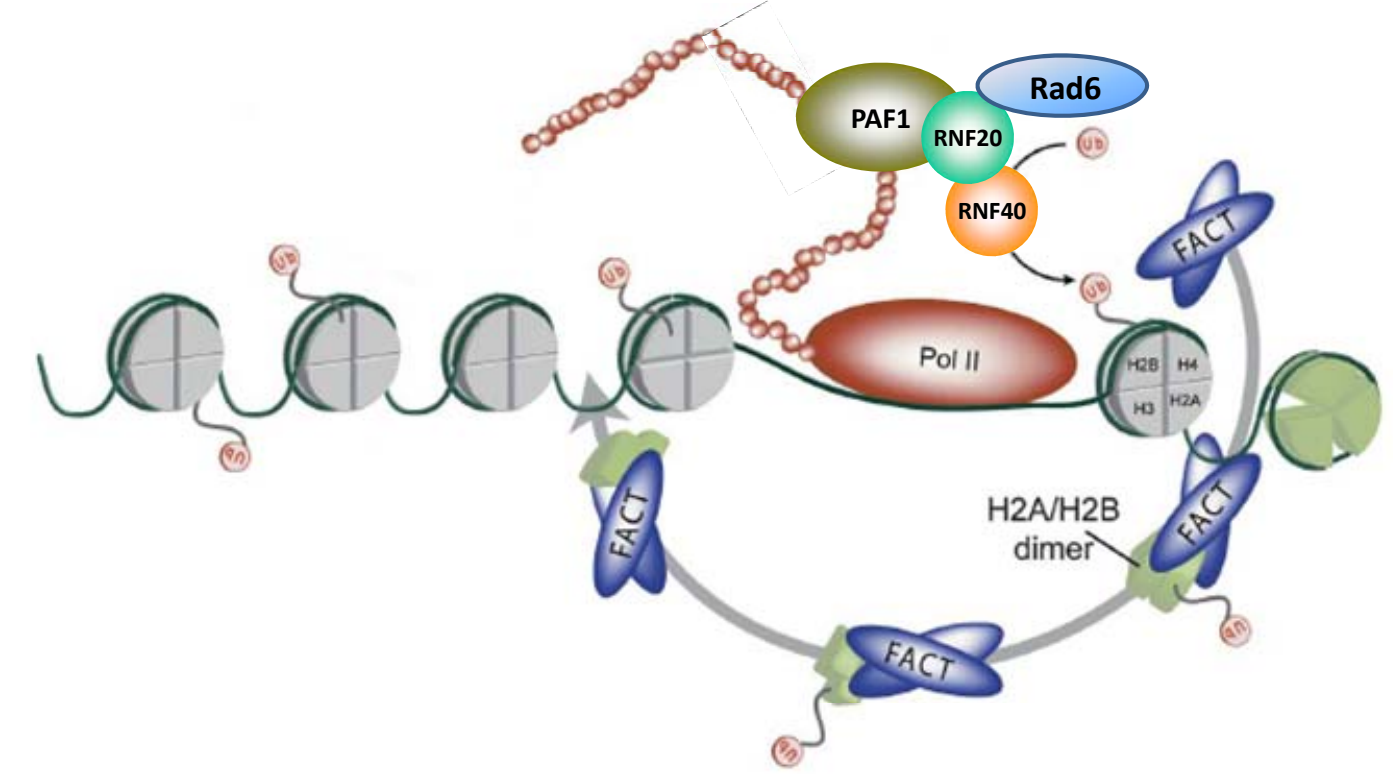

Figure 6. Dynamics and role of H2B monoubiquitination in transcription elongation. Modified from (Laribee et al, 2007)

Quite recently the mechanistic explanation was given for H2Bub1mediated chromatin alterations. It was shown that despite disrupting the 30-nm fiber structure H2Bub1 strongly increases the stability of individual nucleosomes. This, in fact, stabilized the binding of the FACT subunit Spt16 to the nucleosome in front of RNAPII and insures the proper chromatin reconstitution in the wake of RNA polymerase (Chandrasekharan et al, 2009).

In human cells the role of H2Bub1 in supporting the level of histone methylation was also shown. The overexpression of RNF20 led to the accumulation of H3K4me1, H3K4me3 and H3K79me3 (Zhu et al, 2005). The depletion of RNF20 and RNF40 with siRNA resulted in a significant decrease of the same histone methylations. The presence of RNF20/40 was shown to be essential for the expression of genes from HoxA cluster. Most of the genes were upregulated and downregulated by the overexpression and siRNA-mediated depletion of H2B E3 ubiquitin ligases, respectively. Moreover, chromatin immunoprecipitation showed that HoxA genes, which where regulated by H2Bub1, had significant changes of histone H3 methylations upon RNF20/40 overexpression or knockdown. Altogether that provided first robust model of gene 
expression regulation by $\mathrm{H} 2 \mathrm{Bub} 1$ in human cells. Supporting evidence for a positive role of $\mathrm{H} 2 \mathrm{Bub} 1$ in transcription came from further studies in which the retinoic acid-induced transcription of retinoic acid receptor-alpha gene was shown to depend upon RNF20 and 40 in vivo and H2Bub1 in vitro (Pavri et al, 2006).

One of the components of H2B ubiquitinating complex, RNF20 has been found to be a putative tumor suppressor. Surprisingly, it has a repressive influence on the induction of EGF-responsive genes (Shema et al, 2008). Moreover, its depletion promotes cell migration and its promoter is hypermethylated in many tumors.

Not only the expression of genes but also the processing of transcripts is regulated by H2Bub1 in human. The 3'-ends of the replication dependent histone genes are normally processed into stem loop structure by stem loop-binding protein SLBP and U7 small nuclear ribonuclear protein (snRNP) (Marzluff et al, 2008). Recently it has been shown that upon the depletion of RNF20/40 RNAPII with higher probability skips the site of 3'-end processing and synthesizes a longer polyadenylated transcript (Pirngruber et al, 2009b).

In the sites of DNA brakes the chromatin undergoes different modifications. Recent reports show an accumulation of H2Bub1 on the damaged chromatin as well as the interaction of $\mathrm{H} 2 \mathrm{~B}$ ubiquitinating enzymes with DNA repair machinery (Moyal et al, 2011; Nakamura et al, 2011). In accordance with the above mentioned in vitro data H2Bub1 accumulation might play an important role in decompacting the chromatin for the double-stranded DNA break repair.

\subsection{Rad6}

\subsubsection{Rad6 in yeast}

Rad6 was one of the first yeast proteins identified as a regulator of $\mathrm{H} 2 \mathrm{~B}$ ubiquitination. This E2 ubiquitin conjugating enzyme was shown to ubiquitinate H2B in vivo and in vitro (Robzyk et al, 2000). Later it was demonstrated that the in vivo activity of Rad6 is not detected if Bre1, an E3 RING-finger ubiquitin ligase was not present (Wood et al, 2003). 


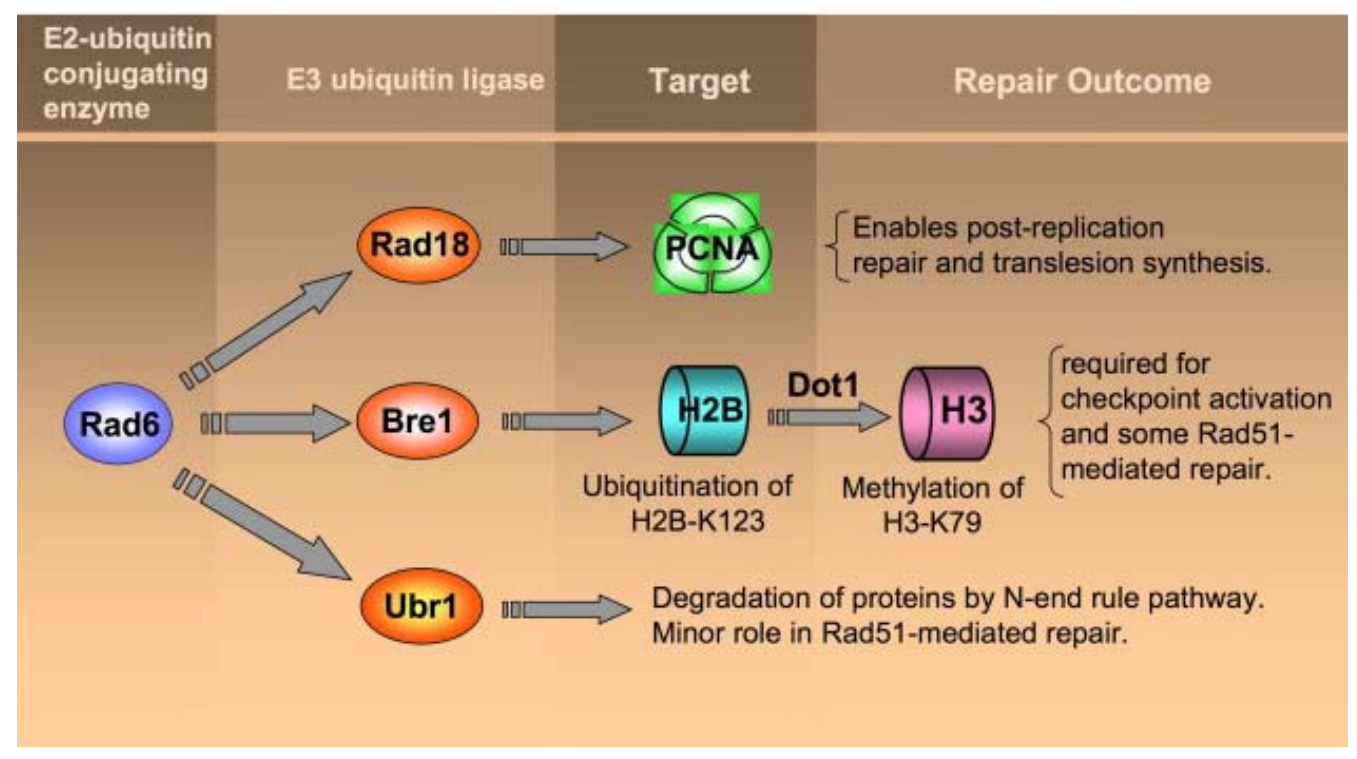

Figure 7. Multiple functions of Rad6 in yeast. Taken from (Game \& Chernikova, 2009)

Like most E2 enzymes, Rad6 is involved in the ubiquitination of several substrates (Fig. 7). Proliferating Cell Nuclear Antigen (PCNA) has been shown to be ubiquitinated at lysine 164 by Rad6 in a complex with the E3 ubiquitin ligase Rad18. In a complex with another E3 ubiquitin ligase, Rad5, Rad6 can convert the monoubiquitination of PCNA into a K63-linked poliubiquitin chain (Hoege et al, 2002). This ubiquitination mark promotes the interaction of DNA polymerase eta with the DNA clamp PCNA to activate the translesion DNA synthesis pathway in both yeast and human (Haracska et al, 2001; Haracska et al, 2004; Kannouche et al, 2004). The N-end rule pathway of protein degradation also makes use of Rad6 where it serves as an E2 enzyme for E3 ubiquitin ligase Ubr1 (Dohmen et al, 1991)

\subsubsection{UBE2A (hRAD6)}

The closest homolog of yeast Rad6 in human are called UBE2A (Fig. 8) and UBE2B. However, UBE2A appears to be the predominantly expressed form. In resemblance to its yeast homolog it is involved in the ubiquitination of histone H2B in a complex with E3 ubiquitin ligases RNF20/RNF40 (Kim et al, 2009). The 
ubiquitination of human PCNA is also mediated by UBE2A in association with E3 ligase hRAD18 (Watanabe et al, 2004).

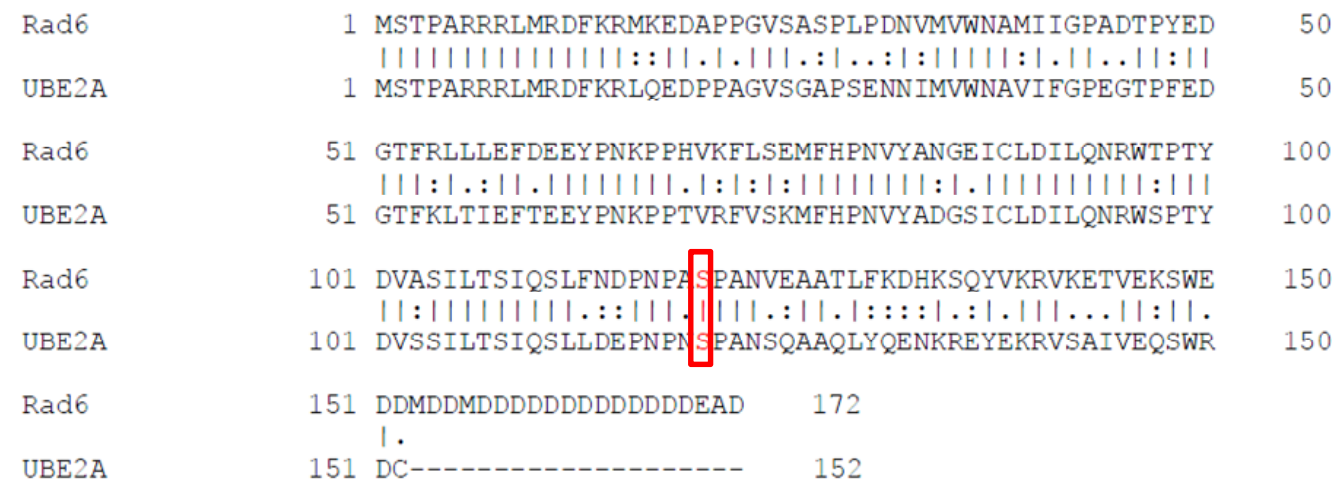

Figure 8. Alignment of amino acid sequences of yeast Rad6 and human UBE2A. Conserved phosphorylated serine residue is marked in red. (Done by EMBOSS alignment tool.)

\subsubsection{Regulation of Rad6 activity}

The Bur1/Bur2 complex is essential for yeast growth and consists of the cdc28-related kinase Bur1 and cyclin T family member Bur2 (Yao et al, 2000). It has been shown to phosphorylate Rad6 at serine 120 in yeast and this phosphorylation is necessary for the ability of Rad6 to ubiquitinate H2B (Wood et al, 2005).

In human cells UBE2A can also be phosphorylated at conserved serine 120 by CDKs 1 and 2 (Sarcevic et al, 2002). In vivo the phosphorylation of UBE2A increases during the $G 2 / \mathrm{M}$ transition. The mutation of serine 120 into alanine abolishes UBE2A activity

\subsection{Loss of H2B ubiquitination}

$\mathrm{H} 2 \mathrm{Bub} 1 \mathrm{is}$ a dynamic chromatin modification. A severe decrease of H2B ubiquitination was shown upon treating cells with different stress-inducing factors such as proteosome inhibitors, heat shock, sodium arsenite, cadmium chloride, doxorubicin, Actinomycin D or DRB (Davie \& Murphy, 1990; Mimnaugh et al, 1997; Minsky et al, 2008). That suggests the existence of a universal mechanism of 
chromatin modification in response to different stresses. As an explanation of the observed effect the depletion of free ubiquitin or the inhibition of transcription were proposed (Davie \& Murphy, 1994).

\subsubsection{Nucleoli and stress conditions}

\subsubsection{Nucleoli overview}

Nucleoli are subnuclear organelles where the production of small and large subunits of ribosomes takes place. Therefore their function must be tightly regulated in different growth conditions (Lempiainen \& Shore, 2009). Three distinct processes occur in the nucleoli: pre-rRNA transcription, processing, and ribosomal RNP assembly. Accordingly, three compartments are distinguished in nucleolar microstructure. The fibrillar center (FC) hosts the transcription, dense fibrillar component (DFC) is a place of rRNA processing while the assembly of ribosomal subunits happens in the granular component (GC) (Boisvert et al, 2007)

\subsubsection{Nucleolar reaction to stress}

In stress conditions the structure of nucleoli undergoes different changes. One of them is called nucleolar segregation and is caused by UV irradiation, topoisomerase inhibitors or actinomycin D. During this process the FC and GC are condensed and separated while the nucleolar cap is formed from nucleolar and nuclear proteins around the nucleolar remnant (Al-Baker et al, 2005; Shav-Tal et al, 2005).

The nucleolar proteome contains about 4500 different proteins while only $30 \%$ of them are directly involved in ribosomal biosynthesis (Ahmad et al, 2009). The rest are involved in DNA replication and repair, apoptosis control, RNP biogenesis and cell cycle regulation. The studies involving quantitative mass spectrometry and fluorescence microscopy of more than 1000 nucleolar proteins revealed a massive translocation of factors involved in nucleolar stress, DNA damage pathway and oxidative stress response upon treatment with the topoisomerase I inhibitor camptothecin. This translocation has been shown to be quite rapid so that some components changed their localization already in two min after adding the drug (Cohen et al, 2008).

A typical mechanism of cell cycle regulation by nucleolar signaling involves the regulation of p53 level. In normally growing cells p53 protein levels 
are kept low due to its constant ubiquitination by the E3 ubiquitin ligase HDM2 which marks p53 for proteosomal degradation (Kruse \& Gu, 2009). The activity of HDM2 can be inhibited by $14^{\text {ARF }}$, a protein with nucleolar localization (Sherr, 2001). The ARF protein is itself very unstable. It is also ubiquitinated by the E3 ligase UlF and subsequently degraded. Another important nucleolar component, nucleophosmin (NPM) has been shown to abrogate ARF degradation thus inhibiting HDM2 activity and stabilizing p53 to block the progression of cell cycle progression (Chen et al, 2010).

\subsubsection{Cajal bodies and nucleoli}

A

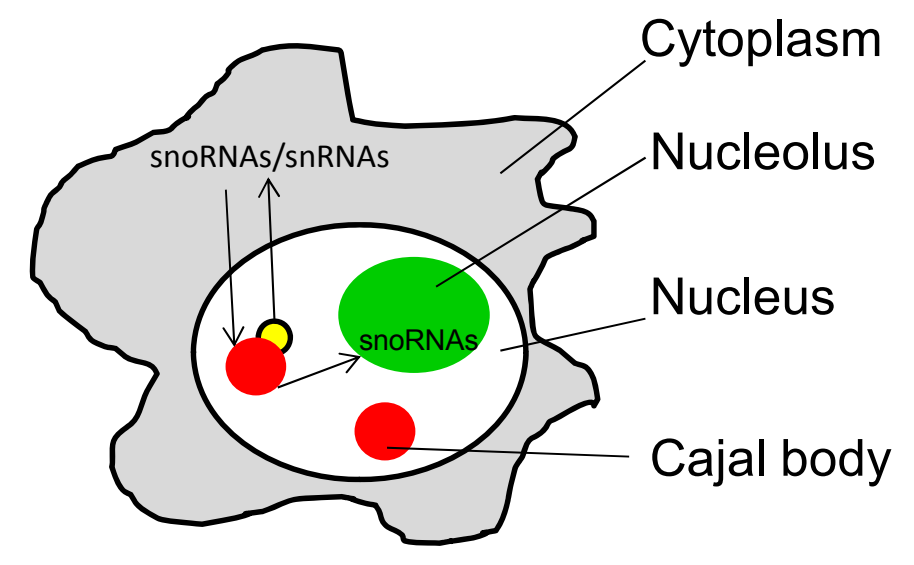

B

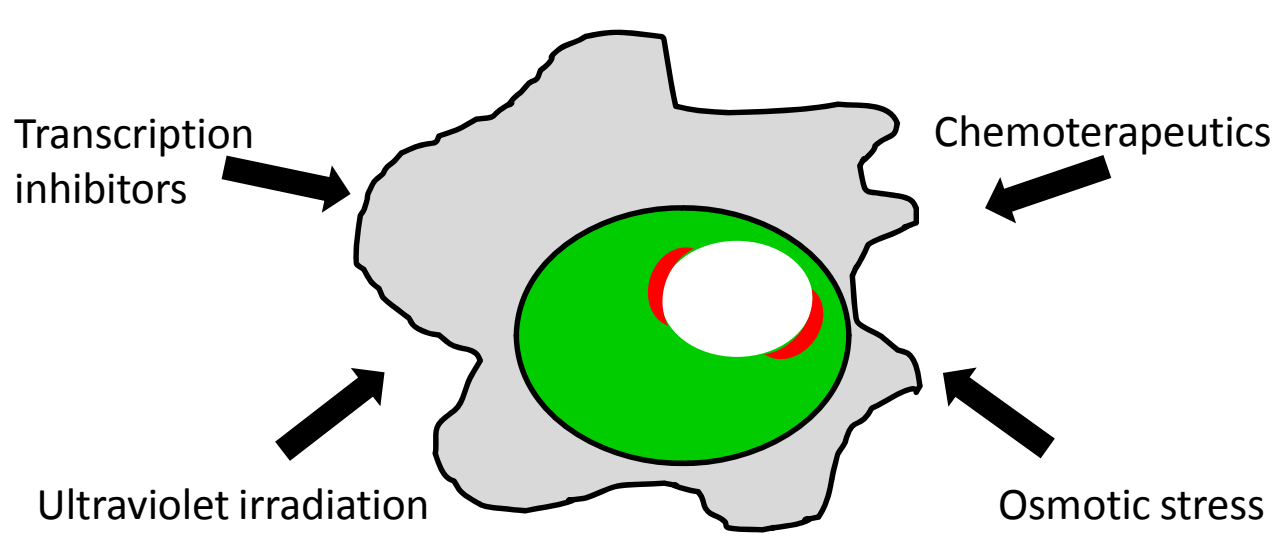

Figure 9. Nucleoli and Cajal bodies. A. Functional interaction between CBs and nucleoli. SnRNAs are transcribed from their locus (yellow) adjacent to CBs (red) (Frey \& Matera, 2001) and then are transported to the cytoplasm (grey) for splicing. After re-import to the nucleus snRNAs undergo final maturation in CBs and migrate to the nucleolus (green) as a 
part of snRNP complexes which are involved in rRNA processing. B. Upon different stress conditions nucleolar components (nucleophosmin, green) are released to the nucleoplasm whereas CB components (p80-coilin, red) migrate to the periphery of the nucleolus.

Cajal bodies (CBs) are distinct nuclear structures which function in the processing of different types of RNAs such as snRNAs, snoRNAs and histone mRNAs (Kiss et al, 2006; Matera et al, 2007; Nizami et al, 2010). One of the main components of CBs, p80-coilin is used as a CB marker and plays an important role in snRNP biogenesis and splicing (Cioce \& Lamond, 2005; Strzelecka et al, 2010).

CBs are linked to nucleoli both physically and functionally. In the nuclei of neurons these organelles are closely associated (Lafarga et al, 1986). The snoRNPs which undergo maturation in $\mathrm{CBs}$ are later transported to the nucleoli to serve for the rRNAs processing (Fig. 9A). Moreover, a constant shuttling of proteins like Nopp140 between the nucleoli and CB makes the connection between these compartments even more obvious. Nopp140 is a snoRNP chaperone and it probably acts as a transporter of snoRNPs to the nucleoli (Isaac et al, 1998). In micronucleated cells coilin was shown to be co-localized with nucleolar components such as fibrillarin, NOR-90 and RNA polymerase I. The functional role of such a protein localization shift remains unclear (Silva et al, 2004) .

\subsubsection{Cajal bodies under stress}

CBs undergo different transformations upon the exposure of cells to different stress conditions. Starvation decreases the number of CBs (Andrade et al, 1993), UV-C irradiation, osmotic stress and heat shock cause redistribution of coilin to nucleoplasmic microfoci as well as formation of so called nucleolar caps which also form upon actinomycin D treatment (Cioce et al, 2006; Handwerger et al, 2002; Shav-Tal et al, 2005). In HeLa cells, the overexpression of a phosphorylation site-mimicking mutant coilin (S202D) resulted in nucleolar localization of this protein together with splicing snRNAs, suggesting the importance of S202 phosphorylation for the localization of CB components (Lyon et al, 1997).

\subsubsection{Nucleoli and JNK signaling}

C-Jun N-terminal kinase JNK belongs to the stress-activated protein kinase (SAPK) family and plays an important role in the cellular reaction to stress factors, regulating the choice between survival and apoptosis (Chen et al, 1996). The 
activity of JNK is increased upon exposure to UV-irradiation, alkylating agents, actinomycin D, hyperosmotic shock and oxidative damage (Martindale \& Holbrook, 2002; Song \& Lee, 2007; Yoon \& Kim, 2004). JNK activity is regulated by phosphorylation of threonine and tyrosine residues in the $\mathrm{T}^{*} \mathrm{PY}$ * motif by SEK1/MKK4 (Derijard et al, 1995). JNK inhibits the function of nucleoli by phosphorylating the key rRNA transcription factor TIF-IA (Bodem et al, 2000; Mayer et al, 2005). The inhibition of RNA polymerase I activity itself results in the development of the so-called "nucleolar stress response" which can cause p53 stabilization by ARF, L5 and L11 (Dai \& Lu, 2004; Lohrum et al, 2003) release as described previously. 


\section{Materials}

\subsection{Equipment}

\begin{tabular}{|c|c|}
\hline Agarose gel chamber & Harnischmacher Labortechnik, Kassel \\
\hline Balance & Sartorius AG, Göttingen \\
\hline Bandelin Sonoplus Sonicator & $\begin{array}{l}\text { Bandelin electr. GmbH \& Co. KG, } \\
\text { Berlin }\end{array}$ \\
\hline $\begin{array}{l}\text { Biological Safety Cabinet "Hera } \\
\text { Safe" }\end{array}$ & $\begin{array}{l}\text { Thermo Fisher Scientific, Waltham, } \\
\text { USA }\end{array}$ \\
\hline Bioruptor & Diagenode SA, Liège, Belgium \\
\hline Centrifuge (Megafuge 1.OR) & $\begin{array}{l}\text { Thermo Fisher Scientific, Waltham, } \\
\text { USA }\end{array}$ \\
\hline Centrifuge $4{ }^{\circ} \mathrm{C}(5417 \mathrm{R})$ & Eppendorf AG, Hamburg \\
\hline C1000TM Thermal Cycler & $\begin{array}{l}\text { Bio-Rad Laboratories GmbH, } \\
\text { München }\end{array}$ \\
\hline $\begin{array}{l}\text { CFX96TM Optical Reaction } \\
\text { Module }\end{array}$ & $\begin{array}{l}\text { Bio-Rad Laboratories GmbH, } \\
\text { München }\end{array}$ \\
\hline $\begin{array}{l}\text { Confocal microscope LSM510 } \\
\text { META }\end{array}$ & Carl Zeiss GmbH \\
\hline Counting chamber (Neubauer) & Brand GmbH \& Co. KG, Wertheim \\
\hline 5100 Cryo $1{ }^{\circ} \mathrm{C}$ Freezing Container & Thermo Fisher Scientific \\
\hline $\begin{array}{l}\text { Electrophoresis \& Electrotransfer } \\
\text { Unit }\end{array}$ & $\begin{array}{l}\text { GE Healthcare Europe GmbH, } \\
\text { München }\end{array}$ \\
\hline Freezer $-20^{\circ} \mathrm{C}$ & Liebherr GmbH, Biberach \\
\hline Freezer $-80^{\circ} \mathrm{C}$ "Hera freeze" & $\begin{array}{l}\text { Thermo Fisher Scientific, Waltham, } \\
\text { USA }\end{array}$ \\
\hline Gel Imager "Gel iX imager” & $\begin{array}{l}\text { Intas Science Imaging } \mathrm{GmbH} \text {, } \\
\text { Göttingen }\end{array}$ \\
\hline Incubator (bacteria) & $\begin{array}{l}\text { Memmert GmbH \& Co. KG, } \\
\text { Schwabach }\end{array}$ \\
\hline Incubator (bacteria culture) & Infors $\mathrm{AG}$, Bottmingen \\
\hline $\begin{array}{l}\text { Incubator (cell culture) "Hera cell } \\
150 "\end{array}$ & $\begin{array}{l}\text { Thermo Fisher Scientific, Waltham, } \\
\text { USA }\end{array}$ \\
\hline $\begin{array}{l}\text { Inverse Microscope "Axiovert } 40 \\
\text { CFL" }\end{array}$ & $\begin{array}{l}\text { Carl Zeiss MicroImaging GmbH, } \\
\text { Göttingen }\end{array}$ \\
\hline Magnet stirrer "MR3001" & $\begin{array}{l}\text { Heidolph GmbH \& Co. KG, } \\
\text { Schwabach }\end{array}$ \\
\hline
\end{tabular}




\begin{tabular}{|l|l|}
\hline Microscope “Axiovert 40 C“ & $\begin{array}{l}\text { Carl Zeiss MicroImaging GmbH, } \\
\text { Göttingen }\end{array}$ \\
\hline Microwave & $\begin{array}{l}\text { Clatronic International GmbH, } \\
\text { Kempen }\end{array}$ \\
\hline $\begin{array}{l}\text { Nano Drop® ND-1000 } \\
\text { Spectrophotometer }\end{array}$ & $\begin{array}{l}\text { Peqlab Biotechnology GmbH, } \\
\text { Erlangen }\end{array}$ \\
\hline Pestle & Sartorius AG, Göttingen \\
\hline pH meter & inoLab® WTW GmbH, Weilheim \\
\hline Phosphoimager TYPHOON 9400 & Amersham Biosciences \\
\hline Pipette Aid® portable XP & $\begin{array}{l}\text { Drummond Scientific Co., Broomall, } \\
\text { USA }\end{array}$ \\
\hline Pipettes "Research" Series & Eppendorf AG, Hamburg \\
\hline Power supply "Power Pack P25T” & Biometra GmbH, Göttingen \\
\hline Refrigerator & Liebherr GmbH, Biberach \\
\hline Repeat Pipette & Eppendorf AG, Hamburg \\
\hline Scanner (CanoScan 8600F) & Canon GmbH, Krefeld \\
\hline Shaker "Rocky" & Schütt Labortechnik GmbH, Göttingen \\
\hline Table centrifuge (GMC-060) & LMS Co., Ltd., Tokyo, Japan \\
\hline Test tube rotator & Schütt Labortechnik GmbH, Göttingen \\
\hline Ultrapure Water System “Aquintus” & membraPure GmbH, Bodenheim \\
\hline Vacuum pump & $\begin{array}{l}\text { Integra Bioscienc. AG, Zizers, } \\
\text { Switzerland }\end{array}$ \\
\hline Vortex mixer & $\begin{array}{l}\text { Scientific Industries, Inc., Bohemia, } \\
\text { USA }\end{array}$ \\
\hline Water bath “TW 20" & $\begin{array}{l}\text { JULABO Labortechnik GmbH, } \\
\text { Seelbach }\end{array}$ \\
\hline X-Ray Cassettes & Rego X-ray GmbH, Augsburg \\
\hline
\end{tabular}

\subsection{Consumables}

\begin{tabular}{|l|l|}
\hline $\begin{array}{l}\text { Cellstar 6- and 12-well cell culture } \\
\text { plate }\end{array}$ & $\begin{array}{l}\text { Greiner Bio-One } \mathrm{GmbH}, \\
\text { Frickenhausen }\end{array}$ \\
\hline Cellstar PP-tube 15 and $50 \mathrm{ml}$ & $\begin{array}{l}\text { Greiner Bio-One } \mathrm{GmbH}, \\
\text { Frickenhausen }\end{array}$ \\
\hline Cellstar tissue culture dish $100 \times 20 \mathrm{~mm}$ & $\begin{array}{l}\text { Greiner Bio-One GmbH, } \\
\text { Frickenhausen }\end{array}$ \\
\hline Cellstar tissue culture dish $145 \times 20 \mathrm{~mm}$ & $\begin{array}{l}\text { Greiner Bio-One GmbH, } \\
\text { Frickenhausen }\end{array}$ \\
\hline Cell scraper $(16 \mathrm{~cm})$ & Sarstedt AG \& Co., Nümbrecht \\
\hline
\end{tabular}




\begin{tabular}{|c|c|}
\hline Cryo TubeTM Vial (1.8 ml) & $\begin{array}{l}\text { Thermo Fisher Scientific, Waltham, } \\
\text { USA }\end{array}$ \\
\hline Falcon ${ }^{\circledR}$ assay plate, 96 well & $\begin{array}{l}\text { VWR Int., LLC, West Chester, } \\
\text { USA }\end{array}$ \\
\hline Gel blotting paper (Whatman paper) & Sartorius AG, Göttingen \\
\hline Glass coverslips $(18 \mathrm{~mm})$ & Gebr. Rettberg GmbH, Göttingen \\
\hline HybondTM-PVDF Transfer Membrane & $\begin{array}{l}\text { GE Healthcare Europe GmbH, } \\
\text { München }\end{array}$ \\
\hline Microtube $1.5 \mathrm{ml}$ & Sarstedt AG \& Co., Nümbrecht \\
\hline Microtube $1.5 \mathrm{ml}$, conical & $\begin{array}{l}\text { VWR International GmbH, } \\
\text { Darmstadt }\end{array}$ \\
\hline Microtube $2 \mathrm{ml}$ & Sarstedt AG \& Co., Nümbrecht \\
\hline 96 Multiply ${ }^{\circledR}$ PCR plate white & Sarstedt AG \& Co., Nümbrecht \\
\hline $\begin{array}{l}\text { 96-well Multiplate } \AA \text { PCR plate white } \\
\text { (low) }\end{array}$ & $\begin{array}{l}\text { Bio-Rad Laboratories } \mathrm{GmbH} \text {, } \\
\text { München }\end{array}$ \\
\hline Parafilm $\AA$ "M" & $\begin{array}{l}\text { Pechiney Plastic Packaging, } \\
\text { Chicago, USA }\end{array}$ \\
\hline Petri dish $92 \times 16 \mathrm{~mm}$ & Sarstedt AG \& Co., Nümbrecht \\
\hline Pipette tips & $\begin{array}{l}\text { Greiner Bio-One GmbH, } \\
\text { Frickenhausen }\end{array}$ \\
\hline Pipette filter tips & Sarstedt AG \& Co., Nümbrecht \\
\hline $\begin{array}{l}\text { Protan }{ }^{\circledR} \text { Nitrocellulose transfer } \\
\text { membrane }\end{array}$ & Whatman GmbH, Dassel \\
\hline X-ray films "Super RX" & Fujifilm Corp., Tokyo, Japan \\
\hline
\end{tabular}

\subsection{Chemicals}

\subsubsection{General chemicals}

\begin{tabular}{|l|l|}
\hline Acetic acid & Carl Roth GmbH \& Co. KG, Karlsruhe \\
\hline $\begin{array}{l}\text { Adefodur WB developing } \\
\text { concentrate }\end{array}$ & Adefo-Chemie GmbH, Dietzenbach \\
\hline Adefodur WB fixing concentrate & Adefo-Chemie GmbH, Dietzenbach \\
\hline Adenosin triphosphate (ATP) & Fermentas GmbH, St. Leon-Rot \\
\hline Agarose & Carl Roth GmbH \& Co. KG, Karlsruhe \\
\hline Albumin Fraction V (BSA) & Carl Roth GmbH \& Co. KG, Karlsruhe \\
\hline Ammonium persulfate (APS) & Carl Roth GmbH \& Co. KG, Karlsruhe \\
\hline Ammonium sulfate (NH4)2SO4 & Carl Roth GmbH \& Co. KG, Karlsruhe \\
\hline Aprotinin & Carl Roth GmbH \& Co. KG, Karlsruhe \\
\hline Bromophenol blue & Sigma-Aldrich Co., St. Louis, USA \\
\hline
\end{tabular}




\begin{tabular}{|l|l|}
\hline Calcium Chloride (CaCl) & Carl Roth GmbH \& Co. KG, Karlsruhe \\
\hline Chelex & Bio-Rad Laboratories GmbH, München \\
\hline Chloramphenicol & Serva Electrophoresis GmbH, Heidelberg \\
\hline Chloroform & Carl Roth GmbH \& Co. KG, Karlsruhe \\
\hline Diethylpyrocarbonate (DEPC) & Carl Roth GmbH \& Co. KG, Karlsruhe \\
\hline Dimethyl sulfoxide (DMSO) & AppliChem GmbH, Darmstadt \\
\hline Dithiothreitol (DTT) & Carl Roth GmbH \& Co. KG, Karlsruhe \\
\hline DMEM & GIBCO®, Invitrogen GmbH, Darmstadt \\
\hline dNTPs & Promega GmbH, Mannheim \\
\hline Doxorubicin & Enzo Life Sciences GmbH, Lörrach \\
\hline Ethanol absolute & Th. Geyer GmbH \& Co. KG, Renningen \\
\hline Ethidium bromide & Carl Roth GmbH \& Co. KG, Karlsruhe \\
\hline $\begin{array}{l}\text { Ethylenediaminetetraacetic acid } \\
\text { (EDTA) }\end{array}$ & Carl Roth GmbH \& Co. KG, Karlsruhe \\
\hline Fetal Bovine Serum (FBS) & Thermo Scientific HyClone, Logan, USA \\
\hline Formaldehyde & Sigma-Aldrich Co., St. Louis, USA \\
\hline Glycerol & Carl Roth GmbH \& Co. KG, Karlsruhe \\
\hline B-Glycerolphosphate (BGP) & Sigma-Aldrich Co., St. Louis, USA \\
\hline Glycine & Carl Roth GmbH \& Co. KG, Karlsruhe \\
\hline GlycoBlue & $\begin{array}{l}\text { Applied Biosystems/Ambion, Austin, } \\
\text { USA }\end{array}$ \\
\hline Hydrochloric acid (HCl) & Carl Roth GmbH \& Co. KG, Karlsruhe \\
\hline Isopropanol & Carl Roth GmbH \& Co. KG, Karlsruhe \\
\hline Kanamycin & AppliChem GmbH, Darmstadt \\
\hline Leupeptin & Carl Roth GmbH \& Co. KG, Karlsruhe \\
\hline Magnesium chloride (MgCl2) & Carl Roth GmbH \& Co. KG, Karlsruhe \\
\hline Methanol & M. Baker B.V., Deventer, Netherlands \\
\hline MG-132 & Biomol GmbH, Hamburg \\
\hline $\begin{array}{l}\text { Monopotassium phosphate } \\
\text { (KH2PO4) }\end{array}$ & Carl Roth GmbH \& Co. KG, Karlsruhe \\
\hline N-ethylmaleimide (NEM) & Sigma-Aldrich Co., St. Louis, USA \\
\hline NonidetTM P40 (NP-40) & Sigma-Aldrich Co., St. Louis, USA \\
\hline Opti-MEM & GIBCO®, Invitrogen GmbH, Darmstadt \\
\hline PBS tablets & GIBCO®, Invitrogen GmbH, Darmstadt \\
\hline Pefabloc SC Protease Inhibitor & Carl Roth GmbH \& Co. KG, Karlsruhe \\
\hline Penicillin-Streptomycin solution & Sigma-Aldrich Co., St. Louis, USA \\
\hline Peptone & Carl Roth GmbH \& Co. KG, Karlsruhe \\
\hline Potassium acetate (KOAc) & Carl Roth GmbH \& Co. KG, Karlsruhe \\
\hline Potassium chloride (KCl) & AppliChem GmbH, Darmstadt \\
\hline & \\
\hline
\end{tabular}




\begin{tabular}{|c|c|}
\hline $\begin{array}{l}\text { Potassium dihydrogen phosphate } \\
\text { (KH2PO4) }\end{array}$ & Carl Roth GmbH \& Co. KG, Karlsruhe \\
\hline Propidium iodide solution & Sigma-Aldrich Co., St. Louis, USA \\
\hline Protein A SepharoseTM CL-4B & GE Healthcare, Uppsala, Sweden \\
\hline RNase inhibitor & $\begin{array}{l}\text { New England Biolabs, Frankfurt am } \\
\text { Main }\end{array}$ \\
\hline RNAiMAX & Invitrogen $\mathrm{GmbH}$, Karlsruhe \\
\hline Roti®-Phenol & QIAGEN Sciences \\
\hline Rotiphorese $\AA$ Gel 30 & Carl Roth GmbH \& Co. KG, Karlsruhe \\
\hline Rotipuran ${ }^{\circledR}$ Chloroform & Carl Roth GmbH \& Co. KG, Karlsruhe \\
\hline Rotipuran ${ }^{\circledR}$ Isoamylalcohol & Carl Roth GmbH \& Co. KG, Karlsruhe \\
\hline Salmon sperm DNA & Stratagene, La Jolla, USA \\
\hline SepharoseTM CL-4B & GE Healthcare, Uppsala, Sweden \\
\hline Skim milk powder & Carl Roth GmbH \& Co. KG, Karlsruhe \\
\hline Sodium acetate & Carl Roth GmbH \& Co. KG, Karlsruhe \\
\hline Sodium chloride $(\mathrm{NaCl})$ & Carl Roth GmbH \& Co. KG, Karlsruhe \\
\hline Sodium deoxycholate & AppliChem GmbH, Darmstadt \\
\hline Sodium dodecylsulfate (SDS) & Carl Roth GmbH \& Co. KG, Karlsruhe \\
\hline $\begin{array}{l}\text { di-Sodium hydrogen phosphate } \\
\text { dihydrate }\end{array}$ & Carl Roth GmbH \& Co. KG, Karlsruhe \\
\hline Sodium hydroxide $(\mathrm{NaOH})$ & Carl Roth GmbH \& Co. KG, Karlsruhe \\
\hline Sodium pyruvate (Na-Pyr) & GIBCO ${ }^{\circledR}$, Invitrogen $\mathrm{GmbH}$, Darmstadt \\
\hline SYBR Green & Roche Diagnostics GmbH, Mannheim \\
\hline TEMED & Carl Roth GmbH \& Co. KG, Karlsruhe \\
\hline$\alpha, \alpha$-Trehalose Dihydrate & USB Corporation, Cleveland, USA \\
\hline Tris & Carl Roth GmbH \& Co. KG, Karlsruhe \\
\hline Triton X-100 & AppliChem GmbH, Darmstadt \\
\hline TRIzol® Reagent & Invitrogen $\mathrm{GmbH}$, Karlsruhe \\
\hline Trypsin-EDTA $(0.05 \%)$ & GIBCO ${ }^{8}$, Invitrogen $\mathrm{GmbH}$, Darmstadt \\
\hline Tween-20 & AppliChem GmbH, Darmstadt \\
\hline Yeast Extract & USB Corporation, Cleveland, USA \\
\hline
\end{tabular}

\subsubsection{Inhibitors}

\begin{tabular}{|l|l|}
\hline Actinomycin D & Sigma-Aldrich \\
\hline alpha-amanitin & Sigma-Aldrich \\
\hline Caffeine & Sigma-Aldrich \\
\hline Camptothecin & Sigma-Aldrich \\
\hline Cholerae toxin & EMD Chemicals \\
\hline
\end{tabular}




\begin{tabular}{|l|l|}
\hline Cisplatin & Zytostatika \\
\hline Cyclosporine A & Sigma-Aldrich \\
\hline Doxorubicin & Enzo Life Sciences \\
\hline DRB & Sigma-Aldrich \\
\hline Etoposide & Sigma-Aldrich \\
\hline Hydroxyurea & Sigma-Aldrich \\
\hline Iodacetamide & Sigma-Aldrich \\
\hline KM05283 & Thermo Fisher Sc. Int. \\
\hline MG132 & Sigma-Aldrich \\
\hline NAC & Affymetrix \\
\hline NiCl2 & Sigma-Aldrich \\
\hline Nutlin-3A & Sigma-Aldrich \\
\hline Ocadaic acid & Tocris \\
\hline Olaparib & Santa Cruz \\
\hline Rapamycin & Calbiochem \\
\hline SB 203580 & Biomol \\
\hline Sorbitol & USB Corporation \\
\hline SP600125 & Sigma-Aldrich \\
\hline Trolox & Sigma-Aldrich \\
\hline
\end{tabular}

\subsection{Kits and reagents}

\begin{tabular}{|l|l|}
\hline LipofectamineTM 2000 & Invitrogen $\mathrm{GmbH}$, Karlsruhe \\
\hline LipofectamineTM RNAiMAX & Invitrogen GmbH, Karlsruhe \\
\hline PureYieldTM Plasmid Midiprep & Promega GmbH, Mannheim \\
\hline QIAprep ${ }^{\circledR}$ Spin Miniprep Kit & Qiagen GmbH, Hilden \\
\hline SuperSignal ${ }^{\circledR}$ West Dura & $\begin{array}{l}\text { Thermo Fisher Scientific, Waltham, } \\
\text { USA }\end{array}$ \\
\hline $\begin{array}{l}\text { SuperSignal }{ }^{\circledR} \text { West Femto } \\
\text { Maximum }\end{array}$ & $\begin{array}{l}\text { Thermo Fisher Scientific, Waltham, } \\
\text { USA }\end{array}$ \\
\hline
\end{tabular}

\subsection{Nucleic acids}

\subsubsection{Plasmids}

\begin{tabular}{|l|l|}
\hline Name & Source \\
\hline pCDNA3.1hygro $(+)$ & Invitrogen \\
\hline
\end{tabular}




\begin{tabular}{|l|l|}
\hline pCDNA3.1hygro(+)-HA-hCDK9 & this study \\
\hline pGEX-6P-1 & GE Healthcare \\
\hline pGEX-6P-1-hUBE2AA-WT & this study \\
\hline pGEX-6P-1-hUBE2AA-S120A & this study \\
\hline pCS2 & (Knockaert et al, 2006) \\
\hline pCS2-Flag-SCP1 & (Knockaert et al, 2006) \\
\hline pCS2-Flag-SCP2 & (Knockaert et al, 2006) \\
\hline pCS2-Flag-SCP3 & (Knockaert et al, 2006) \\
\hline pSTC-TK-WTRpb1-EGFP & D. Eick \\
\hline pSTC-TK-Rpb1-dCTD-EGFP & D. Eick \\
\hline pSTC-TK-Rpb1-1-3+S2A48+52 & D. Eick \\
\hline pSTC-TK-Rpb1-1-3+S5A48+52 & D. Eick \\
\hline pHA-JNK1 & R. Janknecht \\
\hline pHA-MEKKc & R. Janknecht \\
\hline
\end{tabular}

\subsubsection{Oligonucleotides}

2.5.2.1 siRNAs

\begin{tabular}{|l|l|l|l|}
\hline Gene & Cat. Num & Sense sequence & Source \\
\hline CDK9 & S2834 & UGA GAU UUG UCG AAC CAA Att & Ambion \\
\hline CCNT & S2541 & CGACCCAGACAAUAGACUAtt & Ambion \\
\hline NCL & S100300923 & GCUAUGGAGACUACACCAGtt & Qiagen \\
\hline NPM & SI00300979 & GAAUUGCUUCCGGAUGACUtt & Qiagen \\
\hline UBE2A & S14567 & UUCAUAUUCCCGUUUGUUCtc & Ambion \\
\hline RNF20 & S32088 & GGUCCGCAAGGAGUAUGAAtt & Ambion \\
\hline RNF40 & S18962 & GUACUACAGUUCAAGAACAtt & Ambion \\
\hline USP22 & S23566 & GGAGAGAAGUUUUCAACUUtt & Ambion \\
\hline
\end{tabular}

2.5.2.2 Primers

\begin{tabular}{|c|c|c|c|}
\hline Experiment & Name & 5'-3' sequence & Source \\
\hline CDK9 cloning & HA-hCDK9-For & $\begin{array}{l}\text { GCTGACGGATCCGCCA } \\
\text { CCATGTACCCATACGA } \\
\text { TGTTCCAGATTACGCT } \\
\text { GAATTCATGGCAAAGC } \\
\text { AGTACGACTC } \\
\text { GGTGGAGTGCCC }\end{array}$ & This study \\
\hline CDK9 cloning & hCDK9-Rev & $\begin{array}{l}\text { GTCAGCCTCGAGTCAG } \\
\text { AA } \\
\text { GACGCGCTCAAACTCC }\end{array}$ & This study \\
\hline
\end{tabular}




\begin{tabular}{|c|c|c|c|}
\hline & & GTCTG & \\
\hline $\begin{array}{l}\text { Nucleolin } \\
\text { knockdown }\end{array}$ & NCL50F & $\begin{array}{l}\text { TGGCTCCTCCTCCAAA } \\
\text { GGAGGT }\end{array}$ & This study \\
\hline $\begin{array}{l}\text { Nucleolin } \\
\text { knockdown }\end{array}$ & NCL235R & $\begin{array}{l}\text { TGGCTGGTGTGGCAAC } \\
\text { TGCA }\end{array}$ & This study \\
\hline $\begin{array}{l}\text { Nucleophosmin } \\
\text { knockdown }\end{array}$ & NPM250F & $\begin{array}{l}\text { CAGCCAACGGTTTCCC } \\
\text { TTGGG }\end{array}$ & This study \\
\hline $\begin{array}{l}\text { Nucleophosmin } \\
\text { knockdown }\end{array}$ & NPM375R & $\begin{array}{l}\text { TGACTCTGCATCTTCC } \\
\text { TCCACAGC } \\
\end{array}$ & $\begin{array}{l}\text { Gomes et al, } \\
2006\end{array}$ \\
\hline p21 ChIP & $\mathrm{p} 21 \mathrm{TSS} F$ & $\begin{array}{l}\text { GGGGCGGTTGTATATC } \\
\text { AGG }\end{array}$ & $\begin{array}{l}\text { Gomes et al, } \\
2006\end{array}$ \\
\hline p21 ChIP & p21 TSS R & $\begin{array}{l}\text { GGCTCCACAAGGAACT } \\
\text { GACT }\end{array}$ & $\begin{array}{l}\text { Gomes et al, } \\
2006\end{array}$ \\
\hline p21 ChIP & p21 TR for & $\begin{array}{l}\text { CCAGGGCCTTCCTTGT } \\
\text { ATCTCT }\end{array}$ & $\begin{array}{l}\text { Gomes et al, } \\
2006\end{array}$ \\
\hline p21 ChIP & p21 TR rev & $\begin{array}{l}\text { ACATCCCCAGCCGGTT } \\
\text { CT }\end{array}$ & $\begin{array}{l}\text { Gomes et al, } \\
2006\end{array}$ \\
\hline p21 RT-PCR & p21+8000 for_1 & $\begin{array}{l}\text { CTCCAGGTGGCTCTGA } \\
\text { GGT }\end{array}$ & $\begin{array}{l}\text { Gomes et al, } \\
2006\end{array}$ \\
\hline p21 RT-PCR & p21+8000 rev_1 & $\begin{array}{l}\text { GCCCTTCTTCTTGTGTG } \\
\text { TCC }\end{array}$ & $\begin{array}{l}\text { Gomes et al, } \\
2006\end{array}$ \\
\hline UBE2A cloning & $\begin{array}{l}\text { hRad6A HA Hind3 } \\
\text { For }\end{array}$ & $\begin{array}{l}\text { GCTGACAAGCTTGCCA } \\
\text { CCATGTACCCATACGA } \\
\text { TGTTCCAGATTACGCT } \\
\text { CAATTGATGTCCACCC } \\
\text { CGGCTCGGCGGCGCCT } \\
\text { CATG }\end{array}$ & This study \\
\hline UBE2A cloning & hRad6A XhoI Rev & $\begin{array}{l}\text { GTCAGCCTCGAGTCAA } \\
\text { CAATCACGCCAGCTTT } \\
\text { GTTC }\end{array}$ & This study \\
\hline $\begin{array}{l}\text { UBE2A } \\
\text { mutagenesis }\end{array}$ & $\begin{array}{l}\text { hRad6A S120A C- } \\
\text { For }\end{array}$ & $\begin{array}{l}\text { CAATCCCAATGCTCCA } \\
\text { GCAAACAGCCAGGCT } \\
\text { GCTC }\end{array}$ & This study \\
\hline $\begin{array}{l}\text { UBE2A } \\
\text { mutagenesis }\end{array}$ & $\begin{array}{l}\text { hRad6A S120A N- } \\
\text { Rev }\end{array}$ & $\begin{array}{l}\text { GTTTGCTGGAGCATTG } \\
\text { GGATTGGGTTCATCCA } \\
\text { AC }\end{array}$ & This study \\
\hline USP22 cloning & hUSP22For & $\begin{array}{l}\text { GCTGACGGATCCATGG } \\
\text { TGTCCCGGCCAGAGCC } \\
\text { CG }\end{array}$ & This study \\
\hline USP22 cloning & hUSP22Rev & $\begin{array}{l}\text { GTCAGCGCGGCCGCCT } \\
\text { ACT }\end{array}$ & This study \\
\hline
\end{tabular}




\begin{tabular}{|l|l|l|l|}
\hline & $\begin{array}{l}\text { CGTATTCCAGGAACTG } \\
\text { TTTG }\end{array}$ & \\
\hline
\end{tabular}

\subsection{Proteins}

\subsubsection{Protein molecular weight markers}

PageRulerTM Prestained Protein Ladder

\subsubsection{Enzymes}

\begin{tabular}{|l|l|}
\hline c-Jun N-terminal kinase 1 & ProQinase GmbH, Freiburg \\
\hline Cyclin Dependent Kinase 9 & Cell Signaling \\
\hline $\begin{array}{l}\text { Phusion® High-Fidelity DNA } \\
\text { Polymerase }\end{array}$ & New England Biolabs, Frankfurt am Main \\
\hline Proteinase K & Invitrogen GmbH, Karlsruhe \\
\hline Restriction enzymes & New England Biolabs, Frankfurt am Main \\
\hline $\begin{array}{l}\text { Reverse Transcriptase (M- } \\
\text { MuLV) }\end{array}$ & New England Biolabs, Frankfurt am Main \\
\hline RNase A & Qiagen GmbH, Hilden \\
\hline T4 DNA Ligase & New England Biolabs, Frankfurt am Main \\
\hline Taq DNA Polymerase & Prime Tech, Minsk, Belarus \\
\hline
\end{tabular}

2.6.3 Antibodies

2.6.3.1 Primary antibodies

\begin{tabular}{|l|l|l|l|l|l|l|}
\hline Name & Clone & Cat. Number & WB & IP & IF & Source \\
\hline$\beta$-Actin & - & ab6276-100 & $1: 10000$ & - & - & Abcam \\
\hline CCNT1 & H-245 & sc-10750 & $1: 1000$ & $1 \mu \mathrm{g}$ & - & Santa Cruz \\
\hline CDK9 & C-20 & sc-484 & $1: 1000$ & $1 \mu \mathrm{g}$ & - & Santa Cruz \\
\hline Coilin & Pdelta & sc-56298 & $1: 1000$ & - & $1: 50$ & Santa Cruz \\
\hline FLAG & M2 & F1804 & $1: 10000$ & $4 \mu \mathrm{g}$ & - & Sigma \\
\hline H2B & - & $07-371$ & $1: 3000$ & - & - & Upstate \\
\hline H2Bub1 & 56 & $05-1312$ & $1: 5000$ & - & $1: 500$ & Millipore \\
\hline H2Bub1 & - & - & - & 75 & - & $\begin{array}{l}\text { Minsky et al, } \\
\text { 2008 }\end{array}$ \\
\hline HSC70 & B-6 & sc-7298 & $1: 25000$ & - & - & Santa Cruz \\
\hline mouse & - & $12-371$ & - & $1 \mu \mathrm{g}$ & - & Upstate \\
\hline
\end{tabular}


Materials and Methods

\begin{tabular}{|l|l|l|l|l|l|l|}
\hline IgG & & & & & & \\
\hline NPM & - & $32-5200$ & $1: 1000$ & - & $1: 100$ & Invitrogen \\
\hline PCNA & PC10 & ab29100 & $1: 1000$ & - & - & Abcam \\
\hline p-JNK & - & 46685 & $1: 1000$ & - & $1: 100$ & Cell Signaling \\
\hline $\begin{array}{l}\text { p- } \\
\text { UBE2A }\end{array}$ & 5 A10 & - & $1: 5$ & - & - & $\begin{array}{l}\text { D. Eick/ E. } \\
\text { Kremmer }\end{array}$ \\
\hline p-Ser2 & H5 & MMS-129R & - & $2 \mu 1$ & - & Covance \\
\hline p-Ser2 & 3 E10 & - & $1: 10$ & - & - & $\begin{array}{l}\text { Dirk Eick } \\
\text { (Chapman et } \\
\text { al, 2007) }\end{array}$ \\
\hline p-Ser5 & H14 & MMS-134R & $1: 10000$ & $1 \mu 1$ & - & Covance \\
\hline UBE2A & - & A300-282A & $1: 3000$ & - & - & Bethyl \\
\hline RNAPII & N-20 & sc-899 & - & $1 \mu \mathrm{g}$ & - & Santa Cruz \\
\hline RNF20 & - & NB100-2242 & $1: 2000$ & - & - & $\begin{array}{l}\text { Novus } \\
\text { Biologicals }\end{array}$ \\
\hline RNF40 & - & ab26082 & $1: 1000$ & - & - & Abcam \\
\hline USP22 & 2391 & - & $1: 1000$ & - & - & (Zhao et al, \\
2008)
\end{tabular}

2.6.3.2 Secondary antibodies

\begin{tabular}{|c|c|c|c|c|c|}
\hline Name & $\begin{array}{l}\text { Cat. } \\
\text { Number }\end{array}$ & WB & IP & IF & Source \\
\hline Goat Anti-Mouse IgM & M 8644 & - & $\begin{array}{l}3 \\
\mu g\end{array}$ & - & Sigma \\
\hline $\begin{array}{l}\text { Donkey Anti-Mouse IgG- } \\
\text { HRP }\end{array}$ & $\begin{array}{l}715-036- \\
150\end{array}$ & $1: 10000$ & - & - & $\begin{array}{l}\text { Jackson } \\
\text { ImmunoResearch }\end{array}$ \\
\hline $\begin{array}{l}\text { Donkey Anti-Mouse IgM- } \\
\text { HRP }\end{array}$ & $\begin{array}{l}115-035- \\
044\end{array}$ & $1: 3000$ & - & - & $\begin{array}{l}\text { Jackson } \\
\text { ImmunoResearch }\end{array}$ \\
\hline $\begin{array}{l}\text { Donkey Anti-Rabbit IgG- } \\
\text { HRP }\end{array}$ & $\begin{array}{l}711-036- \\
152\end{array}$ & $1: 10000$ & - & - & $\begin{array}{l}\text { Jackson } \\
\text { ImmunoResearch }\end{array}$ \\
\hline $\begin{array}{l}\text { Goat Anti-Rat IgG + IgM- } \\
\text { HRP }\end{array}$ & $\begin{array}{l}112-035- \\
068\end{array}$ & $1: 10000$ & - & - & $\begin{array}{l}\text { Jackson } \\
\text { ImmunoResearch }\end{array}$ \\
\hline $\begin{array}{l}\text { Donkey Anti-Mouse IgG- } \\
\text { Alexa } 488\end{array}$ & A21202 & & & $1: 500$ & Invitrogen \\
\hline
\end{tabular}




\subsection{Cells}

2.7.1 Bacterial cells

\begin{tabular}{|l|l|}
\hline Name & Source \\
\hline BL21 (Ril DE3) & Invitrogen \\
\hline DH10B & M. Dobbelstein, GZMB, Goettingen \\
\hline
\end{tabular}

2.7.2 Eucaryotic cells

\begin{tabular}{|l|l|}
\hline Name & Source \\
\hline H1299 & M. Dobbelstein, GZMB, Goettingen \\
\hline HCT116 WT & M. Dobbelstein, GZMB, Goettingen \\
\hline HEK293 & M. Dobbelstein, GZMB, Goettingen \\
\hline U2-OS & M. Dobbelstein, GZMB, Goettingen \\
\hline
\end{tabular}

\subsection{Buffers and solutions}

\section{RIPA buffer}

PBS 1X

NP40 1\%

Na-deoxycholate $0.5 \%$

SDS $0.1 \%$

\section{X TBS-T}

Tris $0.1 \mathrm{M}$

NaCl $1.5 \mathrm{M}$

Tween-20 0.5\%

$\mathbf{H}_{2} \mathbf{O}$ to 11

Western salts 10X

Tris $0.25 \mathrm{M}$ 
Glycin $0.86 \mathrm{M}$

SDS $0.7 \mathrm{mM}$

$\mathbf{H}_{2} \mathbf{O}$ to 11

PBS-T 10X (pH 7,4)

NaCl $0,73 \mathrm{M}$

KCI $0.027 \mathrm{M}$

$\mathrm{NaH}_{2} \mathbf{P O}_{4} * 7 \mathrm{H}_{2} \mathrm{O} 14.3 \mathrm{mM}$

$\mathbf{K H}_{2} \mathbf{P O}_{4} 14.7 \mathrm{mM}$

Tween 20 1\%

$\mathbf{H}_{2} \mathbf{O}$ to 41

Frackelton buffer

Tris (pH 7.1) $5 \mathrm{mM}$

NaCl $25 \mathrm{mM}$

Triton X-100 0.5\%

DTT $0.2 \%$

Protease and phosphatase inhibitors $1 \mathrm{X}$

\section{$\underline{\text { PCR-Mix 10X }}$}

Tris-HCI (pH 8.8) 750 mM

$\left(\mathbf{N H}_{4}\right)_{2} \mathbf{S O}_{4} 200 \mathrm{mM}$

Tween-20 0.1\%

\section{$\underline{\text { RT-PCR Master Mix }}$}


PCR-Mix 1X

$\mathbf{M g C l}_{2} 3 \mathrm{mM}$

SYBR Green 1:80000

dNTPs $0.2 \mathrm{mM}$

Taq-polymerase 20U/ml

Triton X-100 0.25\%

Trehalose $300 \mathrm{mM}$

Pagano buffer

Tris-HCI (pH 7.4) 20 mM

DTT $2 \mathrm{mM}$

EDTA $0.25 \mathrm{mM}$

$\underline{\text { Deubiquitination buffer }}$

Tris-HCl (pH 7.4) 60 mM

Glycerol 20\%

$\mathbf{M g C l}_{2} 10 \mathrm{mM}$

\section{Blocking solution}

PBST 1X

Milk 5\%

\section{Cell culture freezing medium}

DMEM

FBS 50\% 
DMSO 8\%

\section{ChIP IP buffer}

NaCl 150 mM

EDTA $5 \mathrm{mM}$

Tris (pH 8) $50 \mathrm{mM}$

NP-40 0.5\%

Triton X-100 1\%

Protease and phosphatase inhibitors

Pefabloc $1 \mathrm{mM}$

Aprotinin/Leupeptin $1 \mathrm{ng} / \mu 1$

BGP $10 \mathrm{mM}$

NEM 1 mM

DMEM cell culture “normal” medium

Phenol red-free, high-glucose DMEM

FBS $10 \%$

Penicillin $100 \mathrm{U} / \mathrm{ml}$

Streptomycin $100 \mu \mathrm{g} / \mathrm{ml}$

Sodium pyruvate $1 \mathrm{mM}$

6× Lämmli buffer

Tris (pH 6.8) $0.35 \mathrm{M}$

Glycerol 30\%

SDS $10 \%$ 
DTT $9.3 \%$

Bromphenol blue 0.02\%

\section{$\underline{\text { LB Agar }}$}

LB medium 1X

Agar 1.5\%

\section{$\underline{\text { LB medium }}$}

Peptone 1\%

Yeast extract $0.5 \%$

NaCl 86 mM

\section{SDS separating gel $(\mathrm{X} \%)$}

Acrylamide X\%

Tris-HCl (pH 8.8) 375 mM

SDS $0.1 \%$

APS $0.1 \%$

TEMED $0.04 \%$

\section{SDS stacking gel (5\%)}

Acrylamide 5\%

Tris-HCl (pH 6.8) 125.5 mM

SDS $0.1 \%$

APS $0.1 \%$

TEMED $0.1 \%$ 


\section{TAE buffer (50×)}

Tris $2 \mathrm{M}$

Acetic acid $1 \mathrm{M}$

EDTA $0.1 \mathrm{M}$

\section{$\underline{\text { Transfer buffer }}$}

$10 \times$ Western salts $10 \%$

Methanol 15\%

\section{YT medium}

Peptone 1.6\%

Yeast extract 1\%

NaCl 86 mM

\subsection{Software}

\begin{tabular}{|l|l|}
\hline Primer designing tool & $\begin{array}{l}\text { NCBI/Primer-BLAST } \\
\text { (www.ncbi.nlm.nih.gov/tools/primer-blast/) }\end{array}$ \\
\hline $\begin{array}{l}\text { Confocal pictures } \\
\text { processing }\end{array}$ & LSM viewer, ZEISS \\
\hline
\end{tabular}

\section{Methods}

\subsection{Cell culture}

Culturing cells

H1299 (human non-small cell lung carcinoma), HEK293 (human embryonic kidney) and U2-OS (human osteosarcoma) cells were cultured in phenol red-free high-glucose Dulbecco's modified Eagles medium (DMEM) supplemented with $10 \%$ fetal bovine serum (FBS), 100 units $/ \mathrm{ml}$ penicillin, 100 
$\mu \mathrm{g} / \mathrm{ml}$ streptomycin and $1 \mathrm{mM}$ sodium pyruvate at $37 \mathrm{C}$ under $5 \% \mathrm{CO} 2$ atmosphere. HCT116 (human colorectal carcinoma) cells were cultured in McCoy's 5A medium supplemented with 10\% fetal bovine serum (FBS), 100 units $/ \mathrm{ml}$ penicillin, $100 \mu \mathrm{g} / \mathrm{ml}$ streptomycin and $1 \mathrm{mM}$ sodium pyruvate in the same conditions.

\section{Plasmid DNA transfection in 6-well plate}

$2.4 \mu \mathrm{g}$ of plasmid DNA were diluted in $200 \mu \mathrm{l}$ of Opti-MEM. In a separate tube $8 \mu \mathrm{l}$ of Lipofectamine 2000 were diluted in $200 \mu \mathrm{l}$ of Opti-MEM. After $5 \mathrm{~min}$ DNA- and Lipofectamine 2000-containing solutions were mixed and incubated for $20 \mathrm{~min}$ at room temperature. After the incubation transfecting mixture was added to a well with adherent $80 \%$-confluent cells cowered with $2 \mathrm{ml}$ of DMEM-FBS. After $4 \mathrm{~h}$ of transfection cells were washed with PBS and covered with fresh DMEM-FBS-P/S.

\section{siRNA transfection protocol in 6-well plate}

30 pmol siRNA and $5 \mu 1$ RNAiMAX were diluted in $500 \mu$ l OptiMEM. Components were incubated at room temperature for $20 \mathrm{~min}$ and mixed with 2.5 $\mathrm{ml}$ antibiotic-free normal growth medium containing 2.0-3.0 $\times 10^{5}$ cells. The medium was replaced with a fresh one after $24 \mathrm{~h}$. Cells were harvested in $48 \mathrm{~h}$ after transfection.

\section{$\underline{\text { Immunofluorescence }}$}

Cells were grown on glass cover slips on a 12 well plate. After washing with PBS cells were fixed for 20 min with $4 \%$ formaldehyde and permeabilized for 10 min with $0.1 \%$ TritonX-100. Further cells were blocked with Blocking Solution $(10 \%$ FCS in PBS) for 10 min and treated with primary antibodies in Blocking Solution for 1-12 h. Secondary antibodies were applied in the dark for $30 \mathrm{~min}$ together with DAPI stain. Cover slips were removed from the plate and mounted on a glass slide for the microscopy.

\subsection{Molecular biology}




\section{$\underline{\text { Molecular cloning }}$}

The expression constructs used in this study were created by amplifying the gene from cDNA using specific primers and Phugene polymerase. The product of PCR and appropriate vector molecule were digested with Fermantas restriction enzymes, gel-purified and ligated with T4 DNA ligase from Fermentas. The mutagenesis was performed by amplifying the plasmid with the gene using the primers, containing the mutation. The product of PCR was treated with DpnI to degrade the template DNA and transformed into E.coli DH10B cells.

\section{TRIZOL RNA isolation from 6-well plates}

Cells were washed twice with ice-cold PBS. $500 \mu 1$ Trizol reagent were added to each well. Cells were scraped and transferred to $1.5 \mathrm{ml}$ tube. $100 \mu \mathrm{l}$ of chloroform were added followed by vortexing for $15 \mathrm{~s}$. After $20 \mathrm{~min}$ of centrifugation at maximum speed, the aqueous phase was taken and washed with $100 \mu 1$ of chloroform again. The resultant solution was mixed with equal volume of isopropanol and kept at $-20 \mathrm{C}$ for $2 \mathrm{~h}$. The mixture was centrifuged for $20 \mathrm{~min}$ at full speed, the pellet was washed once with $500 \mu \mathrm{l}$ of $70 \%$ ethanol and dried. Dry RNA was dissolved in $40 \mu \mathrm{l}$ of DEPC water and its concentration was measured with a NanoDrop.

\section{cDNA synthesis by reverse transcription}

1 microgram of total RNA was mixed with $2 \mathrm{ul} 15 \mathrm{uM}$ random nonamer, dT23VN or combined primers and $4 \mu 1$ of $2.5 \mathrm{mM}$ dNTPs and heated at $70 \mathrm{C}$ for 5 min. After cooling on ice $4 \mu \mathrm{l}$ of mastermix were added, containing 10X reaction buffer, 10 units of RNAse inhibitors and 25 units of M-MuLV Reverse Transcriptase. The reaction was incubated at $42 \mathrm{C}$ for 1 hour and stopped by heating to $95 \mathrm{C}$ for $5 \mathrm{~min}$.

\section{Real-time PCR}

$14 \mu 1$ of RT-PCR Master Mix were mixed with primers (final concentration $0.3 \mu \mathrm{M}), 1 \mu \mathrm{l}$ of ChIP-DNA or cDNA and water to final volume $25 \mu 1$. The PCR was performed according to the following program:

$2 \min -95 \mathrm{C}$

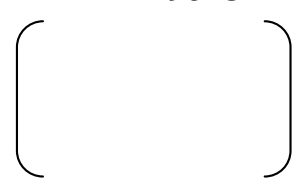


$15 \mathrm{sec}-95 \mathrm{C}$

$1 \min -60 \mathrm{C} \quad \mathrm{x} 40$

Melting curve 55-95 C to ensure primer specificity

\section{Chromatin Immunoprecipitation}

ChIP analysis was performed essentially as described (Pirngruber et al., 2009). In brief, growing medium was removed from plates and cells were crosslinked by adding $1.42 \%$ formaldehyde diluted in PBS. After 15 min of incubation at room temperature the crosslink was quenched by adding glycine to a final concentration of $125 \mathrm{mM}$. 5 min later cells were washed twice with PBS and scraped in $1 \mathrm{ml}$ of ChIP buffer. All further manipulations were performed on ice or at 4 C. Scraped cells were cleared from the buffer by centrifugation $(12000 \mathrm{~g}$ x 10 $\mathrm{min}$ ) and washed again with $1 \mathrm{ml}$ of ChIP buffer. After second centrifugation the pellet was resuspended in $300 \mu \mathrm{l}$ of ChIP buffer and sonicated by Bioruptor $(3 \times 10$ min) at " $\mathrm{H}$ " setting with $10 \mathrm{~s}$ breaks between $10 \mathrm{~s}$ pulses. The soluble chromatin was cleared from the debris by centrifugation (12000g x $10 \mathrm{~min}$ ) and pre-cleaned with $100 \mu \mathrm{l}$ of $50 \%$ slurry sepharose beads for 1 hour. After the pre-clean the chromatin was centrifuged, aliquoted, frozen in liquid nitrogen and stored at $-80 \mathrm{C}$. For the analysis $50 \mu \mathrm{l}$ of chromatin were diluted up to $0.5 \mathrm{ml}$ with ChIP buffer and incubated overnight with indicated amounts of antibodies. Immunobound complexes were precipitated by adding $30 \mu \mathrm{l}$ of $50 \%$ slurry Protein-A or Protein-G sepharose and incubation for another $2 \mathrm{~h}$. After the incubation samples were centrifuged (2000g x $2 \mathrm{~min}$ ). The beads were washed with ChIP buffer 6 times and the crosslink was reversed by adding 10\% slurry Chelex with subsequent heating to $95 \mathrm{C}$ for $10 \mathrm{~min}$. The proteins in the sample were eliminated by adding $40 \mu \mathrm{g}$ of Proteinase $\mathrm{K}$ and incubating for $30 \mathrm{~min}$ at $55 \mathrm{C}$. The samples were centrifuged (12000g x $1 \mathrm{~min}$ ) and the supernatant was analysed by RT-PCR. The inputs were prepared by precipitating the DNA from $50 \mu$ of undiluted chromatin by standard ethanol precipitation.

\subsection{Protein biochemistry}




\section{$\underline{\text { In vitro deubiquitination }}$}

Cells were washed with PBS and scraped in Pagano buffer. After mixing cells were sonicated with tip sonicator for $15 \mathrm{~s}$ and centrifuged at full speed to remove the cell debris. 1 volume of target supernatant was mixed with 1 volume of effector supernatant and 2 volumes of Deubiquitination buffer. The reaction was performed with shaking at $37 \mathrm{C}$ for $15 \mathrm{~min}$ and stopped by adding $6 \mathrm{X}$ Laemmli buffer and heating to $95 \mathrm{C}$ for $5 \mathrm{~min}$. The products of reaction was analyzed by SDS-PAGE Western blot.

\section{$\underline{\text { Protein co-immunoprecipitation }}$}

After washing with PBS cells were scraped in $1 \mathrm{ml}$ Frackelton buffer. Cells were vortexed for $15 \mathrm{~s}$ and tumbled for $45 \mathrm{~min}$ at $4 \mathrm{C}$. Cell lysate was cleared by centrifugation and the supernatant was pre-cleaned by adding $50 \mu 1$ of sepharose beads for 1 hour. The pre-cleaned supernatant was incubated with 1-3 $\mathrm{g}$ of antibodies for $2 \mathrm{~h}$ and $30 \mu \mathrm{l}$ of protein A or G coupled sepharose beads for 1 hour at $4 \mathrm{C}$. Beads were washed 4 times with Frackelton buffer and heated at $95 \mathrm{C}$ with $70 \mu 1$ of $2 \mathrm{X}$ Laemmli buffer. The supernatant was analyzed by SDS-PAGE and Western blot.

\section{$\underline{\text { GST protein purification }}$}

BL21 E. coli strain containing a plasmid coding for an appropriate gene under GST tag was grown in $2 \mathrm{X}$ YT medium to the $\mathrm{OD}_{600} 300$, then induced with $1 \mathrm{mM}$ IPTG and incubated overnight at $16 \mathrm{C}$. The bacteria were harvested by centrifugation and lysed in a GST Lysis Buffer containing $0.2 \mathrm{mg} / \mathrm{ml}$ Lysozyme. Cells were lysed by sonication ( 5 pulses $30 \mathrm{~s}$ each, full power). The solution was cleared by centrifugation and incubated with glutathione-sepharose beads for $2 \mathrm{~h}$ at 4 C. After triple washing with GST Lysis Buffer protein was eluted with $25 \mathrm{mM}$ glutathione in Lysis Buffer for 1 hour at 4 C. Eluted protein was analyzed by SDSPAGE and measured by Coomasie staining in comparison to the serial dilution of BSA, then stored at $-80 \mathrm{C}$.

\section{In vitro kinase assay}

$150 \mathrm{ng}$ of recombinant kinase were diluted in $20 \mu \mathrm{l}$ of Kinase buffer and incubated for $30 \mathrm{~min}$ at $30 \mathrm{C}$ to block all possible auto-phosphorylation sites with 
non-radioactive phosphates. After that $500 \mathrm{ng}$ of target protein and $50 \mathrm{uCi}$ of $\gamma\left[{ }^{32} \mathrm{P}\right]-$ ATP in kinase buffer were added to the final volume of $30 \mu 1$. The reaction was performed for $20 \mathrm{~min}$ at $30 \mathrm{C}$ and stopped by adding 6X Laemmli buffer and heating up to $95 \mathrm{C}$ for $5 \mathrm{~min}$. Later it was separated by SDS-PAGE, the gel was dried and analyzed by phosphoimager to detect the phosphorylated proteins.

\section{$\underline{\text { SDS-PAGE }}$}

Protein extracts were separated by sodium dodecylsulfate polyacrylamide gel electrophoresis (SDS-PAGE) (Laemmli, 1970). Adherent cells were lysed with RIPA buffer with Pefabloc $(1 \mathrm{mM})$, Aprotinin/Leupeptin (1 $\mathrm{ng} / \mathrm{ul})$, betaglycerol phosphate $(10 \mathrm{mM})$ and $\mathrm{N}$-ethylenmaleimid $(1 \mathrm{mM})$. The extracts were then sonicated for $15 \mathrm{~s}$ with Bandelin Sonoplus tip sonicator to shear the genomic DNA. The extracts were mixed with Laemmli buffer and heated at $95 \mathrm{C}$ for $5 \mathrm{~min}$. Proteins were separated in $8 \%$ or $15 \%$ acrylomide gels in SDS running buffer at 25 $\mathrm{mA}$.

\section{$\underline{\text { Western blot analysis }}$}

Separated proteins were transferred to nitrocellulose membranes by Western blot procedure (Towbin et al., 1979). The transfer was performed at 100V for 1 hour using Transfer buffer. The membrane was blocked in Blocking solution (PBS-T with 5\% dry milk) and incubated overnight with primary antibodies diluted in Blocking solution. On the next day the membrane was washed 3 times with PBS-T and incubated for 1 hour with secondary HRP-coupled antibodies in Blocking solution. After the incubation the membrane was washed with PBS-T 3 times and developed using the enhanced chemoluminiscence solution and X-ray films. 


\section{Results}

In this study different mechanisms of regulation of $\mathrm{H} 2 \mathrm{~B}$ monoubiquitination were examined.

First, the role of P-TEFb complex in maintaining the level of H2Bub1 was described. P-TEFb was found to be responsible not only for gene-specific but also for a global level of H2B ubiquitination.

Second, the role of UBE2A regulation by CDK9 through site-specific phosphorylation has been demonstrated. The ubiquitination of PCNA, another target of UBE2A, was also shown to be dependent upon P-TEFb activity.

The last part of this study describes strong and rapid loss of H2B monoubiquitination caused by various stress-inducing factors, such as chemotherapeutics, $\mu$ ltraviolet radiation, osmotic shock, etc. The signaling and deubiquitinating enzymes responsible for this global epigenetic shift were identified.

\subsection{CDK9 positively regulates global and gene-specific levels of $\mathrm{H} 2 \mathrm{~B}$} monoubiquitination.

\subsubsection{CDK9 activity is necessary for supporting global level of H2Bub1.}

Since phosphorylation of Ser2 of RNAPII CTD and H2Bub1 have the same pattern of accumulation on a gene, we hypothesized that the activity of the P-TEFb complex including CDK9 and CCNT1 is important for H2B monoubiquitination. H1299 cells treated with different inhibitors of CDK9 demonstrated a loss of H2Bub1 (Fig. 10A). The overexpression of the recombinant CDK9 led to the increased p-Ser2 and H2Bub1, whereas the knockdown of CDK9 by a specific siRNA caused a strong reduction of p-Ser2 as well as H2Bub1 (Fig. 10B,C). RNAPII carboxy-terminal domain (CTD) phosphatases SCP1, SCP2 and SCP3 were found to have high specificity towards Ser2 in comparison to Ser5 (Fig. S1). The overexpression of these phosphatases reduced both the phosphorylation of Ser2 of RNAPII CTD and monoubiquitination of H2B (Fig. 10D). 
To address the question whether Ser2 of RNAPII CTD is really the target of CDK9 which regulates H2Bub1 the following experiment was performed. Recombinant large RNAPII subunits resistant to $\alpha$-amanitin and having either wild type or mutated CTD were overexpressed in HEK293 cells. The cells were treated with $\alpha$-amanitin for $48 \mathrm{~h}$ to block all the transcription by endogenous RNAPII. The result of the experiment clearly shows that cells which had no CTD or CTD with S2A mutations had a significantly lower level of global H2B monoubiquitination whereas cells with wild type CTD or S5A mutations maintain a similar levels of H2Bub1 (Fig. 10E).

A

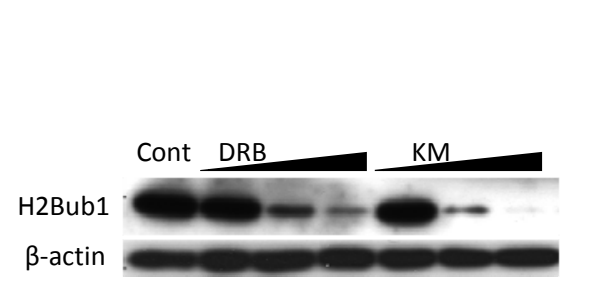

D

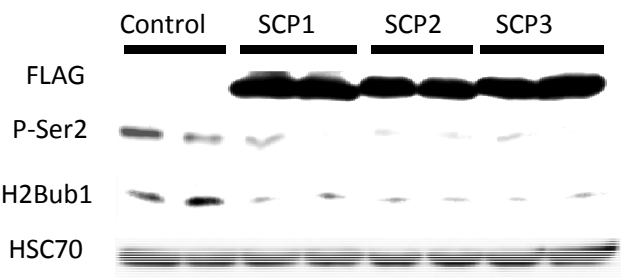

B

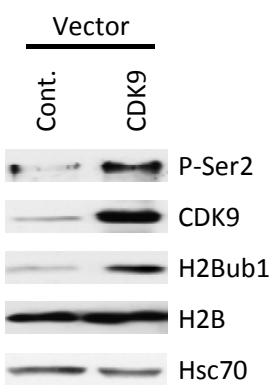

C

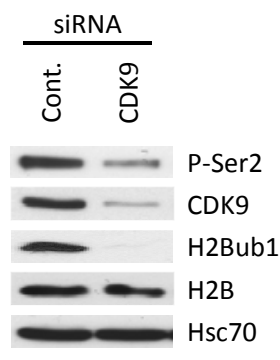

Figure 10. CDK9 activity and RNAPII CTD Ser2 phosphorylation regulate H2B ubiquitination. A. H1299 cells were treated with 10,50 and $100 \mu \mathrm{M}$ of CDK9 inhibitors 5,6dichloro-1-beta-D-ribofuranosylbenzimidazole (DRB) and 8-(methylthio)-4,5dihydrothieno[3', $\left.4^{\prime}: 5,6\right]$ benzoisoxazole-6-carboamide (KM05283) for $4 \mathrm{~h}$ and analyzed by Western blot. B. H1299 cells were transfected with an empty vector or recombinant hCDK9 expression vector. Following $48 \mathrm{~h}$ of expression cell extracts were analyzed by Western blot. C. H1299 cells were transfected with control or anti-CDK9 siRNAs for $48 \mathrm{~h}$ and analyzed by Western blot. D. H1299 cells were transfected with plasmids encoding for FLAG-tagged CTD phosphatases SCP1, SCP2 and SCP3. $72 \mathrm{~h}$ after transfection protein extracts were analyzed by 
Western blot with specified antibodies. E. HEK293 cells were transfected with plasmids encoding $\alpha$-amanitin resistant large RNAPII subunit with different mutations in the CTD. After $24 \mathrm{~h}$ of expression cells were grown in medium containing $10 \mathrm{mM} \alpha$-amanitin for another $48 \mathrm{~h}$. Protein extracts were analyzed by Western blot.

\subsubsection{CDK9, not transcription per se is required for maintaining H2Bub1 on an actively transcribed gene.}

In an attempt to test whether CDK9 activity plays a positive role in the maintaining $\mathrm{H} 2 \mathrm{~B}$ ubiquitination on a single gene chromatin immunoprecipitation analyses were performed using the p21 gene as a model system. The p21 gene is unique in that it could be transcribed in the absence of active P-TEFb complex (Gomes et al, 2006). The gene was induced by two different chemicals. First, Nutlin-3A, is a selective inhibitor of HDM2, the E3 ubiquitin ligase that targets p53 for proteosomal degradation. Following Nutlin-3A treatment the polyubiquitination and subsequent degradation of $\mathrm{p} 53$ is blocked which leads to its rapid accumulation and induction of p53-regulated genes, such as p21 (Vassilev et al, 2004). DRB (5, 6-dichloro-b-D-ribofuranosyl benzimidazole) can also induce transcription of some p53 target genes while paradoxically inhibiting CDK9 activity.

Due to the different nature of the two drugs the dynamics of p21 induction are different as well. A time-course of the two drugs was performed to estimate an appropriate time point for the experiment. As seen from the graph in $8 \mathrm{~h}$ after the treatment both drugs actively induced p21 expression (Fig. 11A).

Both Nutlin-3A and DRB increased the occupancy of RNAPII to the transcribed region (Fig. 11B, C), whereas only upon Nutlin-3A treatment did the CTD of RNAPII remain phosphorylated at Ser2 since DRB prevents this phosphorylation by inhibiting CDK9 (Fig. 11D). In accordance with our model H2B ubiquitination is detected only following Nutlin-3A-induced gene induction while the transcription of $\mathrm{p} 21$ in the absence of CDK9 activity does not lead to the accumulation of this transcription-related chromatin mark (Fig. 11E). 


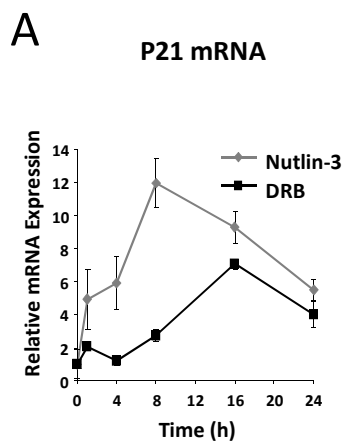

D

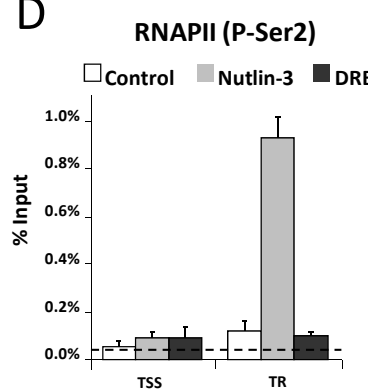

B

RNAPII

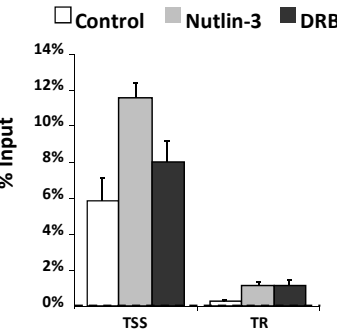

C

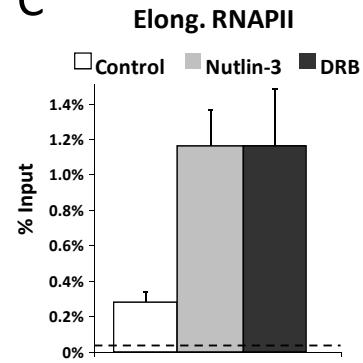

Figure 11. H2Bub1 depends on CDK9 activity but not on transcription per se. A. Nutlin-3A and DRB induce p21 expression. U2OS cells were treated with $8 \mu \mathrm{M}$ of Nutlin-3A and $50 \mu \mathrm{M}$ of DRB for 4, 8, 16 and $24 \mathrm{~h}$. RNA was extracted and reverse transcribed. The cDNA was analyzed by real-time PCR and results were normalized to mitochondrial 16S rRNA. B-E. $\mathrm{H} 2 \mathrm{Bub} 1$ increases on the p21 gene only in the presence of Ser2-phosphorylated RNAPII. U2OS cells were treated with Nutlin-3A and DRB for $8 \mathrm{~h}$ and the chromatin was immunoprecipitated using the antibodies against total RNAPII (B,C), pSer2 RNAPII (D) and H2Bub1 (E). Chromatin was analyzed by real-time PCR, the data was normalized to input DNA and expressed as percent of recovery, mean values + standard deviation, $n=3$. Dotted lines represent the experimental background. TSS - transcription start site, TR - transcribed region.

\subsection{CDK9 regulates UBE2A by site-specific phosphorylation}

\subsubsection{CDK9 and CCNT1 interact with UBE2A}

UBE2A (hRad6A) is an E2 ubiquitin conjugating enzyme involved in the ubiquitination of histone H2B and DNA clamp PCNA. In yeast Rad6A is activated 
by phosphorylation of serine 120 . The kinase responsible for this phosphorylation, called Burl (Wood et al, 2005) is homologous to human CDK9. Furthermore, the human homolog UBE2A was also shown to be phosphorylated at the same position by other cyclin-dependent kinase members (Sarcevic et al, 2002). We hypothesized that human UBE2A function may also be regulated by CDK9-mediated sitespecific phosphorylation.

In order to test whether CDK9 and UBE2A interact in human cells we performed coimmunoprecipitation studies between the kinase and its putative substrate. We were able to successfully demonstrate the binding of endogenous UBE2A with CDK9 and Cyclin T1 (Fig. 12A) as well as CDK9 with UBE2A (Fig. $12 \mathrm{~B})$.
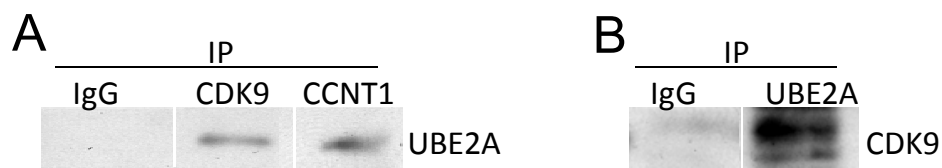

Figure 12. UBE2A interacts with CDK9 and CCNT1. H1299 cells were harvested and coimmunoprecipitation was performed using the antibodies against endogenous CDK9, Cyclin T1 (A) and UBE2A (B) as well as unspecific IgGs. The presence of coimmunoprecipitated proteins was detected by Western blot with specific antibodies.

\subsubsection{CDK9 phosphorylates UBE2A in vitro and in vivo}

Besides the binding we also wanted to demonstrate site-specific kinase activity of CDK9 towards UBE2A. For that wild type UBE2A as well as S120A mutant were purified from E. coli as GST-fusion proteins and phosphorylated by CDK9 in vitro using $\gamma-\left[{ }^{32} \mathrm{P}\right]$-ATP. Serine 120 is homologous to the yeast Rad6 phosphorylation site (also S120) of human UBE2A. By mutating it to alanine we expected to abolish the CDK9-mediated phosphorylation.

While GST alone and the S120A mutant of UBE2A were only mildly phosphorylated (Fig. 13A), wild-type GST-UBE2A was significantly phosphorylated by $\mathrm{P}-\mathrm{TEFb}$ in vitro. After quantifying the intensity of bands and normalizing them to the molecular weights of proteins the specificity of P-TEFb for S120 became clear, since the S120A mutant was phosphorylated at a level similar to GST alone (Fig. 13B). 
In collaboration with Dirk Eick and Elisabeth Kremmer (Helmholtz Center for Environmental Health, Center for Integrated Protein Science, Munich) we generated a mouse monoclonal antibody that specifically recognizes S120phosphorylated form of UBE2A. Importantly, the signal of this antibody in Western blot is strongly decreased following the knockdown of either CDK9 or UBE2A suggesting that the phosphorylation of UBE2A in vivo depends on CDK9 activity (Fig. 13C).
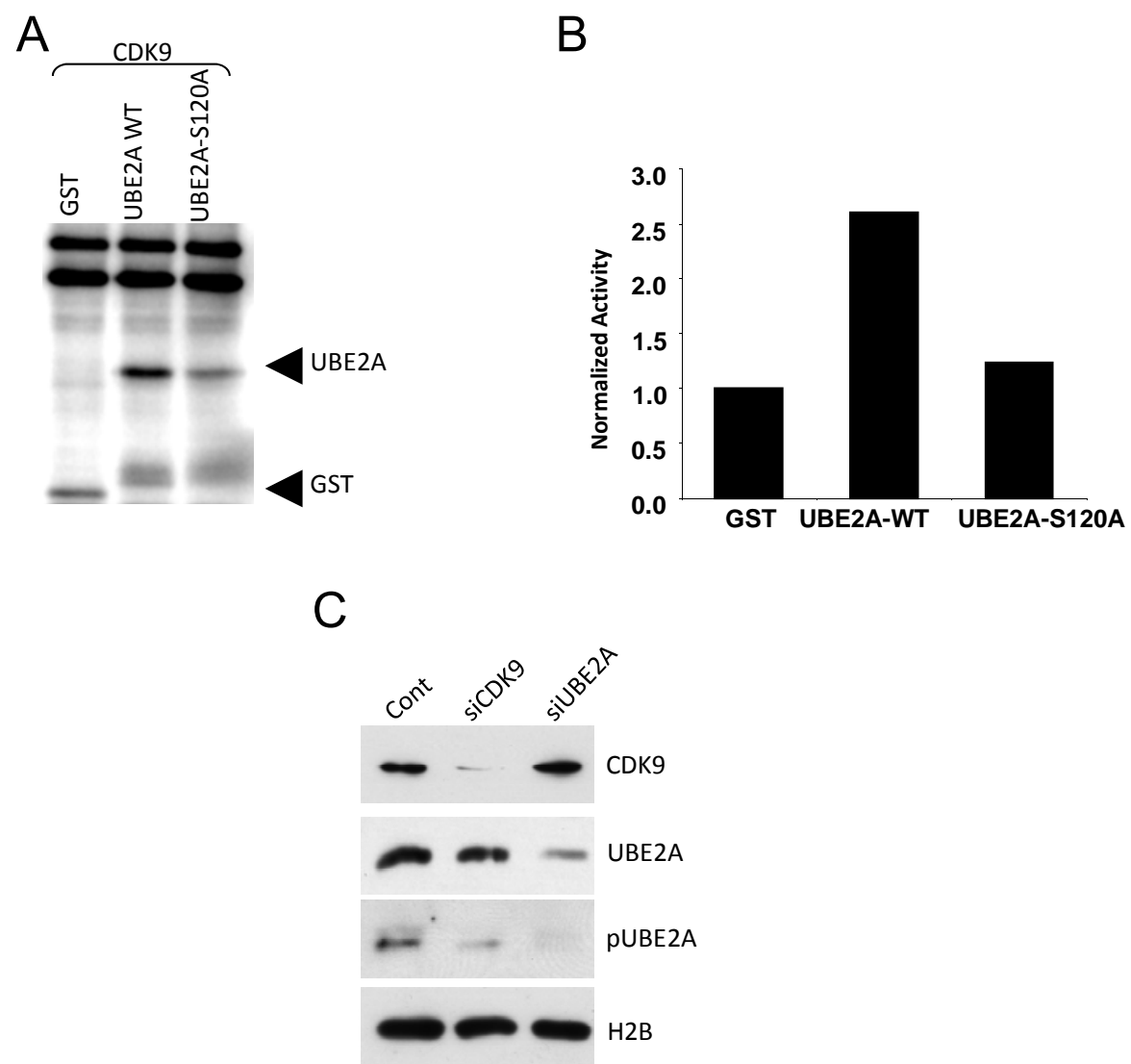

Figure 13. CDK9 phosphorylates UBE2A in vitro and in vivo. A. GST-UBE2A fusions were phosphorylated by CDK9 in the presence of $\gamma-\left[{ }^{32} \mathrm{P}\right]-\mathrm{ATP}$. Arrows indicate specific bands obtained with phosphoimager. High molecular weight bands represent the products of auto-phosphorylation of kinase complex components. B. Quantification of band intensity was performed using TYPHOON Scanner Control 3.0 software. Results were normalized to the protein size and presented as fold relative to GST background. C. HCT116 cells were transfected 
with siRNAs against CDK9 or UBE2A. Protein extracts were analyzed by Western blot $48 \mathrm{~h}$ after transfection.

\subsubsection{CDK9 is necessary for both H2B and PCNA monoubiquitination}

As is typical for most E2 ubiquitin conjugating enzymes, UBE2A supplies the ubiquitin for several E3 ubiquitin ligase complexes. In this case RAD18 and RNF20/40 which ubiquitinate PCNA and H2B, respectively, both utilize UBE2A for substrate ubiquitination (Kim et al, 2009; Watanabe et al, 2004). Assuming that CDK9 might regulate UBE2A function we hypothesized both ubiquitinations may be affected by changing the level of CDK9. Indeed, the reduction of PCNA and H2B monoubiquitinations in UVC-treated CDK9-depleted cells was comparable to the effect of knocking down UBE2A alone (Fig. 14A).

Cyclin $\mathrm{T} 1$ is the major cyclin component of P-TEFb and is known to be necessary for its activity (Peng et al, 1998). As predicted by our model the depletion of CCNT1 also led to the reduction of H2B monoubiquitination as well as PCNA monoubiquitination following the treatment by UVC and hydroxyurea (Fig. 14B).

A

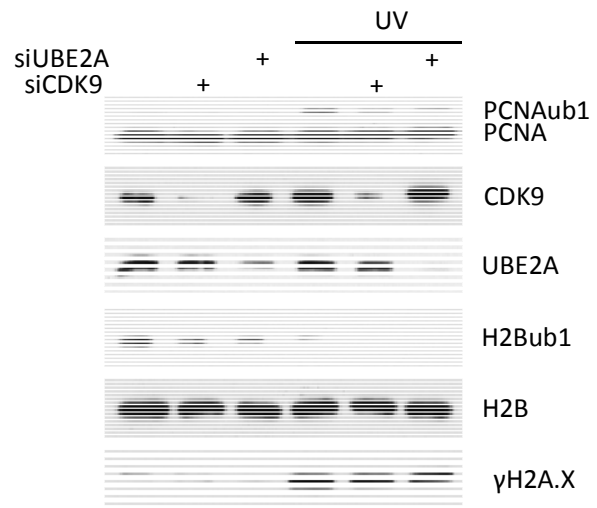

B

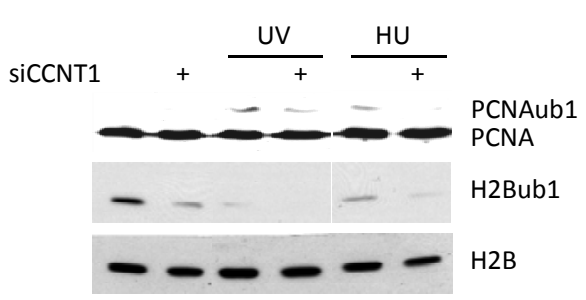

Figure 14. CDK9 regulates PCNA monoubiquitination. A. HCT116 cells were transfected with siRNAs against CDK9 or UBE2A. After $48 \mathrm{~h} 80 \mathrm{~J} / \mathrm{m}^{2} \mathrm{UVC}$ was applied and cells were harvested $3 \mathrm{~h}$ later. B. HCT116 cells were transfected with a control siRNA or an siRNAs against Cyclin T1. 80J/m2 UVC and $3 \mathrm{mM}$ of hydroxyurea were applied 3 and $20 \mathrm{~h}$ before harvesting protein extract. 


\subsection{H2B is rapidly deubiquitinated following various stress conditions}

\subsubsection{Different stress factors rapidly reduce H2B monoubiquitination}

As shown in the previous chapter treatment with $\mu$ ltraviolet light drastically reduced the levels of H2Bub1 (Fig. 14A). In the course of this study we observed a severe reduction of histone $\mathrm{H} 2 \mathrm{~B}$ monoubiquitination caused by a wide palette of factors, such as DNA-damaging chemotherapeutic drugs (doxorubicin, camptothecin, etoposide, cisplatin, hydroxyurea), proteasome inhibitors (MG132), heat shock, osmotic stress and nucleolar function disruption (Fig. 14B, 15A, S2). Surprisingly we were able to rescue this effect by pre-treating the cells with caffeine, which is widely used to inhibit the activity of PI3-kinase-related protein kinases following DNA damage (Fig. 15B).

A

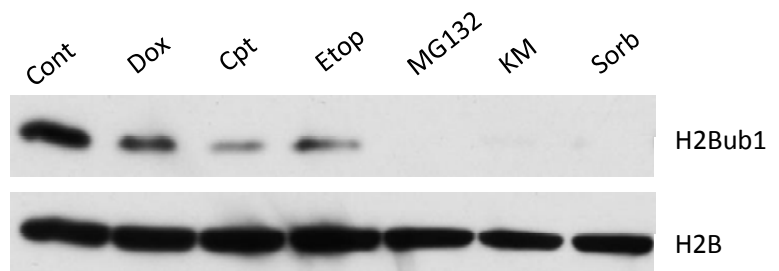

B

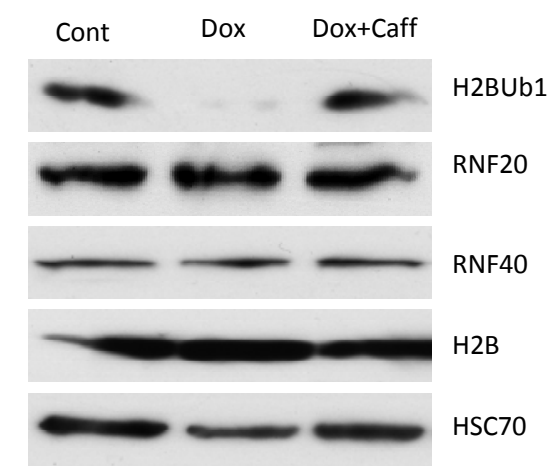

Figure 15. Various factors downregulate the H2B ubiquitination. A. H1299 cells were treated for $1 \mathrm{~h}$ with $7.5 \mu \mathrm{M}$ doxorubicin, $10 \mu \mathrm{M}$ camptothecin, $100 \mu \mathrm{M}$ etoposide, $20 \mu \mathrm{M}$ MG132, $30 \mu \mathrm{M}$ KM05283 and $0.5 \mathrm{M}$ sorbitol. Protein extracts were analyzed by Western blot. 
B. H1299 cells were pretreated with $4 \mathrm{mM}$ of caffeine for $1 \mathrm{~h}$, then treated with $7.5 \mu \mathrm{M}$ doxorubicin for $3.5 \mathrm{~h}$. Protein extracts were analyzed by Western blot.

The chemotherapeutic drugs used in this study cause the formation of single- or double-strand DNA breaks. Ultraviolet light, heat shock and osmotic stress can also act as DNA-damaging factors. Caffeine which is able to rescue the H2Bub1 is a well known inhibitor of DNA damage response PI3-kinases. Therefore, we further tested whether DNA damage per se causes a loss of H2B ubiquitination. Surprisingly, cells irradiated with 10 Gy of $\gamma$-radiation showed no significant decrease of H2Bub1 (Fig. 16A). Moreover, in a concentration course of the DNA-damaging drug doxorubicin we can clearly see that the cells develop a strong DNA-damage response (as indicated by the level of $\gamma \mathrm{H} 2 \mathrm{AX}$ ) at concentrations which do not affect H2Bub1 (Fig. 16B). We therefore analyzed several signaling pathways which are known to be activated by cell stress and potentially lie downstream of the effects of caffeine to determine if these are involved in the stress-induced loss of H2Bub1. As seen from Table 1 only a few of these could rescue the post-stress H2Bub1 levels.

\begin{tabular}{|l|l|l|c|}
\hline Target & Rationale & Inhibition & Effect \\
\hline ATM & inhibited by caffeine (Sarkaria et al, 1999) & KU55933, siRNA & - \\
\hline ATR & inhibited by caffeine (Sarkaria et al, 1999) & siRNA & - \\
\hline DNA-PK & inhibited by caffeine (Block et al, 2004) & siRNA & - \\
\hline PI3Ks & Include ATM, ATR and DNA-PK & Wortmannin & - \\
\hline JNK & Stress-activated (Ip \& Davis, 1998) & SP600125 & + \\
\hline p38 & Stress-activated (Roux \& Blenis, 2004) & SB203580 & - \\
\hline PP1, 2A & CDK9 phosphatases (Chen et al, 2008) & Okadaic acid & - \\
\hline PP2B & CDK9 phosphatases (Chen et al, 2008) & Cyclosporin A & - \\
\hline PARP & Activated by stresses (Nicoletti \& Stella, 2003) & Olaparib & - \\
\hline mTOR & stress-activated (Reiling \& Sabatini, 2006) & Rapamycin & - \\
\hline G-protein & regulates cAMP level, as caffeine does & Cholera toxin & - \\
\hline ROS & Produced by various stresses & NAC/Trolox & - \\
\hline DUBs & remove ubiquitin tags & NiCl2/IAA & + \\
\hline
\end{tabular}

Table 1. Signaling pathways analyzed in the course of the study.

Most of these drugs used require transport mechanisms and subsequent steps in order to get inside the cell and cause the damage. Thus in order to analyze the dynamics of $\mathrm{H} 2 \mathrm{Bub} 1$ reduction we treated cells with ultraviolet radiation and followed the effects of treatment on global H2Bub1 levels. From the results of a 
time course treatment it is clear that most of H2Bub1 loss happens within 15 min after the treatment indicating that $\mathrm{H} 2 \mathrm{~B}$ ubiquitination and deubiquitination are very fast and highly dynamic processes (Fig. 16C).

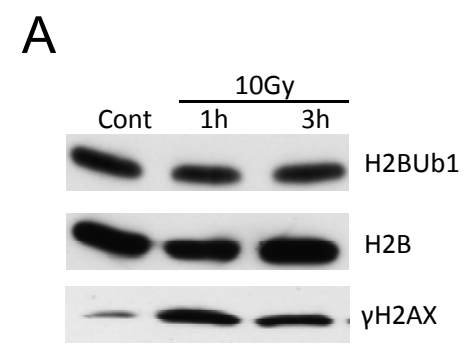

B

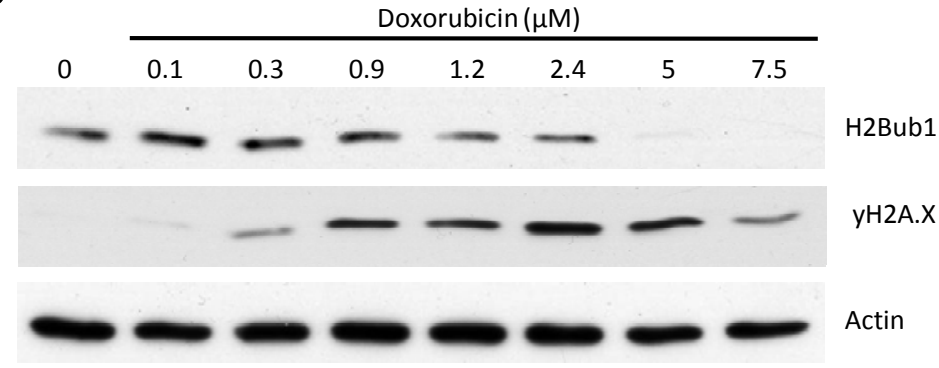

C

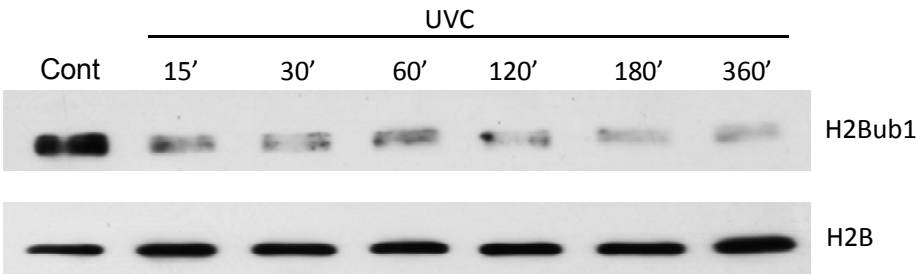

Figure 16.The reduction of H2B ubiquitination happens rapidly but is not caused by DNA damage per se. A. $\mathrm{H} 1299$ cells were irradiated with 10 Gy $\gamma$-irradiation 1 and $3 \mathrm{~h}$ before harvesting for Western blot analysis. B. H1299 cells were treated with the indicated concentrations of doxorubicin for $3.5 \mathrm{~h}$, proteins were analyzed by Western blot. C. H1299 cells were treated with UVC $\left(80 \mathrm{~J} / \mathrm{m}^{2}\right)$ and harvested for Western blot after indicated times.

\subsubsection{Nucleolar function is necessary for maintaining H2B ubiquitination}

Nucleoli are known to quickly respond to different stress factors by exchanging their components with the nucleoplasm (Boulon et al, 2010). Some consider nucleoli to be one of the most important stress sensors in the cell (Mayer 
et al, 2005; Olson, 2004). We hypothesized that this effect could be involved in the regulation of H2Bub1 upon stress. At low concentrations Actinomycin D is a potent RNAPI inhibitor and can rapidly disrupt the function of nucleoli by blocking ribosomal RNA transcription (Perry \& Kelley, 1968). Concentration course studies showed that the decrease of H2Bub1, stress-induced release of the nucleolar protein nucleophosmin (NPM) and activation of the stress-responsive kinase JNK happen in the same range of concentrations (Fig. 17A, B, S3).

Nucleophosmin and nucleolin are two important components of nucleoli and are essential for proper rRNA processing and ribosomal subunits biogenesis (Ginisty et al, 1998; Lindstrom, 2011). Nucleophosmin is a chaperone and one of its functions is retaining the ARF protein in the nucleolus (Colombo et al, 2005). Upon stress-induced nucleoplasmic translocation NPM releases ARF to the nucleus where it can trigger p53-signaling in previously described manner. The knockdown of nucleophosmin and nucleolin led to the reduction of $\mathrm{H} 2 \mathrm{~B}$ ubiquitination indicating that ribosomal function is needed for H2Bub1 maintanence. Since the cells used in the experiment were p53-negative it is unlikely that the observed effects depend on the p53 pathway. (Fig. 17C, D). 
A

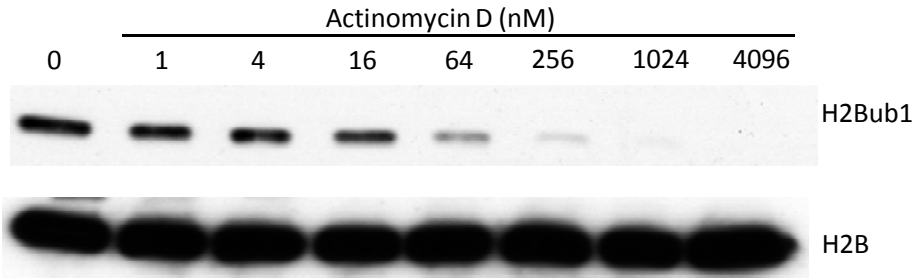

B

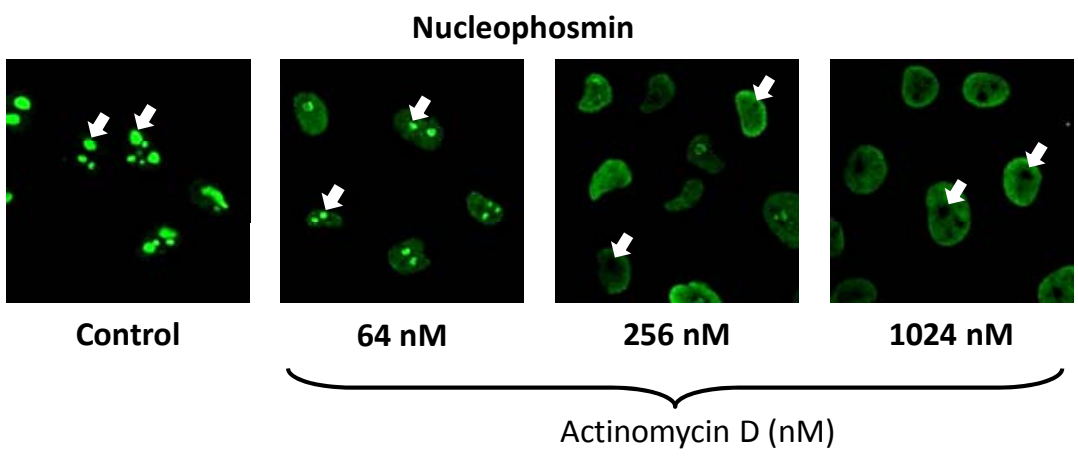

C
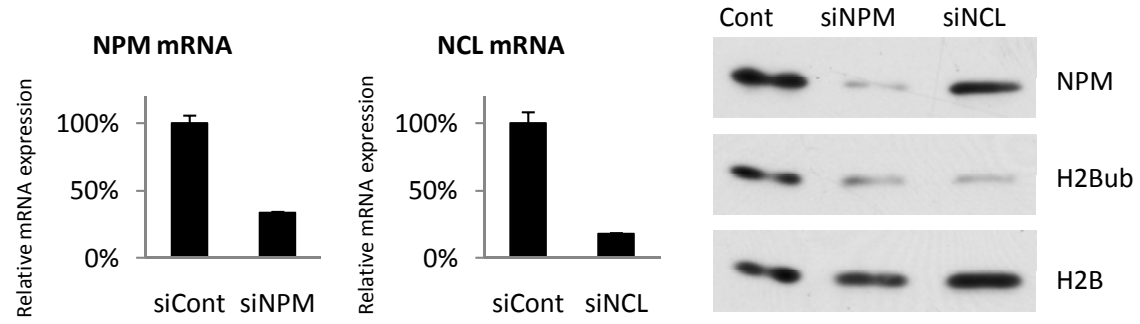

Figure 17. Disruption of nucleolar function causes a loss of histone H2B monoubiquitination. A. H1299 cells were treated with the indicated concentrations of actinomycin D for $3.5 \mathrm{~h}$. Protein extracts were subjected to Western blot analysis. B. H1299 cells were treated with the indicated concentrations of actinomycin D for $3.5 \mathrm{~h}$ and immunostained with antibodies against nucleophosmin. White arrows indicate individual nucleoli with or without nucleophosmin. C. H1299 cell were transfected with siRNAs against nucleophosmin and nucleolin. After $48 \mathrm{~h}$ after transfection total RNA was harvested, reverse transcribed and analyzed by RT-PCR. The results were normalized to 36B4 expression and presented as percent 
of expression. $n=3$, error bars represent standard deviation D. H1299 cell were transfected with siRNAs against nucleophosmin and nucleolin. In $48 \mathrm{~h}$ after transfection cells were harvested and protein extracts were analyzed by Western blot.

Nucleoli tightly interact with specific subnuclear structures involved in snRNA maturation referred to as Cajal bodies (Kiss et al, 2006). This interaction is mediated by protein migration. We observed a massive migration of one of the main Cajal body structural proteins, Coilin, to the periphery of the nucleoli following the induction of stress response by the same factors that induce the loss of $\mathrm{H} 2 \mathrm{Bub1}$. Interestingly, same as $\mathrm{H} 2 \mathrm{~B}$ ubiquitination, proper localization of Coilin can be rescued by caffeine treatment (Fig. 18).

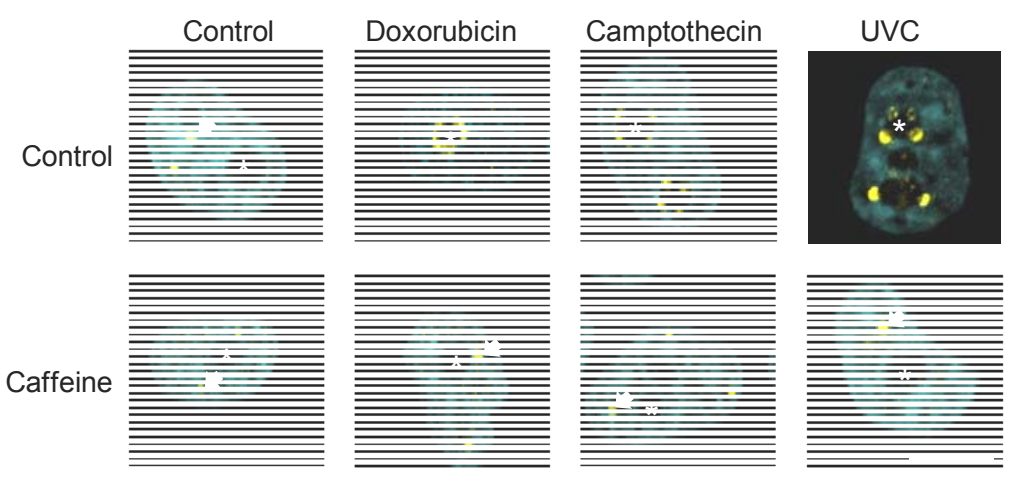

Figure 18. Disruption of Cajal bodies structure upon stress can be rescued by caffeine. H1299 cells were pretreated with $4 \mathrm{mM}$ caffeine for $30 \mathrm{~min}$ and treated with $7.5 \mu \mathrm{M}$ doxorubicin, $10 \mu \mathrm{M}$ camptothecin and $50 \mathrm{~J} / \mathrm{m}^{2}$ UVC. After $3.5 \mathrm{~h}$ cells were fixed and stained with antibodies against Coilin (yellow) and with DAPI (cyan). Stars represent nucleoli, arrows show intact Cajal bodies. Scale bar is $10 \mu \mathrm{m}$.

\subsubsection{JNK activity regulates the level of $\mathrm{H} 2 \mathrm{~B}$ ubiquitination}

Activation of JNK is a hallmark of various stress inducers. Therefore, we used a specific JNK inhibitor SP600125 to determine whether increased JNK activation might be essential for the stress-induced loss of H2Bub1. Indeed, pretreatment with the JNK inhibitor partially blocked the ability of doxorubicin or actinomycin D to decrease global H2Bub1 levels (Fig. 19A, S4).

Further support for the role of JNK in this process was provided by overexpressing it together with constitutively active form of its activating kinase 
MEKK1. As seen from the results of Western blot and immunofluorescence staining, the overexpression of activated JNK leads to the reduction of H2B ubiquitination (Fig. 19B, C). Furthermore, the effect of overexpression can be rescued by the treatment with the JNK inhibitor (Fig. 19D).
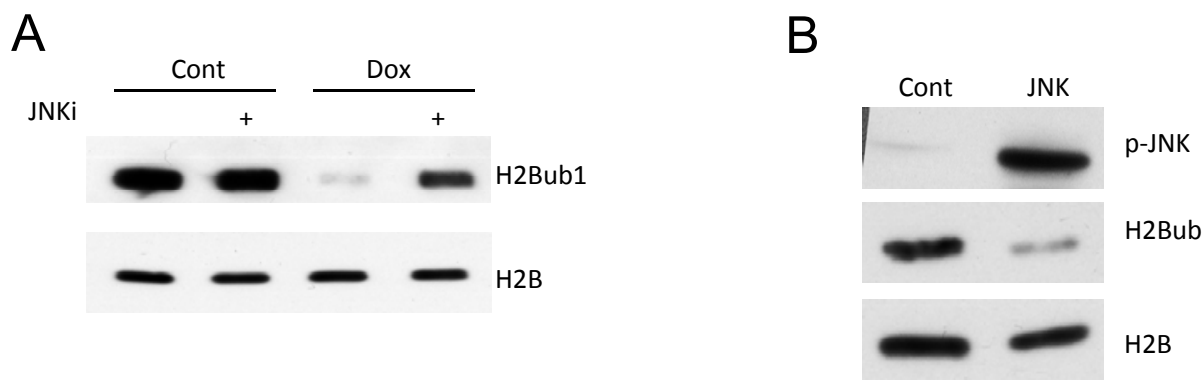

C
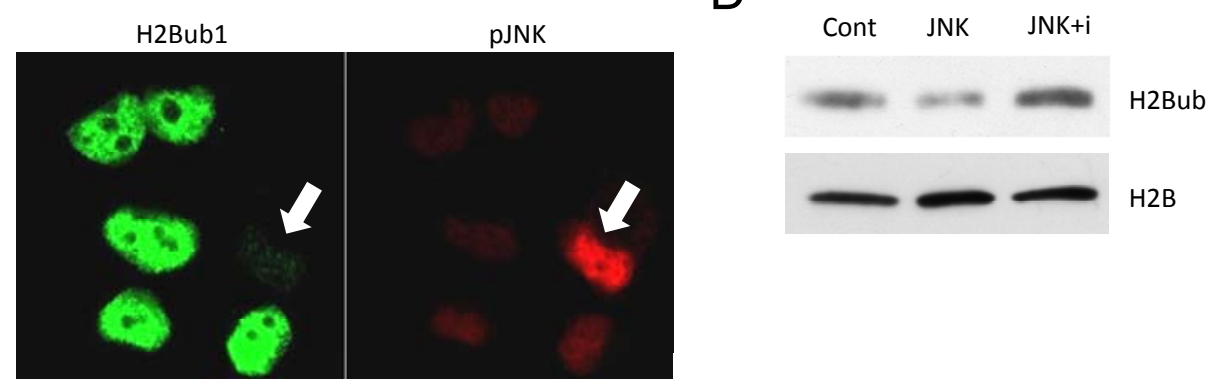

Figure 19. JNK activity regulates the level of H2B ubiquitination. A. H1299 cells were pretreated with $20 \mu \mathrm{M}$ of JNK inhibitor SP600125 for $30 \mathrm{~min}$ before $3.5 \mathrm{~h}$ treatment with $7.5 \mu \mathrm{M}$ of doxorubicin. Proteins were analyzed by Western blot. B, C. H1299 cells were transfected with control vector or plasmids encoding human JNK1 and its activator MEKK1. After $24 \mathrm{~h}$ cells were (B) harvested for Western blot or (C) stained with antibodies against H2Bub1 (green) and phospho-JNK (red). White arrows indicate the nucleus of the cell with overexpressed activated JNK. D. H1299 cells were transfected as in B and $24 \mathrm{~h}$ later treated with $20 \mu \mathrm{M}$ of SP600125 for $3 \mathrm{~h}$ before harvesting for Western blot.

\subsubsection{H2Bub1 levels are reduced due to the activation of a cellular deubiquitinating enzyme}

We questioned whether the activity of deubiquitinating enzymes (DUBs) is responsible for the rapid removal of $\mathrm{H} 2 \mathrm{~B}$ ubiquitination following cellular stress. 
Two wide range DUBs inhibitors, $\mathrm{NiCl}_{2}$ and iodacetamide (IAA), significantly rescued doxorubicin or actinomycin D induced decrease in H2Bub1 (Fig. 20A).

However, based on the data it is not clear whether the effects of $\mathrm{NiCl}_{2}$ and IAA are due to the basal level of DUB activity (i.e. the loss of H2Bub1 is primarily caused by decreased ubiquitination) or whether a specific DUB activity is increased. In order to clarify this question we performed an in vitro deubiquitination experiment (Fig. 20B). In brief, protein extracts from normal cells (substrate) were mixed with extracts from cells where RNF20 and RNF40 were depleated with siRNA to minimize the level of H2Bub1 (effector). The reaction buffer was added to the mixed extracts and they were incubated at $37 \mathrm{C}$. After mixing the substrate extract with the control effector extract we observed no change of H2Bub1 meaning that neither additional ubiquitinated H2B nor any appreciable DUB activity were present in the control effector extract. Note that the level of total H2B doubled at the same time due to additional histones present in the effector extracts. When the doxorubicin-treated cells were used for the effector extract the amount of $\mathrm{H} 2 \mathrm{~B}$ ubiquitination dropped below the basal level indicating that an increased deubiquitinating activity was present in treated cells (Fig. 20C).

In order to prove that the loss of ubiquitination caused by the presence of the doxorubicin-induced effector extract was provided by DUBs we performed another in vitro deubiquitination experiment with DUB inhibitors. The result clearly shows all three DUB inhibitors were able to successfully rescue the level of H2B ubiquitination (Fig. 20D). 


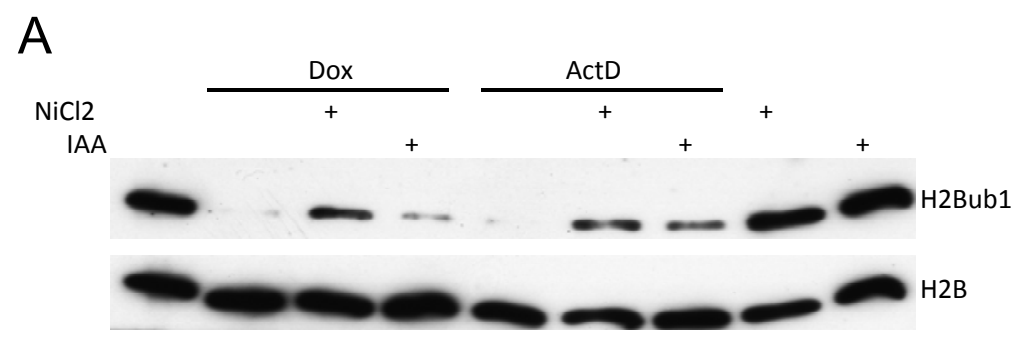

B

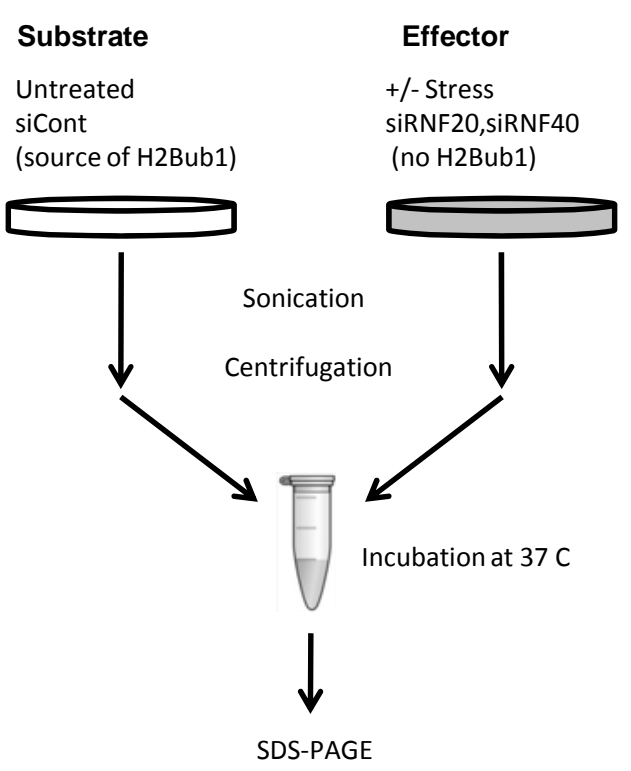

C

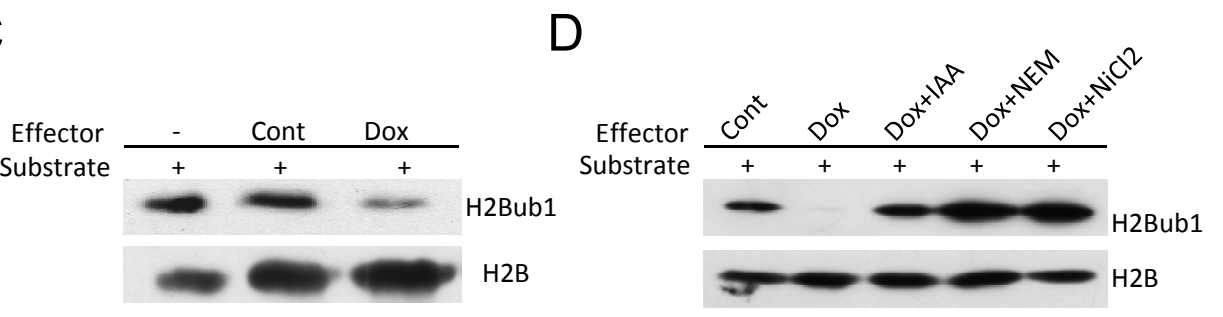

Figure 20. An H2B deubiquitinating activity is increased during cellular stress. A. $\mathrm{H} 1299$ cells were pretreated with $1 \mathrm{mM}$ of $\mathrm{NiCl}_{2}$ and $1 \mu \mathrm{M}$ of iodacetamide for $30 \mathrm{~min}$ before treatment with $3.75 \mu \mathrm{M}$ doxorubicin or $256 \mathrm{nM}$ actinomycin $\mathrm{D}$ for $3.5 \mathrm{~h}$. Protein extracts were analysed by Western blot. B. Scheme of the in vitro deubiquitination experiment. For details see 
"Materials and methods". C. H1299 cells were transfected with control or RNF20/40 siRNA and treated with $7.5 \mu \mathrm{M}$ doxorubicin for $3.5 \mathrm{~h}$ prior to harvesting and performing in vitro deubiquitination assay. D. Cells were treated same way as in C, but DUB inhibitors (IAA $1 \mu \mathrm{M}$, NEM $1 \mathrm{mM}, \mathrm{NiCl}_{2} 1 \mathrm{mM}$ ) were added to the reaction mix.

\subsubsection{USP22 is needed for the stress-induced JNK-regulated deubiquitination}

USP22 has been shown to deubiquitinate nucleosomes containing monoubiquitinated $\mathrm{H} 2 \mathrm{~B}$ in vitro. We hypothesized that its activity could be crucial for the stress-induced deubiquitination as well. As shown in Fig. 21A and supplementary Fig. S5 siRNA-mediated knockdown of USP22 rescues the H2B ubiquitination after treatment with actinomycin D or the DNA-damaging drug cisplatin.

Knowing the role of USP22 in H2B deubiquitination and the importance of JNK activity for this process we suggested the possibility that JNK may directly regulate USP22 activity through phosphorylation. Therefore we performed in vitro kinase assays using GST-tagged E. coli-purified USP22 as a substrate for recombinant JNK in the presence of $\gamma-\left[{ }^{32} \mathrm{P}\right]$-ATP. We could observe specific phosphorylation of USP22 by JNK while phosphorylation of GST alone was nearly undetectable (Fig. 21B). 
A

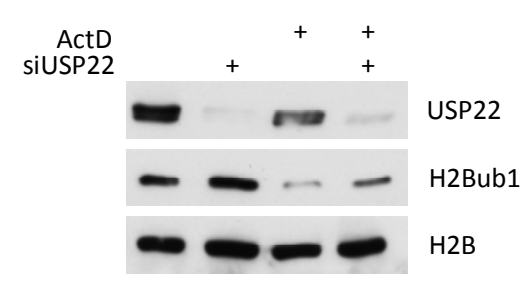

B

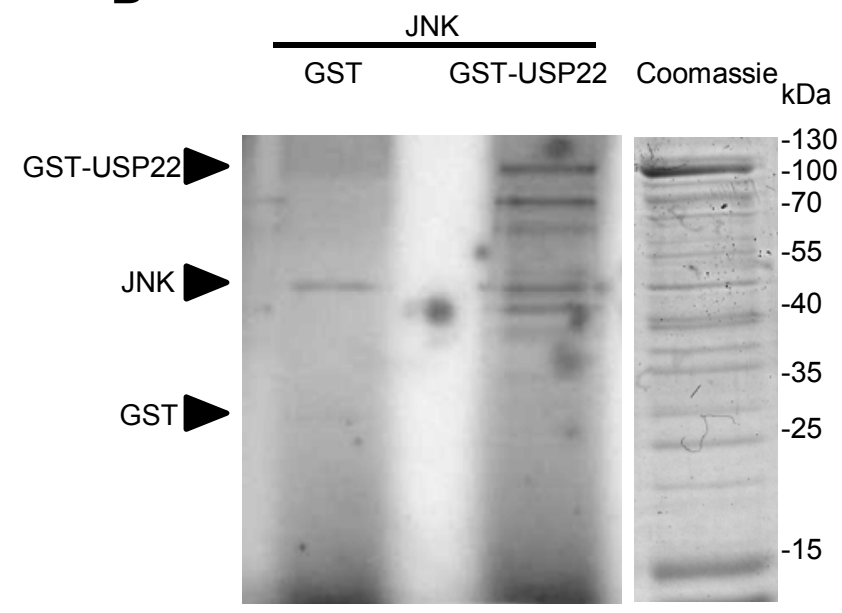

Figure 21. USP22 regulates the level of H2Bub1 and can be phosphorylated by JNK. A. H1299 cells were transfected with siRNAs against USP22. After $48 \mathrm{~h}$ cells were treated with $50 \mathrm{nM}$ of actinomycin D for $3.5 \mathrm{~h}$. Extracts were analyzed by western blot. B. GST-USP22 fusion protein was phosphorylated in vitro by JNK in presence of $\gamma-\left[{ }^{32} \mathrm{P}\right]-\mathrm{ATP}$. The products of the reaction were separated by SDS-PAGE and analysed with phosphoimager. Black arrows indicate phosphorylated full-size GST-USP22, autophosphorylated JNK and GST. Other bands are phosphorylated degradation products of GST-USP22. 
Supplemental material

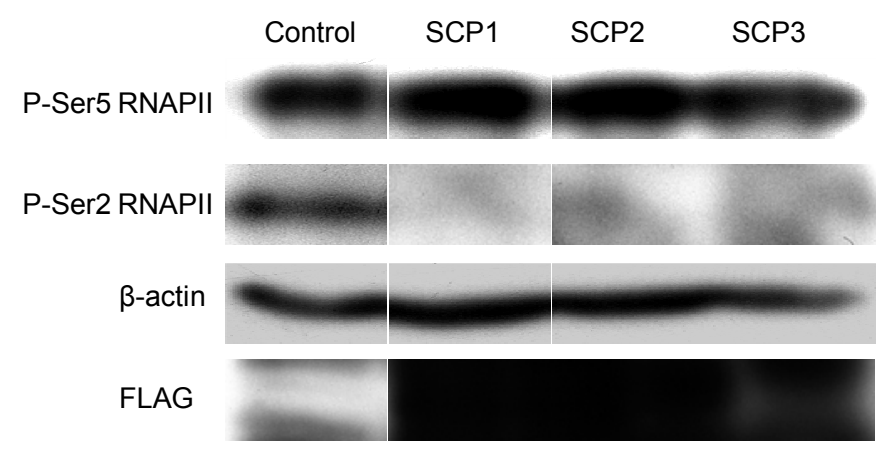

Figure S1. SCP1, SCP2 and SCP3 dephosphorylate Ser2 but not Ser5 of RNAPII CTD. $\mathrm{H} 1299$ cells were transfected with plasmids coding for SCP1, SCP2 and SCP3. After $48 \mathrm{~h}$ cells were harvested for and analyzed by Western blot using the indicated antibodies.

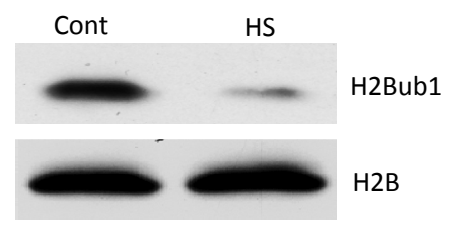

Figure S2. Heat shock reduces H2B ubiquitination. H1299 cells were heat-shocked by incubation at $42 \mathrm{C}$ for $1 \mathrm{~h}$. Protein extracts were analyzed by Western blot. 


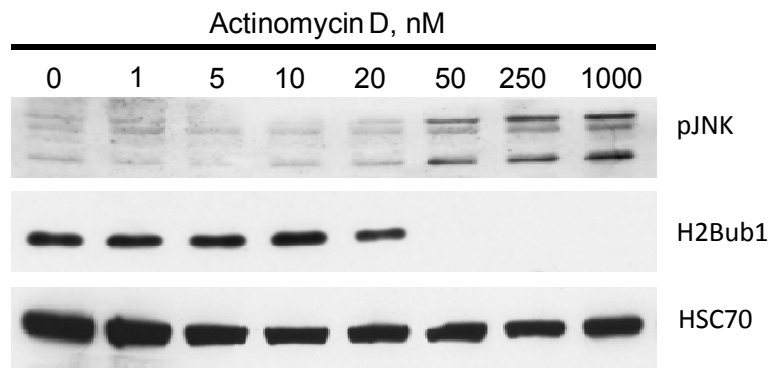

Figure S3. Activation of JNK correlates with the reduction of H2Bub1. H1299 cells were treated with indicated concentrations of actinomycin D for $12 \mathrm{~h}$. Proteins were analyzed by Western blot using the indicated antibodies. These data were kindly provided by Theresa Gorsler.

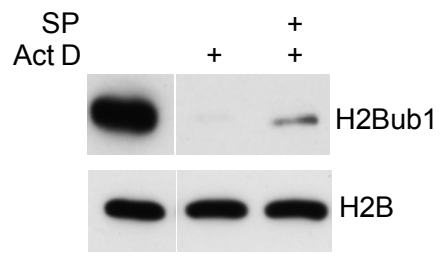

Figure S4. JNK inhibitor rescues H2Bub1 level after actinomycin D treatment. H1299 cells were pretreated with $20 \mu \mathrm{M}$ of JNK inhibitor SP600125 for $1 \mathrm{~h}$ and then treated with $256 \mathrm{nM}$ of actinomycin D for $3.5 \mathrm{~h}$. Protein extracts were harvested and analyzed by Western blot.

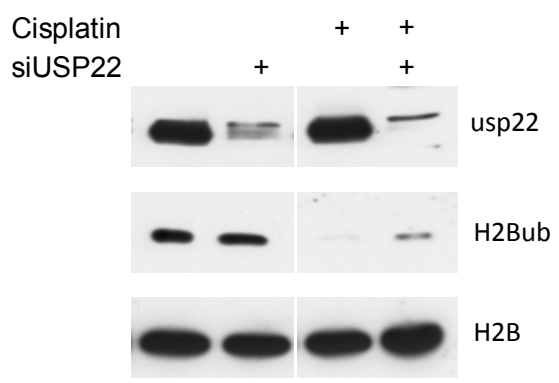

Figure S5. USP22 is needed for cisplatin-mediated reduction of H2Bub1. H1299 cells were transfected with siRNA against USP22. After $48 \mathrm{~h}$ cells were treated with $50 \mu \mathrm{M}$ cisplatin for $12 \mathrm{~h}$. Protein extracts were analyzed by Western blot using the indicated antibodies. These data were kindly provided by Theresa Gorsler. 


\section{Discussion}

Gene transcription is a tightly regulated process. It is controlled at all stages from initiation complex formation to the processing of the 3 '-end of the transcript. One of the important regulatory steps is a decision to switch the paused RNA polymerase complex to the elongation mode. The importance of pausing the transcription for the gene regulation became more obvious in recent years. The paused polymerase can wait for the induction for quite a long time providing the cell the possibility to rapidly activate transcription. In yeast two thirds of genes with paused RNA polymerase appeared to belong to the groups encoding the factors of cellular metabolism reprogramming (Radonjic et al, 2005). Besides that, pausing also provides the chance for improperly assembled transcription complex to fall off. In humans about $30 \%$ of all genes were shown to have a significant amount of RNA polymerased paused in the proximal promoter region while not not producing any detectable amount of RNA (Guenther et al, 2007). The release of RNAPII from pausing is primarily regulated by the Positive Transcription Elongation Factor-b (P-TEFb) (Yamada et al, 2006). The posttranslational modification of histones plays an important regulatory role in coordination of transcription events. Monoubiquitination of lysine 120 of histone H2B (H2Bub1) is an elongation epigenetic mark of actively transcribed genes (Minsky et al, 2008). Despite the high occupancy of H2Bub1 in the transcriptionaly active fraction of the genome relatively little is known about its regulation during the transcription cycle as well as the dynamics of this mark in different physiological conditions.

\subsection{P-TEFb as a key regulator of transcription elongation and co- transcriptional histone modification}

$\mathrm{P}-\mathrm{TEFb}$ is known to regulate the elongation step of transcription. Its kinase component CDK9 phosphorylates multiple target proteins. The phosphorylation of the NELF-E subunit of the Negative Elongation Factor leads to its release from the paused RNA polymerase complex (Fujinaga et al, 2004). Another negative elongation factor, DSIF, stays associated with RNAPII and is converted to a positive elongation factor upon CDK9-mediated phosphorylation (Yamada et al, 2006). The RNA polymerase II itself can also be phosphorylated by CDK9 at second serine residues of its carboxy-terminal domain repeats. This not only 
changes the charge and conformation of the CTD but also provides a binding surface for RNAPII associated factors (Buratowski, 2003; Egloff \& Murphy, 2008).

Based on a similar distribution pattern of H2Bub1 and P-TEFb-mediated RNAPII CTD Ser2 phosphorylation in human cells (Gomes et al, 2006; Komarnitsky et al, 2000; Minsky et al, 2008) we hypothesized that P-TEFb activity might be essential for the accumulation of H2Bub1. Indeed we were able to show that both inhibition and knockdown of the P-TEFb kinase component CDK9 resulted in a strong decrease of H2Bub1 levels while the overexpression of CDK9 had an opposite effect on H2Bub1. We were also able to convincingly show that Ser2 in RNAPII CTD is at least one of the CDK9 targets whose phosphorylation is needed for maintaining H2B ubiquitination. Although H2Bub1 was thought to be a co-transcriptional histone mark we were able to prove that it's only observed on a gene, which is being transcribed by CDK9-phosphorylated RNAPII. It is not detected in the presence of non-phosphorylated RNAPII in cases when the transcription happens in the absence of active P-TEFb. The recent discovery of a new role of $\mathrm{Ww}$ domain-containing Adaptor with Coiled-coil (WAC) protein provided a solid support for our model (Zhang \& Yu, 2011). WAC was shown to be a physical link between phospho-RNAPII and H2Bub1. It can simultaneously bind phosphorylated RNAPII CTD and heterodimeric complex of E3 ubiquitin ligases RNF20/40 which ubiquitinates histone H2B.

The P-TEFb complex has been shown to regulate not only RNA polymerase dynamics but also the co-transcriptional modifications of chromatin. The histone methyl transferase SETD2 is recruited to the CDK9-phosphorylated RNAPII CTD (Egloff \& Murphy, 2008). This leads to the increase of H3K36 trimethylation in the transcribed region of the gene. In addition, H2B monoubiquitination can itself regulate the deposition of tri-methyl marks on H3K4 and $\mathrm{H} 3 \mathrm{~K} 79$ by a trans tail regulation mechanism while its own regulation remains elusive in many aspects (Kim et al, 2005; Zhu et al, 2005).

Other targets of CDK9 appeared to be less important for maintaining H2Bub1 level. The knockdown of NELF-E affected neither H2Bub1 nor H3 methylations dependent on it. The knockdown of the DSIF component SUPT5H also did not change the level of H2Bub1 while the amount of H3K36me3 was 
significantly reduced, proving that $\mathrm{H} 3 \mathrm{~K} 36 \mathrm{me} 3$ is regulated by additional factors besides RNAPII phosphorylation. Both H2Bub1 and H3K36me3 are predominantly localized in the transcribed part of the gene, however different regulation suggests different roles. Indeed, unlike ubiquitously distributed H2Bub1 H3K36me3 is highly enriched on exons (Kolasinska-Zwierz et al, 2009). This localization was found to be connected to pre-mRNA splicing (Luco et al, 2011). It also should be mentioned that some published data is contradictory to our observations. The siRNA-mediated knockdown of SUPT5H was shown to strongly decrease the level of H2Bub1 in human cells (Chen et al, 2009). Additional experiments involving another siRNAs and probably the rescue experiment are needed to clarify the situation. In accordance with previously shown data that H2Bub1 regulates $\mathrm{H} 3 \mathrm{~K} 4 \mathrm{me} 3$ and $\mathrm{H} 3 \mathrm{~K} 79$ me 3 we were able to demonstrate a strong downregulation of all these marks following the CDK9 knockdown (Pirngruber et al, 2009a).

Despite playing a significant role in the coordination of other chromatin marks H2Bub1 may also play an important role in transcription by itself. As was recently observed the ubiquitination of $\mathrm{H} 2 \mathrm{~B}$ disrupts the structure of the chromatin at the level of the $30 \mathrm{~nm}$ fiber (Fierz et al, 2011). This structural change could promote the transcription by opening it for RNAPII. However, previous reports suggest otherwise. The rate of in vitro transcription did not depend on the presence of ubiquitin tags on histones (Kim et al, 2009). The most probable role of H2Bub1 in this case is regulation of other histone modifications which might be more important for the transcription rate. At the same time other researchers reported direct stimulating effect of $\mathrm{H} 2 \mathrm{Bub} 1$ on in vitro transcribing RNAPII. A model was proposed where $\mathrm{H} 2 \mathrm{Bub} 1$ acts as a mark for the FACT complex to remove the $\mathrm{H} 2 \mathrm{~A} / \mathrm{H} 2 \mathrm{~B}$ dimer from the nucleosome thus promoting the movement of RNAPII through the chromatin (Pavri et al, 2006). In general, this provides a novel mechanism of transcriptional regulation by $\mathrm{P}-\mathrm{TEFb}$ through $\mathrm{H} 2 \mathrm{Bub} 1$.

\subsection{P-TEFb and genome integrity}

Despite having a significant role in the regulation of transcription, $\mathrm{P}-\mathrm{TEFb}$ or at least its kinase component CDK9, is clearly involved in maintaining genome integrity. CDK9 was recently isolated in a screen as a HU-sensitivity factor (Yu et al, 2010). Cells lacking CDK9 were less able to recover from HU-induced cell cycle arrest. Cyclin $\mathrm{K}$ was shown to be necessary as the CDK9 partner for this 
activity. The accumulation of $\gamma \mathrm{H} 2 \mathrm{~A} . \mathrm{X}$ in cells depleted of CDK9 was also observed suggesting the inability of cells to repair spontaneous DNA breaks. The interaction of CDK9 with DNA damage-related proteins ATR, ATRIP and Ku70 also provides good evidence for the role of CDK9 in genome integrity maintenance (Yu et al, 2010). However, based on these studies the exact mechanism of CDK9mediated control of DNA damage repair remains unknown.

The yeast CDK9 homolog Bur1 may also be important for DNA damage repair. It specifically phosphorylates and activates Rad6, an E2 ubiquitin ligase for PCNA. PCNA is a DNA clamp and in its ubiquitinated state recruits DNA polymerase eta for the translesion synthesis (Haracska et al, 2001). It is also worth mentioning that the putative phosphorylation site in the human Rad6 homolog UBE2A likely plays an important role in the regulation of its function. Many other members of the UBE family have single or double negatively charged aminoacids in the site where UBE2A has a phosphorylatable serine (Fig. 22). It appears that a strong negative charge in this region is essential for protein function.

\section{UBE $2 A$ \\ UBE2 I \\ UBE2N \\ UBE2NL \\ UBE2T \\ UBE2D1 \\ UBE2D4 \\ $\mathrm{UBE} 2 \mathrm{H}$}

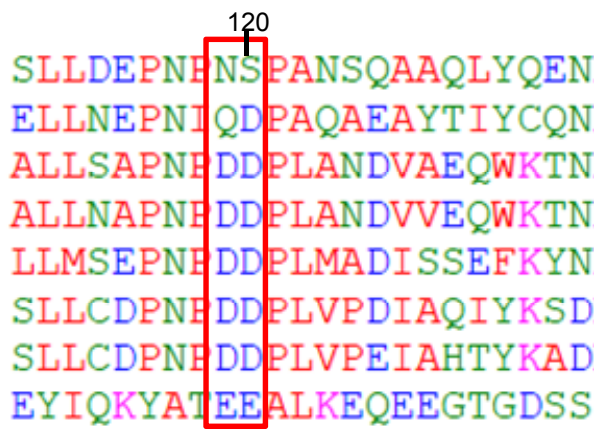

Figure 22. Analysis of UBE-family members. Serine is substituted to one or two negatively charged amino acids in multiple homologues of UBE2A. (Done by ClustalW software).

We hypothesized a positive role for CDK9 in the regulation of the human Rad6 homolog UBE2A. Indeed CDK9 and cyclin T1 can bind a UBE2A and phosphorylate it in vitro at the conserved serine 120 . Moreover, the antibody raised against a UBE2A phosphopeptide showed a decreased signal after siRNAmediated CDK9 depletion. Importantly, the knockdown of CDK9 also reduced the ubiquitination of PCNA and H2B which both depend on Rad6 activity. 
The ubiquitination of PCNA is an important component in the Fanconi anemia network which is essential for the repair of interstrand DNA crosslinks (Geng et al, 2010). Previously the increased sensitivity of Fanconi anemia cells to DNA-crosslinking drugs like mitomycin C (MMC) was demonstrated (Geng et al, 2010). Moreover, the combinatorial treatment with flavopiridol and MMC significantly increased the efficiency of apoptosis induction in breast cancer cells (Schwartz et al, 1997). Since CDK9 is strongly inhibited by flavopiridol we now provide a potential mechanistic model for the observed effects which may provide a rational basis for testing more specific CDK9 inhibitors in combination with interstrand crosslinkers.

Very recently the importance of $\mathrm{H} 2 \mathrm{~B}$ ubiquitination in DNA damage repair was shown (Moyal et al, 2011; Nakamura et al, 2011). Although details are still to be clarified it is already obvious that H2Bub1 in the sites of DNA damage is absolutely crucial for proper repair process. The cumulative effect of DNA breakinducing treatments and potent CDK9 inhibitor flavopiridol on promoting apoptosis in cancer cells has been known for a long time. Flavopiridol was able to induce apoptosis in colon carcinoma HCT116 cells treated with low concentrations of topoisomerase I inhibitor camptothecin (Motwani et al, 2001). Ovarian carcinoma cells exhibited increased radiosensitivity upon flavopiridol treatment (Raju et al, 2003). The deletion of the tumor suppressor p53 and overexpression of the antiapoptotic protein Bcl-2 could not impair the ability of flavopiridol to increase the effect of ionizing radiation (Hara et al, 2008). The radiosensitivity of xenographic mammary carcinoma, ovarian carcinoma, lymphoma and glioma in mice was improved by flavopiridol as well (Mason et al, 2004; Newcomb et al, 2004). Different mechanisms of flavopiridol action were proposed starting from the cell cycle regulation to the modulation of PARP activity. Although some authors mentioned CDK9 as one of the relevant flavopiridol targets no clear connection to the chromatin modifications has been made so far.

Taken together the radiosensitizing activity of CDK9 inhibitor flavopiridol, H2Bub1-dependent dsDNA breaks repair and our data connecting CDK9 and H2Bub1 provide a completely new, distinct mechanism of P-TEFb-mediated genome integrity control. 


\subsection{Stress-induced reduction of H2B ubiquitination}

\subsubsection{H2Bub1 is strongly reduced by various treatments}

In the course of this study we have demonstrated an interesting phenomenon partly described previously. The ubiquitination of histone H2B is rapidly and strongly reduced upon various treatments such as chemotherapeutic drugs (doxorubicin, etoposide, camptothecin, cisplatin), $\mu$ ltraviolet irradiation, osmotic stress (sorbitol) and heat shock. Quite surprisingly ionizing irradiation did not affect H2Bub1 levels although causing significant DNA damage. Remarkably, the chemotherapeutic DNA-damaging drug doxorubicin decreased the H2Bub1 only at concentrations at least 5 fold higher than needed for a strong DNA damageresponse induction. This finding looks, however, less surprising if taken into the context of recent research reporting that $\mathrm{H} 2 \mathrm{~B}$ ubiquitination is rather induced at the sites of DNA damage and needed for the proper repair (Moyal et al, 2011; Nakamura et al, 2011). This suggests the existence of another pathway regulating H2Bub1 under unfavorable conditions.

Previous studies also reported strong reduction of $\mathrm{H} 2 \mathrm{~B}$ ubiquitination following the treatment with proteosome inhibitors, heat shock and inhibitors of transcription (Davie \& Murphy, 1990). The model proposed by authors included the depletion of free monomeric ubiquitin due to the insufficient turnover of polyubiquitinated proteins in the cell. This explanation apparently does not fit the picture we observe since most treatments we apply do not cause the accumulation of polyubiquitinated proteins. Moreover, the reduction of H2Bub1 upon treatment can be rescued by pre-treatment with caffeine. Altogether this data suggests an actively regulated multiple factor-induced pathway of $\mathrm{H} 2 \mathrm{Bub} 1$ reduction.

The physiological role of this massive change of chromatin status is not clear yet. Yeast cells are known to rapidly shut off the transcription of almost all genes within the first 10 min after strong stress like osmotic stress (Miller et al, 2011). The new wave of gene expression which starts after 15 min is already corrected in accordance with new conditions. We can speculate that similar reprogramming takes place in human cells as well. H2Bub1, being a transcriptionspecific chromatin mark, would be expected to be rapidly removed.

Another possible explanation of the observed effects may utilize the novel finding that H2Bub1 keeps the chromatin uncompacted. The dosages of treatments 
needed to induce a quick loss of $\mathrm{H} 2 \mathrm{Bub} 1$ are usually very high and are very likely to induce apoptosis. As we know, one of the apoptotic events is an ATP-dependent chromatin condensation (Kass et al, 1996). Thus, the rapid loss of H2B ubiquitination we observe might be one of early apoptotic events.

\subsubsection{JNK and nucleolar signaling are involved in reduction of H2Bub1}

Nucleoli are known to rapidly respond to a variety of stresses and, what is important for us, their function is tightly controlled by c-Jun N-terminal kinase (JNK) signaling. JNK has been shown to phosphorylate and inactivate TIF-IA, a specific RNAPI transcription factor. It in turn leads to the failed ribosomal biosynthesis and nucleoplasmic translocation of nucleolar proteins like NPM, L5, L11, ARF, etc. (Mayer et al, 2005).

Further analysis of stress-induced H2Bub1 changes revealed a strong dependence of this chromatin modification on the activity of JNK. JNK is known to be activated by various environmental stresses (Minden \& Karin, 1997). Pretreatment of cells with a specific JNK inhibitor partially rescued the effects of both UV and doxorubicin on H2Bub1. Importantly, both these treatments increase JNK activity. In opposite, the overexpression of activated JNK led to the reduction of the global H2Bub1 level. At the moment JNK seems to be the only known kinase whose activity downregulates $\mathrm{H} 2 \mathrm{~B}$ ubiquitination.

Thus, the induction of nucleolar stress via a direct mechanism (e.g. actinomycin D) or indirect mechanisms involving JNK or rRNA processing (i.e. NPM or NCL knockdown) suggest an intimate connection between nucleolar integrity and the maintenance of H2Bub1. It was recently shown that MYBBP1A and MKI67IP proteins are released from nucleoli upon blocking their function by knocking down TIF-IA (Kuroda et al, 2011). The described function of these two proteins is acetylation of p53 in order to stabilize it and induce a p53-response which leads to either cell cycle arrest or apoptosis. However, all our experiments with H2Bub1-reducing treatments were done in the H1299 cell line, which is p53negative. The recent data obtained in our lab shows that MYBBP1A and MKI67IP are also RNF40 binding proteins. We also cannot exclude the possibility that MYBBP1A and MKI67IP not only interact with RNF40 but also inhibit it by acetylation. Nopp140, which is also normally localized in nucleoli, was also shown 
to interact with RNF40 in our experiments. We thus propose an inhibition H2B ubiquitination by stress-released nucleolar components.

\subsubsection{Stress and DUB activity}

According to our data the loss of H2B ubiquitination happens very rapidly which is difficult to explain with inhibition of RNF40 alone. We hypothesized the activation of certain de-ubiquitinating enzymes (DUBs) as a mechanism of quick H2B deubiquitination. We were indeed able to demonstrate the increase of a deubiquitinating activity in cells treated with doxorubicin. This activity was completely abolished by adding DUB inhibitors such as IAA, NEM or $\mathrm{NiCl}_{2}$ proving that it came from one of ubiquitin-specific proteases (USPs). Further analysis allowed us to conclude that USP22 was the enzyme which was at least partially responsible for the stress-induced deubiquitination. USP22 was already shown to deubiquitinate H2B in vitro (Zhao et al, 2008). Normally it is found as a component of Spt-Ada-Gcn5-Acetyltransferase (SAGA) complex and is involved in the deubiquitination of histone H2A and H2B. USP22 was also identified as a component of a so-called "death from cancer" signature, a specific gene expression profile containing several genes whose expression is associated with poor clinical prognosis of cancer patients (Glinsky et al, 2005). We also showed in vitro phosphorylation activity of JNK on USP22. Thus, this phosphorylation may potentially modify the affinity of the USP22 zinc-finger domain to certain interaction partners thereby changing its activity and specificity. For example, the USP22 deubiquitinating module (containing ATXN7L3 and ENY2) may be released from the core SAGA complex and function in a SAGA-independent manner. Consistent with this hypothesis, no effect of the core SAGA component GCN5 was observed on the stress-induced loss of H2Bub1 (data not shown). The knockdown of USP22 gave partial rescue of H2Bub1 level upon several stresses. It is quite possible that several USPs such as USP27 perform this function though.

The above given information provides interesting possibilities for improving the efficiency of X-ray therapy of tumors. As we know from previous research the successful repair of double strand DNA breaks requires the deposition of ubiquitinated H2B into the region of damaged chromatin repair (Moyal et al, 
2011; Nakamura et al, 2011). It is quite easy to imagine the impairment of the DNA repair process in case we were able to abolish the H2Bub1 in tumor tissues.

\subsection{The role of H2Bub1 in cancer biology}

The role of H2Bub1 in tumors biology is another interesting aspect. As we mentioned before the proteins involved in H2Bub1 level regulation are often misexpressed in cancers. It's not easy now to explain the details of this regulation, but most probably H2Bub1 would be reduced in tumors. In support of this, a CpG island in the promoter of the RNF20 gene was shown to be highly methylated in human breast tumors in comparison to normal tissues (Shema et al, 2008). Moreover, changes in the expression or activity of USP22, RNF40 or UBE2A could also potentially be altered during tumorogenesis.

One possible outcome of such a reduction might be an increase of metastatic activity. It is known that diffusion-based hypoxia in tumors promotes the spreading of metastasis (Chaudary \& Hill, 2007). At the same time the activity of H2B E3 ubiquitin ligase RNF20 has been shown to reduce the migration potential of cancer cells (Shema et al, 2008). We can hypothesize that tumor cells which manage to inactivate $\mathrm{H} 2 \mathrm{~B}$ ubiquitinating system would gain an advantage of high motility in hypoxic conditions. Alternatively, hypoxic stress itself, like the other investigated stresses, might lead to a loss of ubiquitination, thereby increasing the cell's propensity.

Another possible role of H2Bub1 loss in tumor biology came out of the experiment in which we observed a strong reduction of $\gamma \mathrm{H} 2 \mathrm{AX}$ upon RNF40 knockdown (data not shown). Some cancer cell lines with a high growth rate demonstrate quite a significant level of $\gamma \mathrm{H} 2 \mathrm{AX}$ in the absence of any DNA damage. This could be a result of so-called replication stress, which is caused by disruption of DNA replication forks during the S-phase of cell cycle. The cells with low levels of H2Bub1 might not recognize such events properly and keep growing at a higher rate meanwhile accumulating chromosomal aberrations, which is typical for cancer cells.

To shed some light on these and other problems further careful and extensive study of this process is required for the development of solid knowledge 
of stress-induced $\mathrm{H} 2 \mathrm{~B}$ deubiquitination and the role of $\mathrm{H} 2 \mathrm{~B}$ monoubiquitination during tumorogenesis and metastasis.

Ahmad Y, Boisvert FM, Gregor P, Cobley A, Lamond AI (2009) NOPdb: Nucleolar Proteome Database--2008 update. Nucleic acids research 37: D181-184

Al-Baker EA, Oshin M, Hutchison CJ, Kill IR (2005) Analysis of UV-induced damage and repair in young and senescent human dermal fibroblasts using the comet assay. Mech Ageing Dev 126: 664-672

Andrade LE, Tan EM, Chan EK (1993) Immunocytochemical analysis of the coiled body in the cell cycle and during cell proliferation. Proceedings of the National Academy of Sciences of the United States of America 90: 1947-1951

Bao Y, Konesky K, Park YJ, Rosu S, Dyer PN, Rangasamy D, Tremethick DJ, Laybourn PJ, Luger K (2004) Nucleosomes containing the histone variant H2A.Bbd organize only 118 base pairs of DNA. The EMBO journal 23: 33143324

Barski A, Cuddapah S, Cui K, Roh TY, Schones DE, Wang Z, Wei G, Chepelev I, Zhao K (2007) High-resolution profiling of histone methylations in the human genome. Cell 129: 823-837

Belotserkovskaya R, Oh S, Bondarenko VA, Orphanides G, Studitsky VM, Reinberg D (2003) FACT facilitates transcription-dependent nucleosome alteration. Science 301: 1090-1093

Bhaumik SR, Smith E, Shilatifard A (2007) Covalent modifications of histones during development and disease pathogenesis. Nat Struct Mol Biol 14: 1008-1016 
Block WD, Merkle D, Meek K, Lees-Miller SP (2004) Selective inhibition of the DNA-dependent protein kinase (DNA-PK) by the radiosensitizing agent caffeine. Nucleic acids research 32: 1967-1972

Bodem J, Dobreva G, Hoffmann-Rohrer U, Iben S, Zentgraf H, Delius H, Vingron M, Grummt I (2000) TIF-IA, the factor mediating growth-dependent control of ribosomal RNA synthesis, is the mammalian homolog of yeast Rrn3p. EMBO Rep 1: $171-175$

Boisvert FM, van Koningsbruggen S, Navascues J, Lamond AI (2007) The multifunctional nucleolus. Nat Rev Mol Cell Biol 8: 574-585

Boulon S, Westman BJ, Hutten S, Boisvert FM, Lamond AI (2010) The nucleolus under stress. Molecular cell 40: 216-227

Buratowski S (2003) The CTD code. Nat Struct Biol 10: 679-680

Burma S, Chen BP, Murphy M, Kurimasa A, Chen DJ (2001) ATM phosphorylates histone $\mathrm{H} 2 \mathrm{AX}$ in response to DNA double-strand breaks. The Journal of biological chemistry 276: $42462-42467$

Carrozza MJ, Li B, Florens L, Suganuma T, Swanson SK, Lee KK, Shia WJ, Anderson S, Yates J, Washburn MP, Workman JL (2005) Histone H3 methylation by Set2 directs deacetylation of coding regions by Rpd3S to suppress spurious intragenic transcription. Cell 123: 581-592

Celeste A, Fernandez-Capetillo O, Kruhlak MJ, Pilch DR, Staudt DW, Lee A, Bonner RF, Bonner WM, Nussenzweig A (2003) Histone H2AX phosphorylation is dispensable for the initial recognition of DNA breaks. Nat Cell Biol 5: 675-679

Chandrasekharan MB, Huang F, Sun ZW (2009) Ubiquitination of histone H2B regulates chromatin dynamics by enhancing nucleosome stability. Proc Natl Acad Sci U S A 106: 16686-16691 
Chapman RD, Heidemann M, Albert TK, Mailhammer R, Flatley A, Meisterernst M, Kremmer E, Eick D (2007) Transcribing RNA polymerase II is phosphorylated at CTD residue serine-7. Science 318: 1780-1782

Chaudary N, Hill RP (2007) Hypoxia and metastasis. Clin Cancer Res 13: $1947-$ 1949

Chen D, Shan J, Zhu WG, Qin J, Gu W (2010) Transcription-independent ARF regulation in oncogenic stress-mediated p53 responses. Nature 464: 624-627

Chen R, Liu M, Li H, Xue Y, Ramey WN, He N, Ai N, Luo H, Zhu Y, Zhou N, Zhou Q (2008) PP2B and PP1alpha cooperatively disrupt 7SK snRNP to release P$\mathrm{TEFb}$ for transcription in response to $\mathrm{Ca} 2+$ signaling. Genes \& development 22: 1356-1368

Chen Y, Yamaguchi Y, Tsugeno Y, Yamamoto J, Yamada T, Nakamura M, Hisatake K, Handa H (2009) DSIF, the Pafl complex, and Tat-SF1 have nonredundant, cooperative roles in RNA polymerase II elongation. Genes \& development 23: 2765-2777

Chen YR, Wang X, Templeton D, Davis RJ, Tan TH (1996) The role of c-Jun Nterminal kinase $(\mathrm{JNK})$ in apoptosis induced by ultraviolet $\mathrm{C}$ and gamma radiation. Duration of JNK activation may determine cell death and proliferation. The Journal of biological chemistry 271: 31929-31936

Cho EJ, Kobor MS, Kim M, Greenblatt J, Buratowski S (2001) Opposing effects of Ctk1 kinase and Fcp1 phosphatase at Ser 2 of the RNA polymerase II Cterminal domain. Genes \& development 15: 3319-3329

Choo JH, Kim JD, Chung JH, Stubbs L, Kim J (2006) Allele-specific deposition of macroH2A1 in imprinting control regions. Hum Mol Genet 15: 717-724

Cioce M, Boulon S, Matera AG, Lamond AI (2006) UV-induced fragmentation of Cajal bodies. J Cell Biol 175: 401-413 
Cioce M, Lamond AI (2005) Cajal bodies: a long history of discovery. Annu Rev Cell Dev Biol 21: 105-131

Cohen AA, Geva-Zatorsky N, Eden E, Frenkel-Morgenstern M, Issaeva I, Sigal A, Milo R, Cohen-Saidon C, Liron Y, Kam Z, Cohen L, Danon T, Perzov N, Alon U (2008) Dynamic proteomics of individual cancer cells in response to a drug. Science 322: 1511-1516

Colombo E, Bonetti P, Lazzerini Denchi E, Martinelli P, Zamponi R, Marine JC, Helin K, Falini B, Pelicci PG (2005) Nucleophosmin is required for DNA integrity and p19Arf protein stability. Molecular and cellular biology 25: 8874-8886

Costanzi C, Pehrson JR (1998) Histone macroH2A1 is concentrated in the inactive $\mathrm{X}$ chromosome of female mammals. Nature 393: 599-601

Dai MS, Lu H (2004) Inhibition of MDM2-mediated p53 ubiquitination and degradation by ribosomal protein L5. The Journal of biological chemistry 279: 44475-44482

Daniel JA, Torok MS, Sun ZW, Schieltz D, Allis CD, Yates JR, 3rd, Grant PA (2004) Deubiquitination of histone H2B by a yeast acetyltransferase complex regulates transcription. The Journal of biological chemistry 279: 1867-1871

Davey CA, Sargent DF, Luger K, Maeder AW, Richmond TJ (2002) Solvent mediated interactions in the structure of the nucleosome core particle at 1.9 a resolution. Journal of molecular biology 319: 1097-1113

Davie JR, Murphy LC (1990) Level of ubiquitinated histone H2B in chromatin is coupled to ongoing transcription. Biochemistry 29: 4752-4757

Davie JR, Murphy LC (1994) Inhibition of transcription selectively reduces the level of ubiquitinated histone $\mathrm{H} 2 \mathrm{~B}$ in chromatin. Biochemical and biophysical research communications 203: 344-350 
Davis RL, Weintraub H, Lassar AB (1987) Expression of a single transfected cDNA converts fibroblasts to myoblasts. Cell 51: 987-1000

Derijard B, Raingeaud J, Barrett T, Wu IH, Han J, Ulevitch RJ, Davis RJ (1995) Independent human MAP-kinase signal transduction pathways defined by MEK and MKK isoforms. Science 267: 682-685

Dohmen RJ, Madura K, Bartel B, Varshavsky A (1991) The N-end rule is mediated by the UBC2(RAD6) ubiquitin-conjugating enzyme. Proceedings of the National Academy of Sciences of the United States of America 88: 7351-7355

Doyen CM, Montel F, Gautier T, Menoni H, Claudet C, Delacour-Larose M, Angelov D, Hamiche A, Bednar J, Faivre-Moskalenko C, Bouvet P, Dimitrov S (2006) Dissection of the unusual structural and functional properties of the variant H2A.Bbd nucleosome. The EMBO journal 25: 4234-4244

Egloff S, Murphy S (2008) Cracking the RNA polymerase II CTD code. Trends Genet 24: 280-288

Egloff S, O'Reilly D, Chapman RD, Taylor A, Tanzhaus K, Pitts L, Eick D, Murphy S (2007) Serine-7 of the RNA polymerase II CTD is specifically required for snRNA gene expression. Science 318: 1777-1779

Emre NC, Ingvarsdottir K, Wyce A, Wood A, Krogan NJ, Henry KW, Li K, Marmorstein R, Greenblatt JF, Shilatifard A, Berger SL (2005) Maintenance of low histone ubiquitylation by Ubp10 correlates with telomere-proximal Sir2 association and gene silencing. Molecular cell 17: 585-594

Fierz B, Chatterjee C, McGinty RK, Bar-Dagan M, Raleigh DP, Muir TW (2011) Histone H2B ubiquitylation disrupts local and higher-order chromatin compaction. Nat Chem Biol 7: 113-119

Fischle W, Wang Y, Allis CD (2003) Histone and chromatin cross-talk. Curr Opin Cell Biol 15: 172-183 
Fleming AB, Kao CF, Hillyer C, Pikaart M, Osley MA (2008) H2B ubiquitylation plays a role in nucleosome dynamics during transcription elongation. Molecular cell 31: 57-66

Frey MR, Matera AG (2001) RNA-mediated interaction of Cajal bodies and U2 snRNA genes. J Cell Biol 154: 499-509

Fu TJ, Peng J, Lee G, Price DH, Flores O (1999) Cyclin K functions as a CDK9 regulatory subunit and participates in RNA polymerase II transcription. The Journal of biological chemistry 274: 34527-34530

Fujinaga K, Irwin D, Huang Y, Taube R, Kurosu T, Peterlin BM (2004) Dynamics of human immunodeficiency virus transcription: $\mathrm{P}-\mathrm{TEFb}$ phosphorylates RD and dissociates negative effectors from the transactivation response element. Molecular and cellular biology 24: 787-795

Game JC, Chernikova SB (2009) The role of RAD6 in recombinational repair, checkpoints and meiosis via histone modification. DNA Repair (Amst) 8: 470-482

Geng L, Huntoon CJ, Karnitz LM (2010) RAD18-mediated ubiquitination of PCNA activates the Fanconi anemia DNA repair network. J Cell Biol 191: 249257

Giglia-Mari G, Coin F, Ranish JA, Hoogstraten D, Theil A, Wijgers N, Jaspers NG, Raams A, Argentini M, van der Spek PJ, Botta E, Stefanini M, Egly JM, Aebersold R, Hoeijmakers JH, Vermeulen W (2004) A new, tenth subunit of TFIIH is responsible for the DNA repair syndrome trichothiodystrophy group A. Nat Genet 36: 714-719

Ginisty H, Amalric F, Bouvet P (1998) Nucleolin functions in the first step of ribosomal RNA processing. The EMBO journal 17: 1476-1486

Glinsky GV, Berezovska O, Glinskii AB (2005) Microarray analysis identifies a death-from-cancer signature predicting therapy failure in patients with multiple types of cancer. J Clin Invest 115: 1503-1521 
Gomes NP, Bjerke G, Llorente B, Szostek SA, Emerson BM, Espinosa JM (2006) Gene-specific requirement for P-TEFb activity and RNA polymerase II phosphorylation within the p53 transcriptional program. Genes \& development 20: 601-612

Grana X, Reddy EP (1995) Cell cycle control in mammalian cells: role of cyclins, cyclin dependent kinases (CDKs), growth suppressor genes and cyclin-dependent kinase inhibitors (CKIs). Oncogene 11: 211-219

Guenther MG, Levine SS, Boyer LA, Jaenisch R, Young RA (2007) A chromatin landmark and transcription initiation at most promoters in human cells. Cell 130: $77-88$

Hake SB, Allis CD (2006) Histone H3 variants and their potential role in indexing mammalian genomes: the "H3 barcode hypothesis". Proceedings of the National Academy of Sciences of the United States of America 103: 6428-6435

Handwerger KE, Wu Z, Murphy C, Gall JG (2002) Heat shock induces mini-Cajal bodies in the Xenopus germinal vesicle. J Cell Sci 115: 2011-2020

Hara T, Omura-Minamisawa M, Kang Y, Cheng C, Inoue T (2008) Flavopiridol potentiates the cytotoxic effects of radiation in radioresistant tumor cells in which p53 is mutated or Bcl-2 is overexpressed. Int J Radiat Oncol Biol Phys 71: 14851495

Haracska L, Kondratick CM, Unk I, Prakash S, Prakash L (2001) Interaction with PCNA is essential for yeast DNA polymerase eta function. Molecular cell 8: 407415

Haracska L, Torres-Ramos CA, Johnson RE, Prakash S, Prakash L (2004) Opposing effects of ubiquitin conjugation and SUMO modification of PCNA on replicational bypass of DNA lesions in Saccharomyces cerevisiae. Molecular and cellular biology 24: 4267-4274 
Henry KW, Wyce A, Lo WS, Duggan LJ, Emre NC, Kao CF, Pillus L, Shilatifard A, Osley MA, Berger SL (2003) Transcriptional activation via sequential histone H2B ubiquitylation and deubiquitylation, mediated by SAGA-associated Ubp8. Genes \& development 17: 2648-2663

Hoege C, Pfander B, Moldovan GL, Pyrowolakis G, Jentsch S (2002) RAD6dependent DNA repair is linked to modification of PCNA by ubiquitin and SUMO. Nature 419: 135-141

Iankova I, Petersen RK, Annicotte JS, Chavey C, Hansen JB, Kratchmarova I, Sarruf D, Benkirane M, Kristiansen K, Fajas L (2006) Peroxisome proliferatoractivated receptor gamma recruits the positive transcription elongation factor $b$ complex to activate transcription and promote adipogenesis. Mol Endocrinol 20: 1494-1505

Ip YT, Davis RJ (1998) Signal transduction by the c-Jun N-terminal kinase (JNK)-from inflammation to development. Curr Opin Cell Biol 10: 205-219

Isaac C, Yang Y, Meier UT (1998) Nopp140 functions as a molecular link between the nucleolus and the coiled bodies. J Cell Biol 142: 319-329

Ivanov D, Kwak YT, Guo J, Gaynor RB (2000) Domains in the SPT5 protein that modulate its transcriptional regulatory properties. Molecular and cellular biology 20: $2970-2983$

Jang MK, Mochizuki K, Zhou M, Jeong HS, Brady JN, Ozato K (2005) The bromodomain protein $\mathrm{Brd} 4$ is a positive regulatory component of $\mathrm{P}-\mathrm{TEFb}$ and stimulates RNA polymerase II-dependent transcription. Molecular cell 19: 523534

Jin C, Felsenfeld G (2007) Nucleosome stability mediated by histone variants H3.3 and H2A.Z. Genes \& development 21: 1519-1529 
Kannouche PL, Wing J, Lehmann AR (2004) Interaction of human DNA polymerase eta with monoubiquitinated PCNA: a possible mechanism for the polymerase switch in response to DNA damage. Molecular cell 14: 491-500

Kao CF, Hillyer C, Tsukuda T, Henry K, Berger S, Osley MA (2004) Rad6 plays a role in transcriptional activation through ubiquitylation of histone H2B. Genes \& development 18: 184-195

Kass GE, Eriksson JE, Weis M, Orrenius S, Chow SC (1996) Chromatin condensation during apoptosis requires ATP. Biochem J 318 ( Pt 3): $749-752$

Keogh MC, Kurdistani SK, Morris SA, Ahn SH, Podolny V, Collins SR, Schuldiner M, Chin K, Punna T, Thompson NJ, Boone C, Emili A, Weissman JS, Hughes TR, Strahl BD, Grunstein M, Greenblatt JF, Buratowski S, Krogan NJ (2005) Cotranscriptional set2 methylation of histone H3 lysine 36 recruits a repressive Rpd3 complex. Cell 123: 593-605

Kim J, Guermah M, McGinty RK, Lee JS, Tang Z, Milne TA, Shilatifard A, Muir TW, Roeder RG (2009) RAD6-Mediated transcription-coupled H2B ubiquitylation directly stimulates H3K4 methylation in human cells. Cell 137: 459-471

Kim J, Hake SB, Roeder RG (2005) The human homolog of yeast BRE1 functions as a transcriptional coactivator through direct activator interactions. Molecular cell 20: $759-770$

Kim JB, Sharp PA (2001) Positive transcription elongation factor B phosphorylates hSPT5 and RNA polymerase II carboxyl-terminal domain independently of cyclin-dependent kinase-activating kinase. The Journal of biological chemistry 276: 12317-12323

Kim YK, Bourgeois CF, Isel C, Churcher MJ, Karn J (2002) Phosphorylation of the RNA polymerase II carboxyl-terminal domain by CDK9 is directly responsible for human immunodeficiency virus type 1 Tat-activated transcriptional elongation. Molecular and cellular biology 22: 4622-4637 
Kiss T, Fayet E, Jady BE, Richard P, Weber M (2006) Biogenesis and intranuclear trafficking of human box C/D and H/ACA RNPs. Cold Spring Harb Symp Quant Biol 71: 407-417

Knockaert M, Sapkota G, Alarcon C, Massague J, Brivanlou AH (2006) Unique players in the BMP pathway: small C-terminal domain phosphatases dephosphorylate Smad1 to attenuate BMP signaling. Proceedings of the National Academy of Sciences of the United States of America 103: 11940-11945

Kolasinska-Zwierz P, Down T, Latorre I, Liu T, Liu XS, Ahringer J (2009) Differential chromatin marking of introns and expressed exons by H3K36me3. Nat Genet 41: 376-381

Komarnitsky P, Cho EJ, Buratowski S (2000) Different phosphorylated forms of RNA polymerase II and associated mRNA processing factors during transcription. Genes \& development 14: 2452-2460

Kruse JP, Gu W (2009) Modes of p53 regulation. Cell 137: 609-622

Kuroda T, Murayama A, Katagiri N, Ohta YM, Fujita E, Masumoto H, Ema M, Takahashi S, Kimura K, Yanagisawa J (2011) RNA content in the nucleolus alters p53 acetylation via MYBBP1A. The EMBO journal 30: 1054-1066

Lafarga M, Gonzalez C, Berciano MT (1986) An improved cytological silver staining method for the demonstration of neuronal nuclear bodies. $J$ Neurosci Methods 18: 317-324

Laribee RN, Fuchs SM, Strahl BD (2007) H2B ubiquitylation in transcriptional control: a FACT-finding mission. Genes \& development 21: 737-743

Lee JS, Shukla A, Schneider J, Swanson SK, Washburn MP, Florens L, Bhaumik SR, Shilatifard A (2007) Histone crosstalk between H2B monoubiquitination and H3 methylation mediated by COMPASS. Cell 131: 1084-1096 
Lee TI, Young RA (2000) Transcription of eukaryotic protein-coding genes. Annu Rev Genet 34: 77-137

Lempiainen H, Shore D (2009) Growth control and ribosome biogenesis. Curr Opin Cell Biol 21: 855-863

Licatalosi DD, Geiger G, Minet M, Schroeder S, Cilli K, McNeil JB, Bentley DL (2002) Functional interaction of yeast pre-mRNA 3' end processing factors with RNA polymerase II. Molecular cell 9: 1101-1111

Lindstrom MS (2011) NPM1/B23: A Multifunctional Chaperone in Ribosome Biogenesis and Chromatin Remodeling. Biochem Res Int 2011: 195209

Liu CL, Kaplan T, Kim M, Buratowski S, Schreiber SL, Friedman N, Rando OJ (2005) Single-nucleosome mapping of histone modifications in S. cerevisiae. PLoS Biol 3: e328

Lohrum MA, Ludwig RL, Kubbutat MH, Hanlon M, Vousden KH (2003) Regulation of HDM2 activity by the ribosomal protein L11. Cancer Cell 3: 577587

Luco RF, Allo M, Schor IE, Kornblihtt AR, Misteli T (2011) Epigenetics in alternative pre-mRNA splicing. Cell 144: 16-26

Luger K, Mader AW, Richmond RK, Sargent DF, Richmond TJ (1997) Crystal structure of the nucleosome core particle at 2.8 A resolution. Nature 389: 251-260

Lyon CE, Bohmann K, Sleeman J, Lamond AI (1997) Inhibition of protein dephosphorylation results in the accumulation of splicing snRNPs and coiled bodies within the nucleolus. Experimental cell research 230: 84-93

Malik HS, Henikoff S (2003) Phylogenomics of the nucleosome. Nat Struct Biol 10: $882-891$ 
Marshall NF, Peng J, Xie Z, Price DH (1996) Control of RNA polymerase II elongation potential by a novel carboxyl-terminal domain kinase. The Journal of biological chemistry 271: 27176-27183

Martindale JL, Holbrook NJ (2002) Cellular response to oxidative stress: signaling for suicide and survival. $J$ Cell Physiol 192: 1-15

Marzluff WF, Wagner EJ, Duronio RJ (2008) Metabolism and regulation of canonical histone mRNAs: life without a poly(A) tail. Nat Rev Genet 9: 843-854

Mason KA, Hunter NR, Raju U, Ariga H, Husain A, Valdecanas D, Neal R, Ang KK, Milas L (2004) Flavopiridol increases therapeutic ratio of radiotherapy by preferentially enhancing tumor radioresponse. Int J Radiat Oncol Biol Phys 59: 1181-1189

Matera AG, Terns RM, Terns MP (2007) Non-coding RNAs: lessons from the small nuclear and small nucleolar RNAs. Nat Rev Mol Cell Biol 8: 209-220

Mayer C, Bierhoff H, Grummt I (2005) The nucleolus as a stress sensor: JNK2 inactivates the transcription factor TIF-IA and down-regulates rRNA synthesis. Genes \& development 19: 933-941

Miller C, Schwalb B, Maier K, Schulz D, Dumcke S, Zacher B, Mayer A, Sydow J, Marcinowski L, Dolken L, Martin DE, Tresch A, Cramer P (2011) Dynamic transcriptome analysis measures rates of mRNA synthesis and decay in yeast. $\mathrm{Mol}$ Syst Biol 7: 458

Mimnaugh EG, Chen HY, Davie JR, Celis JE, Neckers L (1997) Rapid deubiquitination of nucleosomal histones in human tumor cells caused by proteasome inhibitors and stress response inducers: effects on replication, transcription, translation, and the cellular stress response. Biochemistry 36: 1441814429

Minden A, Karin M (1997) Regulation and function of the JNK subgroup of MAP kinases. Biochimica et biophysica acta 1333: F85-104 
Minsky N, Shema E, Field Y, Schuster M, Segal E, Oren M (2008) Monoubiquitinated $\mathrm{H} 2 \mathrm{~B}$ is associated with the transcribed region of highly expressed genes in human cells. Nat Cell Biol 10: 483-488

Motwani M, Jung C, Sirotnak FM, She Y, Shah MA, Gonen M, Schwartz GK (2001) Augmentation of apoptosis and tumor regression by flavopiridol in the presence of CPT-11 in Hct116 colon cancer monolayers and xenografts. Clin Cancer Res 7: 4209-4219

Moyal L, Lerenthal Y, Gana-Weisz M, Mass G, So S, Wang SY, Eppink B, Chung YM, Shalev G, Shema E, Shkedy D, Smorodinsky NI, van Vliet N, Kuster B, Mann M, Ciechanover A, Dahm-Daphi J, Kanaar R, Hu MC, Chen DJ, Oren M, Shiloh Y (2011) Requirement of ATM-Dependent Monoubiquitylation of Histone H2B for Timely Repair of DNA Double-Strand Breaks. Molecular cell 41: 529542

Myers LC, Gustafsson CM, Bushnell DA, Lui M, Erdjument-Bromage H, Tempst P, Kornberg RD (1998) The Med proteins of yeast and their function through the RNA polymerase II carboxy-terminal domain. Genes \& development 12: 45-54

Nakamura K, Kato A, Kobayashi J, Yanagihara H, Sakamoto S, Oliveira DV, Shimada M, Tauchi H, Suzuki H, Tashiro S, Zou L, Komatsu K (2011) Regulation of Homologous Recombination by RNF20-Dependent H2B Ubiquitination. Molecular cell 41: 515-528

Newcomb EW, Tamasdan C, Entzminger Y, Arena E, Schnee T, Kim M, Crisan D, Lukyanov Y, Miller DC, Zagzag D (2004) Flavopiridol inhibits the growth of GL261 gliomas in vivo: implications for malignant glioma therapy. Cell Cycle 3: 230-234

Ng HH, Robert F, Young RA, Struhl K (2003) Targeted recruitment of Set1 histone methylase by elongating Pol II provides a localized mark and memory of recent transcriptional activity. Molecular cell 11: 709-719 
Nguyen VT, Kiss T, Michels AA, Bensaude O (2001) 7SK small nuclear RNA binds to and inhibits the activity of CDK9/cyclin T complexes. Nature 414: 322325

Nicoletti VG, Stella AM (2003) Role of PARP under stress conditions: cell death or protection? Neurochem Res 28: 187-194

Nizami Z, Deryusheva S, Gall JG (2010) The Cajal body and histone locus body. Cold Spring Harb Perspect Biol 2: a000653

Nonet M, Sweetser D, Young RA (1987) Functional redundancy and structural polymorphism in the large subunit of RNA polymerase II. Cell 50: 909-915

Olson MO (2004) Sensing cellular stress: another new function for the nucleolus? Sci STKE 2004: pe10

Paull TT, Rogakou EP, Yamazaki V, Kirchgessner CU, Gellert M, Bonner WM (2000) A critical role for histone H2AX in recruitment of repair factors to nuclear foci after DNA damage. Curr Biol 10: 886-895

Pavri R, Zhu B, Li G, Trojer P, Mandal S, Shilatifard A, Reinberg D (2006) Histone $\mathrm{H} 2 \mathrm{~B}$ monoubiquitination functions cooperatively with FACT to regulate elongation by RNA polymerase II. Cell 125: 703-717

Pehrson JR, Fried VA (1992) MacroH2A, a core histone containing a large nonhistone region. Science 257: 1398-1400

Peng J, Zhu Y, Milton JT, Price DH (1998) Identification of multiple cyclin subunits of human P-TEFb. Genes \& development 12: 755-762

Perry RP, Kelley DE (1968) Persistent synthesis of 5S RNA when production of $28 \mathrm{~S}$ and $18 \mathrm{~S}$ ribosomal RNA is inhibited by low doses of actinomycin D. J Cell Physiol 72: 235-246 
Phatnani HP, Greenleaf AL (2006) Phosphorylation and functions of the RNA polymerase II CTD. Genes \& development 20: 2922-2936

Pickart CM (2001) Mechanisms underlying ubiquitination. Annu Rev Biochem 70: 503-533

Pirngruber J, Shchebet A, Johnsen SA (2009a) Insights into the function of the human $\mathrm{P}-\mathrm{TEFb}$ component $\mathrm{CDK} 9$ in the regulation of chromatin modifications and co-transcriptional mRNA processing. Cell Cycle 8: 3636-3642

Pirngruber J, Shchebet A, Schreiber L, Shema E, Minsky N, Chapman RD, Eick D, Aylon Y, Oren M, Johnsen SA (2009b) CDK9 directs H2B monoubiquitination and controls replication-dependent histone mRNA 3'-end processing. EMBO Rep 10: $894-900$

Radonjic M, Andrau JC, Lijnzaad P, Kemmeren P, Kockelkorn TT, van Leenen D, van Berkum NL, Holstege FC (2005) Genome-wide analyses reveal RNA polymerase II located upstream of genes poised for rapid response upon S. cerevisiae stationary phase exit. Molecular cell 18: 171-183

Raju U, Nakata E, Mason KA, Ang KK, Milas L (2003) Flavopiridol, a cyclindependent kinase inhibitor, enhances radiosensitivity of ovarian carcinoma cells. Cancer Res 63: 3263-3267

Rando OJ, Chang HY (2009) Genome-wide views of chromatin structure. Annu Rev Biochem 78: 245-271

Reiling JH, Sabatini DM (2006) Stress and mTORture signaling. Oncogene 25: 6373-6383

Robzyk K, Recht J, Osley MA (2000) Rad6-dependent ubiquitination of histone $\mathrm{H} 2 \mathrm{~B}$ in yeast. Science 287: 501-504

Rogakou EP, Boon C, Redon C, Bonner WM (1999) Megabase chromatin domains involved in DNA double-strand breaks in vivo. J Cell Biol 146: 905-916 
Roux PP, Blenis J (2004) ERK and p38 MAPK-activated protein kinases: a family of protein kinases with diverse biological functions. Microbiol Mol Biol Rev 68: 320-344

Russo AA, Jeffrey PD, Pavletich NP (1996) Structural basis of cyclin-dependent kinase activation by phosphorylation. Nat Struct Biol 3: 696-700

Ruthenburg AJ, Li H, Patel DJ, Allis CD (2007) Multivalent engagement of chromatin modifications by linked binding modules. Nat Rev Mol Cell Biol 8: 983994

Santos-Rosa H, Schneider R, Bannister AJ, Sherriff J, Bernstein BE, Emre NC, Schreiber SL, Mellor J, Kouzarides T (2002) Active genes are tri-methylated at K4 of histone H3. Nature 419: 407-411

Sarcevic B, Mawson A, Baker RT, Sutherland RL (2002) Regulation of the ubiquitin-conjugating enzyme hHR6A by CDK-mediated phosphorylation. The EMBO journal 21: 2009-2018

Sarkaria JN, Busby EC, Tibbetts RS, Roos P, Taya Y, Karnitz LM, Abraham RT (1999) Inhibition of ATM and ATR kinase activities by the radiosensitizing agent, caffeine. Cancer Res 59: 4375-4382

Schones DE, Cui K, Cuddapah S, Roh TY, Barski A, Wang Z, Wei G, Zhao K (2008) Dynamic regulation of nucleosome positioning in the human genome. Cell 132: $887-898$

Schwartz GK, Farsi K, Maslak P, Kelsen DP, Spriggs D (1997) Potentiation of apoptosis by flavopiridol in mitomycin-C-treated gastric and breast cancer cells. Clin Cancer Res 3: 1467-1472

Shav-Tal Y, Blechman J, Darzacq X, Montagna C, Dye BT, Patton JG, Singer RH, Zipori D (2005) Dynamic sorting of nuclear components into distinct nucleolar caps during transcriptional inhibition. Mol Biol Cell 16: 2395-2413 
Shaw PE (2007) Peptidyl-prolyl cis/trans isomerases and transcription: is there a twist in the tail? EMBO Rep 8: 40-45

Shema E, Tirosh I, Aylon Y, Huang J, Ye C, Moskovits N, Raver-Shapira N, Minsky N, Pirngruber J, Tarcic G, Hublarova P, Moyal L, Gana-Weisz M, Shiloh Y, Yarden Y, Johnsen SA, Vojtesek B, Berger SL, Oren M (2008) The histone H2B-specific ubiquitin ligase RNF20/hBRE1 acts as a putative tumor suppressor through selective regulation of gene expression. Genes \& development 22: 26642676

Sherr CJ (2001) The INK4a/ARF network in tumour suppression. Nat Rev Mol Cell Biol 2: 731-737

Silva NP, Christofolini DM, Mortara RA, Andrade LE (2004) Colocalization of coilin and nucleolar proteins in Cajal body-like structures of micronucleated PtK2 cells. Braz J Med Biol Res 37: 997-1003

Simone C, Stiegler P, Bagella L, Pucci B, Bellan C, De Falco G, De Luca A, Guanti G, Puri PL, Giordano A (2002) Activation of MyoD-dependent transcription by cdk9/cyclin T2. Oncogene 21: 4137-4148

Song JJ, Lee YJ (2007) Differential activation of the JNK signal pathway by UV irradiation and glucose deprivation. Cell Signal 19: 563-572

Stiff T, O'Driscoll M, Rief N, Iwabuchi K, Lobrich M, Jeggo PA (2004) ATM and DNA-PK function redundantly to phosphorylate H2AX after exposure to ionizing radiation. Cancer Res 64: 2390-2396

Strahl BD, Allis CD (2000) The language of covalent histone modifications. Nature 403: 41-45

Strzelecka M, Trowitzsch S, Weber G, Luhrmann R, Oates AC, Neugebauer KM (2010) Coilin-dependent snRNP assembly is essential for zebrafish embryogenesis. Nat Struct Mol Biol 17: 403-409 
Thorne AW, Sautiere P, Briand G, Crane-Robinson C (1987) The structure of ubiquitinated histone H2B. The EMBO journal 6: 1005-1010

Turner BM (2007) Defining an epigenetic code. Nat Cell Biol 9: 2-6

Usheva A, Maldonado E, Goldring A, Lu H, Houbavi C, Reinberg D, Aloni Y (1992) Specific interaction between the nonphosphorylated form of RNA polymerase II and the TATA-binding protein. Cell 69: 871-881

Vassilev LT, Vu BT, Graves B, Carvajal D, Podlaski F, Filipovic Z, Kong N, Kammlott U, Lukacs C, Klein C, Fotouhi N, Liu EA (2004) In vivo activation of the p53 pathway by small-molecule antagonists of MDM2. Science 303: 844-848

Wada T, Takagi T, Yamaguchi Y, Ferdous A, Imai T, Hirose S, Sugimoto S, Yano K, Hartzog GA, Winston F, Buratowski S, Handa H (1998a) DSIF, a novel transcription elongation factor that regulates RNA polymerase II processivity, is composed of human Spt4 and Spt5 homologs. Genes \& development 12: 343-356

Wada T, Takagi T, Yamaguchi Y, Watanabe D, Handa H (1998b) Evidence that P$\mathrm{TEFb}$ alleviates the negative effect of DSIF on RNA polymerase II-dependent transcription in vitro. The EMBO journal 17: 7395-7403

Ward IM, Minn K, Jorda KG, Chen J (2003) Accumulation of checkpoint protein 53BP1 at DNA breaks involves its binding to phosphorylated histone $\mathrm{H} 2 \mathrm{AX}$. The Journal of biological chemistry 278: 19579-19582

Watanabe K, Tateishi S, Kawasuji M, Tsurimoto T, Inoue H, Yamaizumi M (2004) Rad18 guides poleta to replication stalling sites through physical interaction and PCNA monoubiquitination. The EMBO journal 23: 3886-3896

Wood A, Krogan NJ, Dover J, Schneider J, Heidt J, Boateng MA, Dean K, Golshani A, Zhang Y, Greenblatt JF, Johnston M, Shilatifard A (2003) Bre1, an E3 ubiquitin ligase required for recruitment and substrate selection of Rad6 at a promoter. Molecular cell 11: 267-274 
Wood A, Schneider J, Dover J, Johnston M, Shilatifard A (2005) The Bur1/Bur2 complex is required for histone H2B monoubiquitination by Rad6/Bre1 and histone methylation by COMPASS. Molecular cell 20: 589-599

Wu SY, Chiang CM (2007) The double bromodomain-containing chromatin adaptor Brd4 and transcriptional regulation. The Journal of biological chemistry 282: $13141-13145$

Xiao T, Kao CF, Krogan NJ, Sun ZW, Greenblatt JF, Osley MA, Strahl BD (2005) Histone $\mathrm{H} 2 \mathrm{~B}$ ubiquitylation is associated with elongating RNA polymerase II. Molecular and cellular biology 25: 637-651

Yamada T, Yamaguchi Y, Inukai N, Okamoto S, Mura T, Handa H (2006) PTEFb-mediated phosphorylation of hSpt5 C-terminal repeats is critical for processive transcription elongation. Molecular cell 21: 227-237

Yamaguchi Y, Takagi T, Wada T, Yano K, Furuya A, Sugimoto S, Hasegawa J, Handa H (1999) NELF, a multisubunit complex containing RD, cooperates with DSIF to repress RNA polymerase II elongation. Cell 97: 41-51

Yang Z, Yik JH, Chen R, He N, Jang MK, Ozato K, Zhou Q (2005) Recruitment of $\mathrm{P}-\mathrm{TEFb}$ for stimulation of transcriptional elongation by the bromodomain protein Brd4. Molecular cell 19: 535-545

Yang Z, Zhu Q, Luo K, Zhou Q (2001) The 7SK small nuclear RNA inhibits the CDK9/cyclin T1 kinase to control transcription. Nature 414: 317-322

Yao S, Neiman A, Prelich G (2000) BUR1 and BUR2 encode a divergent cyclindependent kinase-cyclin complex important for transcription in vivo. Molecular and cellular biology 20: 7080-7087

Yik JH, Chen R, Nishimura R, Jennings JL, Link AJ, Zhou Q (2003) Inhibition of $\mathrm{P}-\mathrm{TEFb}$ (CDK9/Cyclin T) kinase and RNA polymerase II transcription by the coordinated actions of HEXIM1 and 7SK snRNA. Molecular cell 12: 971-982 
Yoh SM, Cho H, Pickle L, Evans RM, Jones KA (2007) The Spt6 SH2 domain binds Ser2-P RNAPII to direct Iws1-dependent mRNA splicing and export. Genes \& development 21: 160-174

Yoon HS, Kim HA (2004) Prologation of c-Jun N-terminal kinase is associated with cell death induced by tumor necrosis factor alpha in human chondrocytes. $J$ Korean Med Sci 19: 567-573

Yu DS, Zhao R, Hsu EL, Cayer J, Ye F, Guo Y, Shyr Y, Cortez D (2010) Cyclindependent kinase 9-cyclin $\mathrm{K}$ functions in the replication stress response. EMBO Rep 11: 876-882

Zhang F, Yu X (2011) WAC, a Functional Partner of RNF20/40, Regulates Histone H2B Ubiquitination and Gene Transcription. Mol Cell 41: 384-397

Zhang XY, Varthi M, Sykes SM, Phillips C, Warzecha C, Zhu W, Wyce A, Thorne AW, Berger SL, McMahon SB (2008) The putative cancer stem cell marker USP22 is a subunit of the human SAGA complex required for activated transcription and cell-cycle progression. Molecular cell 29: 102-111

Zhang Y, Kim Y, Genoud N, Gao J, Kelly JW, Pfaff SL, Gill GN, Dixon JE, Noel JP (2006) Determinants for dephosphorylation of the RNA polymerase II Cterminal domain by Scp1. Molecular cell 24: 759-770

Zhao Y, Lang G, Ito S, Bonnet J, Metzger E, Sawatsubashi S, Suzuki E, Le Guezennec X, Stunnenberg HG, Krasnov A, Georgieva SG, Schule R, Takeyama K, Kato S, Tora L, Devys D (2008) A TFTC/STAGA module mediates histone $\mathrm{H} 2 \mathrm{~A}$ and $\mathrm{H} 2 \mathrm{~B}$ deubiquitination, coactivates nuclear receptors, and counteracts heterochromatin silencing. Molecular cell 29: 92-101

Zhu B, Zheng Y, Pham AD, Mandal SS, Erdjument-Bromage H, Tempst P, Reinberg D (2005) Monoubiquitination of human histone H2B: the factors involved and their roles in HOX gene regulation. Molecular cell 20: 601-611 


\section{Aknowledgement}

I would like to express my gratitude to Prof. Dr. Steven A. Johnsen for the great opportunity to work in his lab. His material and, not unimportantly, moral support at the end let me finish my project and to achieve many goals.

Also, I want to thank my colleagues, especially the lab members. It was a nice team to work in, indeed. I'm going to miss it.

At last, I thank my family and friends for countless "It's gonna be OK "-s. Despite everything you were right and it actually is. 


\section{Curriculum Vitae}

\section{Personal Information}

Name Andrei Shchebet

Address Petrikirchstr. 12-45

37077 Göttingen

Date of birth August 04, 1984 in Stolin, Belarus

\section{University}

since 10/2007 $\mathrm{PhD}$ thesis

$$
\begin{aligned}
& \text { "Regulation of histone H2B } \\
& \text { monoubiquitination" } \\
& \text { University of Göttingen, Department of } \\
& \text { Molecular Oncology }
\end{aligned}
$$

09/2006 - 09/2007 Graduate studies

International Max Planck Research School for Molecular Biology,

University of Göttingen, Germany.

09/2001 - 06/2006 Diploma studies

$$
\begin{aligned}
& \text { "Construction of the In Vivo Expression } \\
& \text { Technology (IVET) system for host-induced } \\
& \text { genes search in Erwinia carotovora." } \\
& \text { Belarusian State University, Minsk, Belarus }
\end{aligned}
$$

\section{Education}

09/1997 - 05/2001 High school \#2, Glubokoe, Belarus. 